UNIVERSIDADE DE SÃO PAULO

Escola de Engenharia de São Carlos

Departamento de Engenharia de Transportes

Programa de Pós-Graduação em Engenharia de Transportes

Juliana Mitsuyama Cardoso

\title{
Efeitos da chuva e da luminosidade sobre o tráfego em rodovias paulistas
}



Juliana Mitsuyama Cardoso

\title{
Efeitos da chuva e da luminosidade sobre o tráfego em rodovias paulistas
}

\author{
Versão corrigida - versão original \\ disponível \\ no Serviço de Pós-Graduação da EESC-USP
}

Dissertação submetida à Escola de Engenharia de São Carlos da Universidade de São Paulo para a obtenção do título de Mestre em Ciências no Programa de Pós-Graduação em Engenharia de Transportes.

Área de concentração: Planejamento e Operação de Sistemas de Transportes

Orientador: Prof. Dr. José Reynaldo Setti

São Carlos

2019 
AUTORIZO A REPRODUÇÃO TOTAL OU PARCIAL DESTE TRABALHO, POR QUALQUER MEIO CONVENCIONAL OU ELETRÔNICO, PARA FINS DE ESTUDO E PESQUISA, DESDE QUE CITADA A FONTE.

Ficha catalográfica elaborada pela Biblioteca Prof. Dr. Sérgio Rodrigues Fontes da EESC/USP com os dados inseridos pelo(a) autor(a).

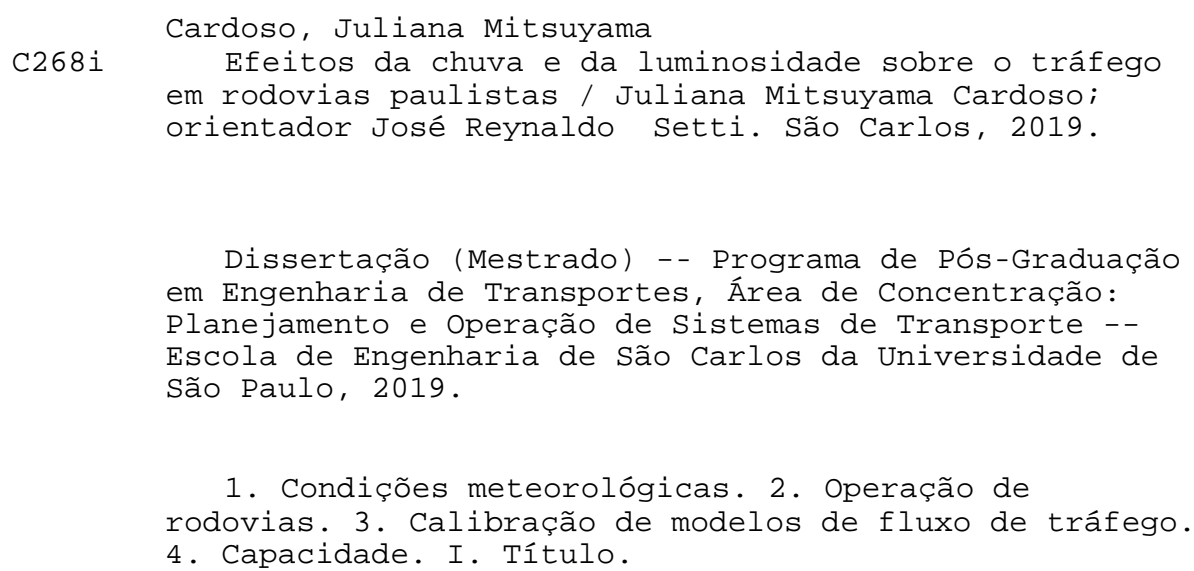

1. Condições meteorológicas. 2. Operação de rodovias. 3. Calibração de modelos de fluxo de tráfego. 4. Capacidade. I. Título.

Eduardo Graziosi Silva - CRB - 8/8907 


\section{FOLHA DE JULGAMENTO}

Candidata: Bacharela JULIANA MITSUYAMA CARDOSO.

Título da dissertação: " Efeitos da chuva e da luminosidade sobre o tráfego em rodovias paulistas".

Data da defesa: 13/12/2019.

Comissão Julgadora:

Prof. Titular Jose Reynaldo Anselmo Setti (Orientador)

(Escola de Engenharia de São Carlos/EESC)

Prof. Dr. Cassiano Augusto Isler

(Escola Politécnica/EP-USP)

Profa. Dra. Helena Beatriz Bettella Cybis

(Universidade Federal do Rio Grande do Sul/UFRGS)
Resultado:
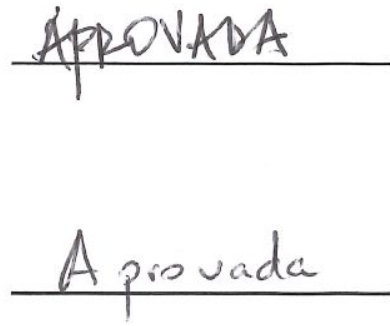

APRONABA

Coordenadora do Programa de Pós-Graduação em Engenharia de Transportes:

Profa. Associada Ana Paula Camargo Larocca

Presidente da Comissão de Pós-Graduação:

Prof. Titular Murilo Araujo Romero 



\section{Agradecimentos}

Agradeço à minha família, especialmente aos meus pais, por me apoiarem em todas as etapas da minha vida.

Agradeço ao meu orientador José Reynaldo Setti por toda atenção, dedicação, conhecimento sobre o tema estudado e disponibilidade em me ajudar e sanar minhas dúvidas.

Agradeço aos bons professores que tive durante a vida por me auxiliarem na caminhada que me trouxe até aqui.

Agradeço àqueles que me auxiliaram na realização da pesquisa de forma mais direta, Samuel, Vanessa e Guilherme por terem me ajudado no georreferenciamento e utilização do QGIS, ao Luan, André e Aurenice por sanarem minhas dúvidas em relação à programação em Python e organização do banco de dados e ao Lucas por ter me auxiliado no ajuste do modelo.

Agradeço aos amigos do STT por toda conversa e todo o tempo que passamos juntos nos almoços, cafés, jantares, churrascos, eventos, festas e comemorações. Estes momentos fizeram com que meu mestrado fosse mais leve. Cada um de vocês deixou um pouco dos seus pensamentos, personalidade e do jeito de ser, espero também ter deixado um pouco de mim em cada um de vocês.

Agradeço à ARTESP e ao IPMet por cederem os dados utilizados nesta pesquisa e por serem sempre solícitos e atenciosos.

Agradeço à CAPES pelo apoio financeiro à esta pesquisa. 



\section{Resumo}

Cardoso, J. M. Efeitos da chuva e da luminosidade sobre o tráfego em rodovias paulistas. 80 p. Dissertação - Escola de Engenharia de São Carlos, Universidade de São Paulo, 2019.

As condições meteorológicas adversas exercem influência no fluxo de tráfego, pois interferem na visibilidade e sensação de segurança dos motoristas. Este trabalho investiga a influência da luminosidade e da precipitação na operação de rodovias do estado de São Paulo. Dados de 12 estações permanentes de monitoramento de tráfego localizadas em rodovias de pista dupla, cobrindo seis anos, foram combinados com os dados de precipitação obtidos por meio da aplicação de visão computacional a imagens de radares meteorológicos. Os dados foram segregados em condições chuvosas e condições ideais e foram usados para ajustar o modelo fluxo-velocidade-densidade de Van Aerde por meio de um algoritmo genético. O teste de Wilcoxon mostrou que há um efeito estatisticamente significativo da chuva sobre a capacidade $(p=0,002)$ e sobre a densidade na capacidade $(p=0,002)$, mas não sobre os demais parâmetros do modelo (velocidade livre, velocidade na capacidade e densidade de congestionamento). Os dados indicam que a chuva provoca uma redução média de $10 \%$ na capacidade e de $11 \%$ na densidade na capacidade. Para investigar os efeitos combinados da chuva e da luminosidade foi usado o teste de Friedman, sendo que os dados foram segregados em quatro configurações: período diurno sem chuva, diurno com chuva, noturno sem chuva, e noturno com chuva. Os resultados do teste estatístico indicam que há efeitos individuais e um efeito combinado das condições meteorológicas e da luminosidade na velocidade na capacidade, no fluxo na capacidade e na densidade na capacidade.

Palavras-chave: Condições meteorológicas. Operação de rodovias. Calibração de modelos de fluxo de tráfego. Capacidade. 



\section{Abstract}

Cardoso, J. M. Effects of rain and daylight on the traffic stream on expressways in the State of São Paulo. 80 p. Master Thesis - São Carlos School of Engineering, University of São Paulo, 2019.

Adverse environmental conditions influence the traffic stream flow, because, as visibility lowers, drivers feel unsafe and reduce travel speed. This thesis investigates the influence of weather and daylight conditions on the traffic stream on expressways in the state of São Paulo, Brazil. Traffic data from 12 permanent monitoring stations covering a period of six years were fused with weather data obtained applying computer vision techniques to weather radar images. The resulting database was used to adjust the Van Aerde traffic flow model using a genetic algorithm. The Wilcoxon test results show that rain causes a statistically significant reduction on capacity $(p=0.002)$ and on density at capacity $(p=0.002)$, but does not affect significantly the other model parameters (free speed, speed at capacity and jam density). An average reduction of $10 \%$ in capacity and $11 \%$ in the density at capacity were observed under rainy conditions. The Friedman test was used to study the combined effects of weather and daylight conditions. The data were disaggregated into four conditions: daytime/no rain, daytime/rain, nighttime/no rain, and nighttime/rain. The results of statistical analyses indicate that there are individual and combined effects of adverse weather and daylight conditions on capacity, speed at capacity and density at capacity.

Keywords: Adverse weather condition. Highway operations. Traffic model calibration. Capacity. 



\section{Sumário}

1 Introdução 13

1.1 Justificativa . . . . . . . . . . . . . . . . . . . . 13

1.2 Questões de pesquisa e objetivos . . . . . . . . . . . . . . . . . . 14

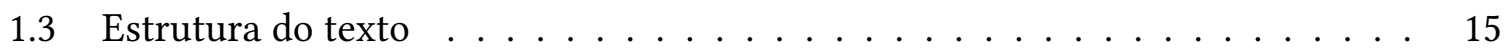

2 Fusão de dados $\quad 17$

2.1 Obtenção dos dados de tráfego e meteorológicos . . . . . . . . . . . 18

2.2 Georreferencimento das estações de monitoramento de tráfego . . . . . . . 19

2.3 Identificação da condição meteorológica nos locais das estações de monitoramento . . . . . . . . . . . . . . . . . . . . . 20

2.4 Identificação da luminosidade nos locais de coleta dos dados . . . . . . . . . . 23

2.5 Tratamento e organização dos dados de tráfego . . . . . . . . . . . . . . . 23

2.6 Fusão dos dados de tráfego com as condições meteorológicas . . . . . . . . . 24

2.7 Criação do banco de dados para o estudo . . . . . . . . . . . . . . . . . . 25

$3 \quad$ Ajuste de modelos de fluxo de tráfego com base em VLDB 29

3.1 Revisão da literatura . . . . . . . . . . . . . . . . . . . . . . . 29

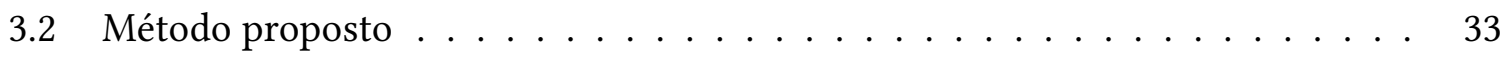

3.2.1 Redução e filtragem inicial dos dados de tráfego . . . . . . . . . . . 33

3.2.2 Ajuste do modelo de Van Aerde através do algoritmo hill climbing . . 35 
3.2.3 Ajuste do modelo de Van Aerde através do algoritmo genético . . . . 37

3.3 Análise dos resultados . . . . . . . . . . . . . . . . . . . . 39

3.4 Considerações finais . . . . . . . . . . . . . . . . . . . . . 41

4 Influência das condições adversas na operação do tráfego 43

4.1 Revisão da literatura . . . . . . . . . . . . . . . . . . . . 43

4.2 Efeito das condições meteorológicas sobre o comportamento do tráfego . . . 45

4.3 Efeito combinado da precipitação com a luminosidade . . . . . . . . . . . . 49

4.3.1 Análise dos efeitos da luminosidade . . . . . . . . . . . 50

4.3.2 Análise dos efeitos da precipitação . . . . . . . . . . . . . . . 53

5 Conclusões e recomendações $\quad 59$

5.1 Conclusões . . . . . . . . . . . . . . . . . . . . . . . 59

5.2 Recomendações . . . . . . . . . . . . . . . . . . 60

$\begin{array}{ll}\text { Referências } & 63\end{array}$

$\begin{array}{ll}\text { Apêndices } & 69\end{array}$

$\begin{array}{lll}\text { APÊNDICE A Sensores automáticos de tráfego } & 71\end{array}$

$\begin{array}{lll}\text { APÊNDICE B Análise do efeito das condições meteorológicas } & 73\end{array}$

APÊNDICE C Análise do efeito combinado da meteorologia com a luminosidade 77 


\section{Capítulo}

\section{Introdução}

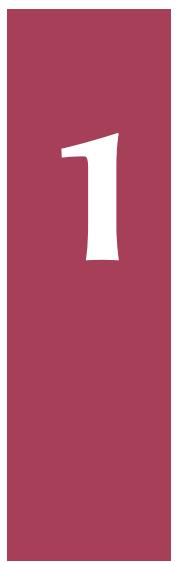

As condições meteorológicas afetam o comportamento dos motoristas pois interferem na percepção e sensação de segurança. Os motoristas tendem a diminuir suas velocidades para aumentar a distância de segurança entre os veículos (GOODWIN, 2002). Em uma escala macroscópica, este comportamento influencia na operação das rodovias.

Na sua versão mais recente, o Highway Capacity Manual (HCM) recomenda fatores de ajuste da capacidade e da velocidade de fluxo livre desenvolvida nas freeways de acordo com as condições meteorológicas evidenciadas. Os fatores de ajuste apresentam a influência da chuva, neve, frio severo e da perda de visibilidade para cada intervalo de velocidade desenvolvida pelos motoristas (TRB, 2016, p. 11-43). No entanto, o HCM ressalta que estes fatores de ajuste foram concebidos a partir da realidade norte-americana, e são necessários estudos que busquem compreender as realidades climáticas e operacionais de cada localidade.

Em São Paulo, a Agência de Transporte do Estado de São Paulo (ARTESP) utiliza o HCM com seus parâmetros originais para verificar o atendimento aos padrões de desempenho operacional das rodovias concessionadas. Portanto, não ocorre uma adaptação completa à realidade local apesar do próprio manual recomendar que adaptações sejam realizadas. Segundo Setti (2009) as adaptações realizadas para as condições brasileiras, muitas vezes, não apresentam um embasamento técnico-científico, o que compromete a qualidade do serviço percebida pelos usuários da via.

\subsection{Justificativa}

No Brasil, existem poucos estudos que buscam compreender o impacto das condições meteorológicas na operação das rodovias. Os estudos existentes foram desenvolvidos em locais que apresentam condições climáticas distintas das condições paulistas e abordaram um outro 
enfoque. Caleffi et al. (2016) estudaram o efeito da chuva na segurança viária e Zechin et al. (2018) focaram na probabilidade de breakdown da corrente de tráfego, usando dados coletados na BR-290, na região metropolitana de Porto Alegre. Em Fortaleza, estudou-se a influência da chuva na velocidade de fluxo livre e fluxo de saturação em vias urbanas (MOREIRA; COSTA; CUNTO, 2017).

Dessa forma, surge uma lacuna de pesquisa e este trabalho buscou analisar o impacto combinado da precipitação com a luminosidade na operação das rodovias do estado de São Paulo. Nesta análise foram utilizadas imagens de radares meteorológicos para se determinar as condições meteorológicas devido à espacialidade das estações de monitoramento de tráfego e ao fato das imagens serem registradas a cada 15 minutos, mesmo intervalo dos dados de tráfego.

\subsection{Questões de pesquisa e objetivos}

As questões de pesquisa em que este trabalho foi baseado são as seguintes:

- A chuva interfere no comportamento da corrente de tráfego em rodovias de pista dupla no estado de São Paulo?

- A intensidade da precipitação interfere na operação do tráfego?

- A luminosidade exerce influência sobre a operação das rodovias?

- A combinação entre chuva e luminosidade interfere na operação do tráfego?

O objetivo principal desta pesquisa é analisar a influência combinada das condições meteorológicas e de luminosidade na operação das rodovias paulistas de pista dupla a partir dos parâmetros de modelos de fluxo de tráfego. Para atingir este objetivo, foram estabelecidos os seguintes objetivos específicos:

1. Obter e tratar uma amostra representativa de dados de tráfego nas condições ideais e chuvosas, considerando a intensidade da precipitação e a influência da luminosidade;

2. Desenvolver um método de tratamento e redução dos dados para ajuste de modelos de fluxo de tráfego usando bases de dados muito grandes;

3. Ajustar modelos de fluxos de tráfego para os locais estudados, para as diversas combinações de condições de chuva e luminosidade;

4. Analisar o impacto da chuva nos parâmetros dos modelos de tráfego, a partir da amostra disponível;

5. Analisar o impacto da luminosidade nos parâmetros dos modelos de tráfego, e 
6. Analisar a influência combinada das condições meteorológicas com a luminosidade e verificar os impactos nos parâmetros dos modelos de tráfego.

Para isto, foram utilizados dados de sensores de tráfego localizados em rodovias do estado de São Paulo e imagens geradas pelos radares meteorológicos de Bauru e Presidente Prudente. Os dados de tráfego foram fornecidos pela Agência de Transporte do Estado de São Paulo (ARTESP) e os dados meteorológicos foram fornecidos pelo Centro de Meteorologia de Bauru (IPMet/UNESP).

\subsection{Estrutura do texto}

Este trabalho está organizado em cinco capítulos. O primeiro capítulo consiste nesta introdução em que foram expostos a justificativa, as questões de pesquisa e os objetivos.

O Capítulo 2 apresenta o banco de dados, explicando o método utilizado para o georreferencimento dos sensores de tráfego, leitura das imagens dos radares meteorológicos, identificação da luminosidade, tratamento dos dados de tráfego e fusão do banco de dados de tráfego com o banco de dados de precipitação. No Capítulo 3 é apresentado o método para tratamento e ajuste dos dados quando se dispõe de uma base de dados muito grande. No Capítulo 4 são apresentados os resultados do ajuste do modelo de Van Aerde sob as diferentes condições meteorológicas e de luminosidade. Por fim, o Capítulo 5 discute as conclusões obtidas nesta pesquisa, sugerindo-se algumas recomendações para futuros trabalhos. 


\section{Capítulo}

\section{Fusão de dados}

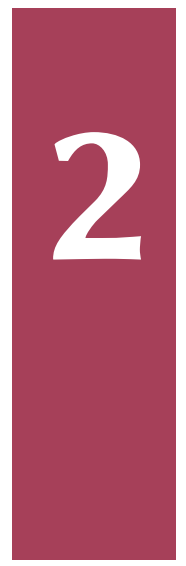

Para avaliar o impacto da precipitação no fluxo de tráfego, os dados meteorológicos e os dados de tráfego são fundidos. Estes dados devem ser coletados por um longo período de tempo para que existam dados suficientes nas condições ideais e adversas.

Agarwal, Maze e Souleyrette (2005) constataram que a qualidade dos dados de superfície do pavimento obtidos pelos sensores do sistema de informação meteorológica rodoviária (Road Weather Information Systems, RWIS) não são apropriados para a análise da relação entre a precipitação e as variáveis de tráfego. Diversos estudos (BRILON; PONZLET, 1996; SMITH et al., 2004; CAMACHO; GARCÍA; BELDA, 2010; TU et al., 2010; ZECHIN et al., 2018) utilizaram dados de estações meteorológicas na correlação com os dados de tráfego. Entretanto, Billot, El Faouzi e Vuyst (2009) alertam para a necessidade de se garantir que os pontos de coleta de tráfego sejam suficientemente próximos das estações meteorológicas para que as informações climáticas sejam espacialmente representativas e estejam correlacionadas às condições de tráfego.

Quando não se dispõe de uma densa rede de pluviômetros que estejam próximos dos sensores de tráfego, a medição realizada por radares meteorológicos se torna uma alternativa viável. Hooper, Chapman e Quinn (2014b) utilizaram dados do radar meteorológico NIMROD para determinar o impacto da precipitação na velocidade desenvolvida em uma autoestrada no Reino Unido. Após uma análise utilizando um sistema de informação geográfica, os autores criaram mapas para a obtenção dos valores de precipitação correspondentes aos dados de tráfego.

Os radares meteorológicos começaram a ser utilizados em 1960 para determinar as condições climáticas em tempo real (WILSON et al., 1998). Os radares meteorológicos Doppler fornecem a velocidade radial do vento, largura espectral e refletividade. Com estas três variáveis é possível estimar o campo de precipitação utilizando diferentes formas de visualização (Plan Position Indicator - PPI, Constant Altitute Plan Position Indicator - CAPPI, Range Height Indicator - RHI, dentre outras). A refletividade $Z$ é o parâmetro que mede a intensidade da precipitação. A uni- 
dade de medida utilizada é o decibel (dBZ) e seus valores variam de 0 à $60 \mathrm{dBZ}$. Quanto maior o valor da refletividade, maiores são os diâmetros dos hidrometeoros e, consequentemente, maior será a intensidade estimada da precipitação (CALVETTI; BENETI; ZANDONÁ, 2002).

Neste estudo, os dados meteorológicos são provenientes de imagens dos radares meteorológicos do Centro de Meteorologia de Bauru (IPMet/UNESP), localizados em Bauru e Presidente Prudente. Os dados foram segregados em condições de tempo bom ou chuvoso, nos períodos diurno e noturno, e posteriormente realizou-se a fusão com o banco de dados de tráfego.

Os dados de tráfego são informações referentes à contagem dos veículos pesados e de passeio e a média das velocidades desenvolvidas em períodos agregados de 15 minutos.

Neste capítulo são apresentadas as etapas para a fusão dos dados utilizados neste trabalho:

1. Obtenção dos dados de tráfego e meteorológicos;

2. Georreferencimento das estações de monitoramento de tráfego;

3. Identificação da condição meteorológica nos locais das estações de monitoramento;

4. Identificação da luminosidade nos locais de coleta dos dados;

5. Tratamento e organização dos dados de tráfego;

6. Fusão dos dados de tráfego com as condições meteorológicas;

7. Criação do banco de dados para o estudo.

\subsection{Obtenção dos dados de tráfego e meteorológicos}

Os dados de tráfego foram fornecidos pela Agência de Transporte do Estado de São Paulo (ARTESP) e consistem na contagem dos veículos pesados e de passeio e nas velocidades médias verificadas, agregadas em 15 minutos. Os dados foram obtidos de sensores de tráfego localizados em 17 trechos de rodovias de pista dupla e autoestradas de São Paulo durante o período de 2011 a 2017.

As informações meteorológicas consistem em imagens compostas obtidas dos radares meteorológicos do Centro de Meteorologia de Bauru (IPMet/UNESP). Os radares são do modelo banda-S com efeito Doppler, estão localizados em Bauru (22 $21^{\prime} 28^{\prime \prime} \mathrm{S} ; 49^{\circ} 1^{\prime} 36^{\prime \prime} \mathrm{W} ; 624 \mathrm{~m}$ ao nível médio do mar) e em Presidente Prudente ( $22^{\circ} 10^{\prime} 30^{\prime \prime} \mathrm{S} ; 51^{\circ} 22^{\prime} 21^{\prime \prime} \mathrm{W} ; 460 \mathrm{~m}$ ao nível médio do mar). As principais características dos radares são: abertura de feixe de $2^{\circ}$ com resolução de $1 \mathrm{~km}$ na radial e $1^{\circ}$ em azimute e resolução temporal máxima de 15 minutos. Os radares registram e armazenam refletividades, velocidades radiais e largura espectral em um raio de $450 \mathrm{~km}$ de alcance em modo vigilância e $240 \mathrm{~km}$ em modo de varredura volumétrica, cobrindo todo o estado de São Paulo (HELD; GOMES; CALHEIROS, 2008).

As imagens também são geradas a cada 15 minutos, o que facilita a compatibilização entre as informações de tráfego e de precipitação. Dessa forma, este trabalho utilizou dados agregados 


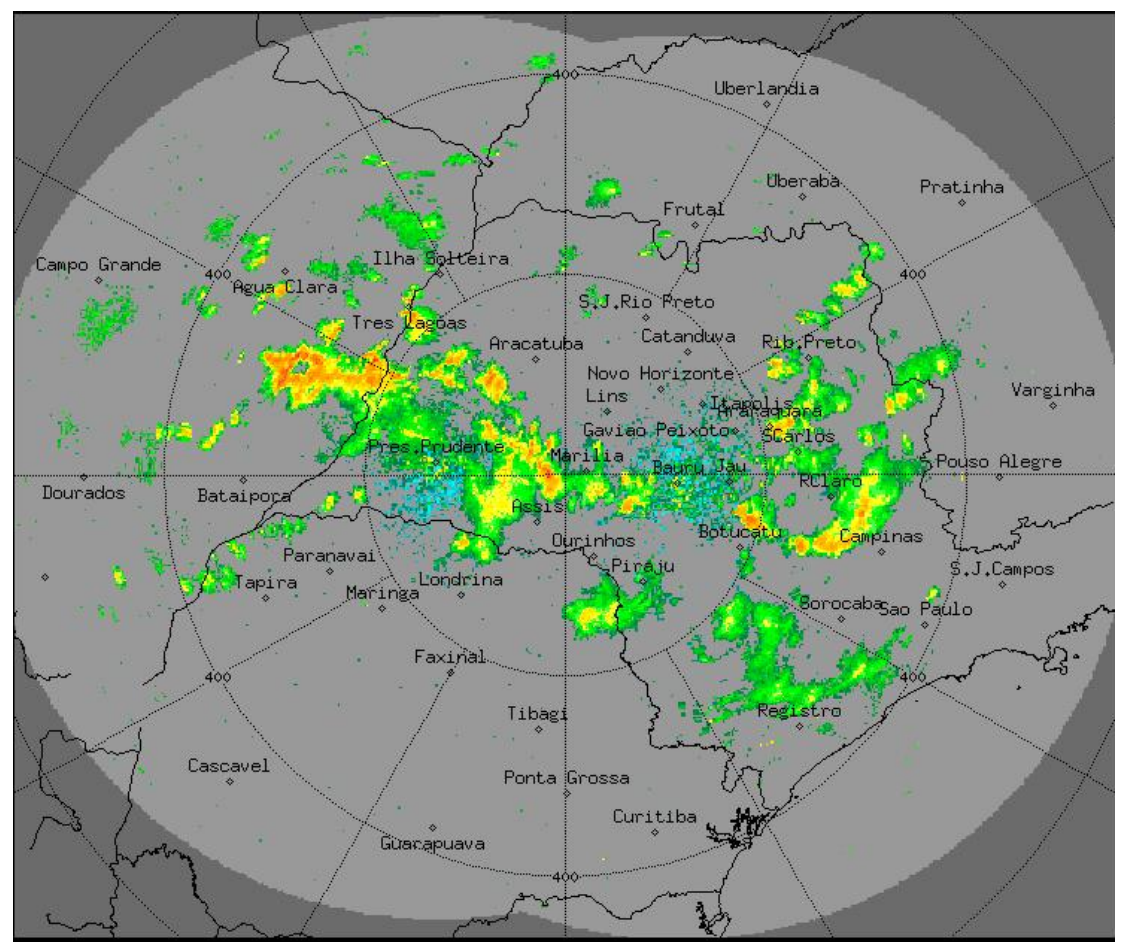

Figura 2.1: Área de cobertura dos radares meteorológicos [fonte: IPMet-UNESP]

de 15 minutos por ser o período correspondente aos dados fornecidos pela ARTESP e pelo IPMet.

\subsection{Georreferencimento das estações de monitoramento de tráfego}

No georreferenciamento das imagens dos radares foi utilizada uma transformação geométrica no plano. A transformação que apresentou os menores desvios foi a transformação afim. $\mathrm{Na}$ calibração desta transformação são utilizados seis parâmetros: dois parâmetros de escala, dois parâmetros de translação, um parâmetro de rotação e um parâmetro de não ortogonalidade.

Todas as imagens fornecidas pelo IPMet estão no fomato .tiff (Tagged Image File Format), foram geradas da mesma forma e possuem a mesma dimensão, 900×625 pixels. Assim, após o georreferenciamento de uma imagem, é possível estabelecer uma correspondência entre a posição geográfica dos sensores de tráfego com os pixels das imagens geradas pelos radares. Na Figura 2.1 é apresentada uma imagem gerada pelos radares sobreposta ao mapa do estado de São Paulo. A localização geográfica dos dois radares e as cidades indicadas na figura foram utilizadas como pontos de entrada no software Plot Digitizer para realizar a transformação afim.

O sistema de equações obtido da transformação afim foi:

$$
\left\{\begin{array}{l}
X=a \cdot \text { longitude }+b \cdot \text { latitude }+e \\
Y=-c \cdot \text { longitude }+d \cdot \text { latitude }+f
\end{array}\right.
$$


em que:

$$
\begin{aligned}
a & =69,1189 \pm 0,1 \text { graus }^{-1} \\
b & =0,3660 \pm 0,2 \text { graus }^{-1} \\
c & =-0,1543 \pm 0,1 \text { graus }^{-1} \\
d & =-74,9243 \pm 0,2 \text { graus }^{-1} \\
e & =3845,4991 \pm 6,3 \text { pixels } \\
f & =-1345,9958 \pm 6,3 \text { pixels } \\
(X, Y) & =\text { posição dos sensores na imagem, em pixels }
\end{aligned}
$$

Dessa forma, a partir da latitude e da longitude dos sensores de tráfego é possível determinar o pixel equivalente $(X, Y)$ nas imagens geradas pelos radares pela transformação afim. Posteriormente, pode-se selecionar esses pixels na imagem para determinar a intensidade de precipitação verificada em cada sensor de tráfego durante o período a que se refere a imagem do radar.

\subsection{Identificação da condição meteorológica nos locais das estações de monitoramento}

A condição meteorológica está associada à refletividade, intensidade do eco refletido pelo radar dada em decibel (dBZ). Quanto maior o dBZ, maior a taxa de precipitação (mm/h). A Tabela 2.1 mostra a correspondência entre a intensidade do pulso refletido com as características da precipitação e a segregação das intensidades adotada neste trabalho.

Tabela 2.1: Correspondência entre a refletividade e a intensidade de chuva [fonte: IPMetUNESP]

\begin{tabular}{llll}
\hline Intensidade (dBZ) & Precipitação & Intensidade & Segregação adotada \\
\hline 60 & Acima de $200 \mathrm{~mm} / \mathrm{h}$ & Extrema & \\
55 & 100 a $200 \mathrm{~mm} / \mathrm{h}$ & Muitíssimo forte & Chuva forte \\
50 & 50 a $100 \mathrm{~mm} / \mathrm{h}$ & Muito forte & \\
45 & 25 a $50 \mathrm{~mm} / \mathrm{h}$ & Forte & \\
\hline 40 & 12 a $25 \mathrm{~mm} / \mathrm{h}$ & Moderada forte & \\
35 & 6 a $12 \mathrm{~mm} / \mathrm{h}$ & Moderada & Chuva moderada \\
30 & 3 a $6 \mathrm{~mm} / \mathrm{h}$ & Moderada fraca & \\
\hline 25 & 1,5 a $3 \mathrm{~mm} / \mathrm{h}$ & Fraca & \\
20 & 1 a $1,5 \mathrm{~mm} / \mathrm{h}$ & Muito fraca & Chuva fraca \\
15 & 0,5 a $1 \mathrm{~mm} / \mathrm{h}$ & Garoa & \\
\hline
\end{tabular}

A Figura 2.2 apresenta uma imagem gerada pelos radares no dia 20 de Novembro de 2015. Nesta figura é possível notar a intensidade da chuva registrada pela escala de cores utilizada.

A intensidade da chuva pode ser obtida pela determinação do sistema de cores RGB (Red, Green e Blue) dos pixels da imagem. Cada um dos parâmetros R, G e B variam de 0 à 255 e 


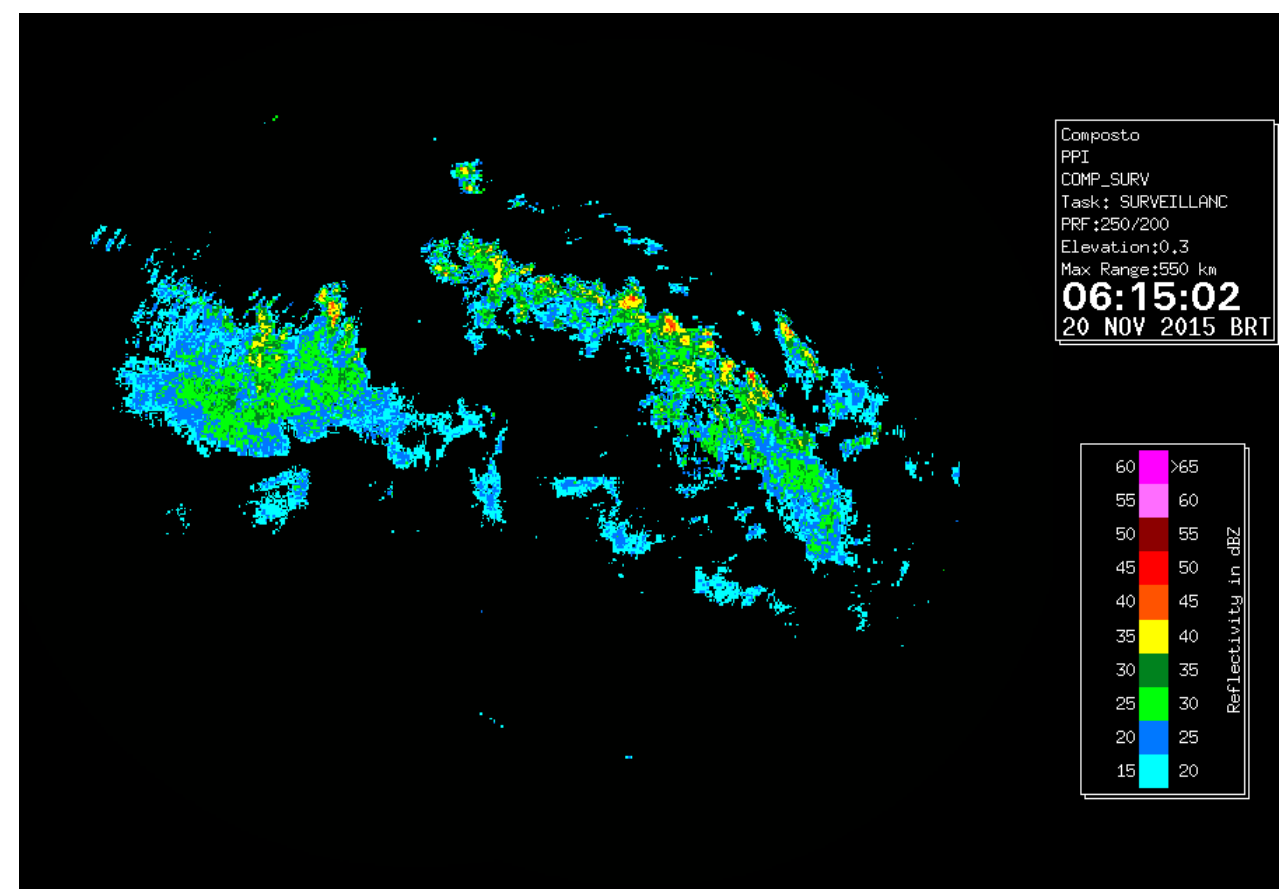

Figura 2.2: Imagem registrada pelos radares meteorológicos no dia 20 de Novembro de 2015 [fonte: IPMet-UNESP]

a combinação dos três reproduz um espectro cromático. Nas imagens geradas pelos radares meteorológicos, a cor preta - RGB $(0,0,0)$ - indica ausência de sinal refletido, ou seja, não está chovendo na região, e quando o pixel apresenta um valor RGB diferente de preto, significa que há precipitação no local analisado.

Para esta pesquisa foi desenvolvido um programa em Python que identifica o valor RGB dos pixels correspondentes à localização dos sensores de tráfego. Se o valor RGB apresentado pelo pixel for $(0,0,0)$ - representando a cor preta, classifica-se esta observação como "sem chuva". No entanto, se o valor RGB for diferente da cor preta significa que há precipitação e faz-se uma segunda análise que identifica a cor do pixel e o associa à intensidade de precipitação.

Na segunda análise, os valores RGB do pixel de interesse são comparados aos valores RGB da escala de precipitação. As imagens fornecidas pelo IPMet apresentam uma escala de cores discreta, segregadas nos dez intervalos de precipitação mostrados na Tabela 2.1.

A comparação entre as cores foi realizada utilizando a distância euclidiana entre os valores RGB do pixel de interesse e os valores RGB de cada cor da escala de cores. A distância euclidiana mede a hipotenusa de um triângulo de ângulo reto entre os três pontos no espaço RGB. Dessa forma, para cada pixel de interesse é possível calcular a distância euclidiana entre a cor deste pixel com as dez cores disponíveis na escala. Quando a distância euclidiana apresentar o menor valor, significa que o pixel de interesse apresenta a intensidade de precipitação correspondente à cor verificada na escala de cores. A segregação entre a intensidade da precipitação é possível porque o código calcula as dez distâncias euclidianas em ordem (da parte superior da escala à parte inferior, começando na posição 0 e terminando na posição 9). Assim, os da- 
dos são segregados por meio da determinação da posição da menor distância eucliana, ou seja, chuva forte (posição 0 - 3), chuva moderada (posição 4 - 6) e chuva fraca (posição 7 - 9).

Dessa forma, é possível determinar a condição meteorológica e classificá-la em: chuva fraca, moderada ou forte. O pseudocódigo utilizado na análise é:

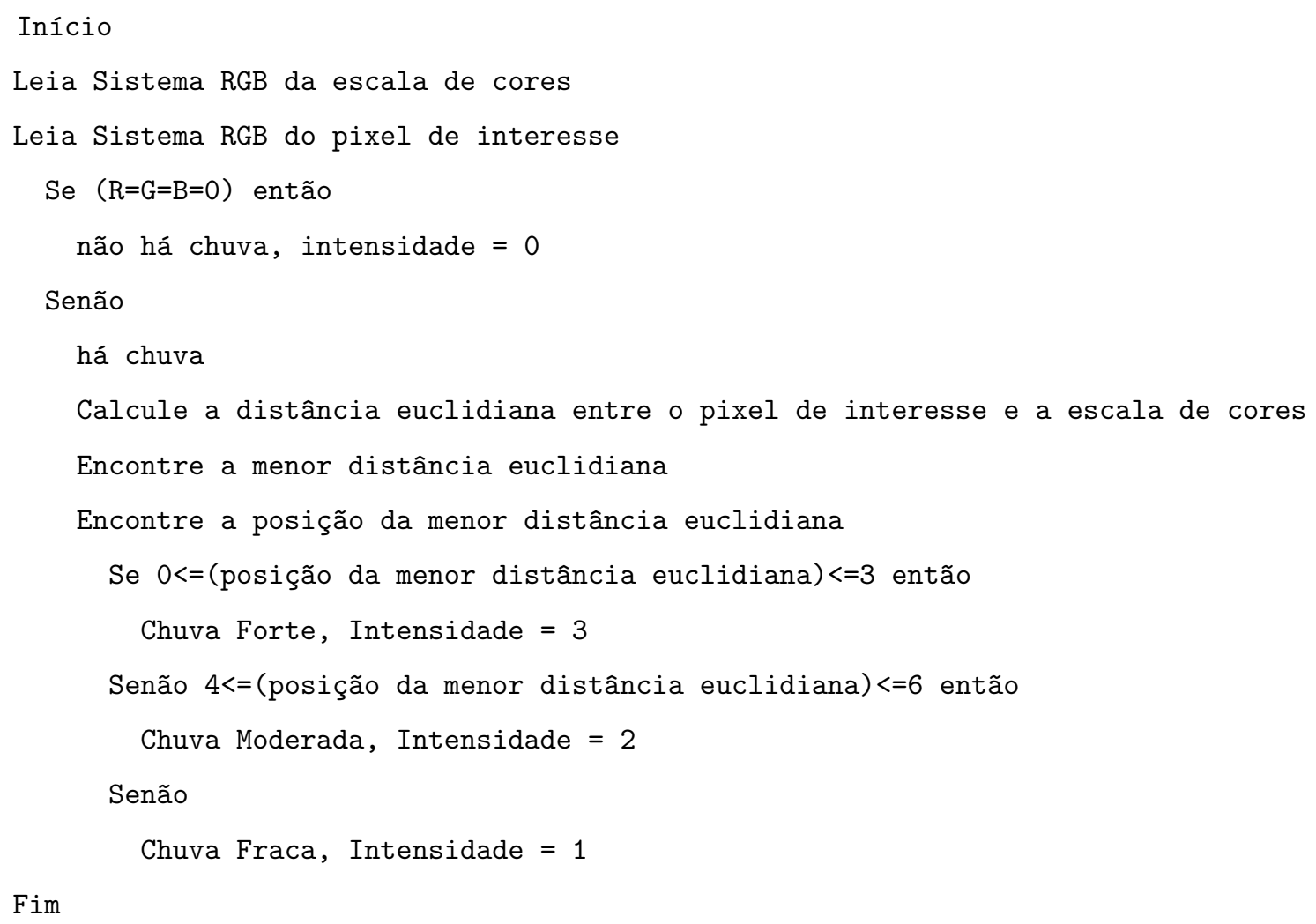

O IPMet disponibilizou 173.843 imagens que correspondem ao período de 1/9/2011 a 31/12/2017. Após o georreferenciamento dos sensores automáticos de tráfego (SATs) que, inicialmente, foram utilizados neste estudo, o código em Python realizou a leitura destas imagens e foram obtidas as seguintes quantidades de observações para os casos "sem chuva", "chuva fraca", "chuva moderada" e "chuva forte", apresentadas na Tabela 2.2. A lista dos sensores inicialmente utilizados neste estudo encontra-se no Apêndice A.

Tabela 2.2: Número de observações da intensidade de chuva nos locais de coleta dos dados de tráfego

\begin{tabular}{rrrrrr}
\hline Ano & Imagens & Sem chuva & Chuva fraca & Chuva moderada & Chuva forte \\
\hline 2011 & 8.802 & 805.901 & 17.639 & 3.733 & 115 \\
2012 & 26.119 & 2.384 .747 & 53.158 & 16.999 & 282 \\
2013 & 27.234 & 2.412 .802 & 49.717 & 97.259 & 218 \\
2014 & 25.477 & 2.334 .115 & 34.302 & 26.313 & 108 \\
2015 & 34.924 & 3.202 .091 & 45.902 & 34.728 & 135 \\
2016 & 26.697 & 2.458 .277 & 31.786 & 19.376 & 79 \\
2017 & 24.590 & 2.187 .780 & 35.965 & 87.661 & 54 \\
\hline Total & 173.843 & 15.785 .713 & 268.469 & 286.069 & 991 \\
\hline
\end{tabular}


Com a leitura de todas as imagens fornecidas pelo IPMet foi possível a criação de um banco de dados de precipitação nos locais de contagem de tráfego com as seguintes informações: ID do sensor de tráfego, data, hora e precipitação (sem chuva, chuva fraca, chuva moderada e chuva forte). Durante o período analisado faltam algumas imagens devido à falhas técnicas ou em função da manutenção dos radares, como: queda de raio, pintura da torre, perda de dados devido a queda de energia, dentre outros problemas enfrentados pelo IPMet. Dessa forma, os períodos em que não há o registro das imagens foram classificados como "sem informação" e foram excluídos do banco de dados de chuva.

\subsection{Identificação da luminosidade nos locais de coleta dos dados}

A segregação dos dados de tráfego em períodos diurnos e noturnos foi realizada utilizando as bibliotecas Astral e Datetime do Python. A biblioteca Astral determina os horários do alvorecer, nascer do sol, horário solar aparente, pôr do sol, crepúsculo, dentre outros horários para cada posição geográfica (latitude - longitude). A biblioteca Datetime foi utilizada para determinar os dias em que seriam determinados os horários solares. Dessa forma, foram determinados os horários do nascer do sol e do pôr do sol para cada sensor de tráfego durante todo o período estudado, entre os dias 1/9/2011 e 31/12/2017.

A determinação do período diurno foi feita adotando o quarto de hora mais próximo do horário do nascer do sol até o quarto de hora mais próximo ao horário do pôr do sol. Os demais horários foram adotados como período noturno. Estes intervalos foram estabelecidos para facilitar a compatibilização com as informações obtidas dos sensores de tráfego e com as informações obtidas pelas imagens dos radares meteorológicos, já que as duas informações estão em intervalos agregados de 15 minutos.

Por exemplo, para o sensor da SP-280 km 26,9 Leste, no dia 26 de Setembro de 2017, os horários entre as $06 \mathrm{~h} 00$ e $18 \mathrm{~h} 15$ foram considerados "período diurno" e receberam a variável binária 0 na criação da coluna correspondente à luminosidade no banco de dados. Os demais intervalos, antes das $6 \mathrm{~h}$ e após as $18 \mathrm{~h} 15$, foram considerados "período noturno" e receberam a variável binária 1 no banco de dados.

\subsection{Tratamento e organização dos dados de tráfego}

A ARTESP forneceu dados dos SATs presentes em 17 trechos de rodovias de São Paulo. Estes trechos estão sob a concessão de seis empresas: CCR AutoBAn, CCR ViaOeste, CCR RodoAnel Oeste, Ecovias, Ecopistas e Rota das Bandeiras. As concessionárias disponibilizam estes dados em intervalos agregados de 15 minutos, porém com informações e formatos de apresentação diferentes. Dessa forma, foi necessário padronizar as observações de todos os sensores para a criação do banco de dados de tráfego. 
As informações fornecidas incluem: data, hora do início do intervalo, hora do fim do intervalo, número de automóveis, número de veículos pesados e velocidade média dos veículos. Com o banco de dados apresentando estas informações, foi necessário eliminar as observações com erros aparentes do funcionamento dos SATs, dentre eles: presença de valores repetidos várias vezes, valores muito discrepantes em relação à serie temporal e ausência de informações. Estas observações foram excluídas do banco de dados de tráfego.

\subsection{Fusão dos dados de tráfego com as condições meteorológicas}

Após a padronização dos dados de tráfego e a análise das condições meteorológicas nos locais em que os sensores estão localizados, as duas informações foram combinadas, gerando um único banco de dados com informações de tráfego e chuva para intervalos de 15 minutos, entre 0 h00 de 1/9/2011 e 24 h00 de 31/12/2017.

No entanto, as imagens dos radares meteorológicos são geradas a cada 15 minutos e os sensores de tráfego registram a velocidade média e contagem dos veículos durante estes 15 minutos. Assim, é necessário analisar duas imagens consecutivas para deduzir a condição meteorológica no intervalo correspondente.

Se uma imagem apresentar tempo bom e a imagem seguinte apresentar tempo chuvoso, não é possível determinar quando começou a chover e quando a chuva começou a impactar a operação do tráfego. O mesmo problema é verificado se uma imagem apresentar tempo chuvoso e a imagem seguinte apresentar tempo bom, já que também neste caso não é possível determinar quando parou de chover neste local. Entretanto, vale ressaltar que caso seja verificada chuva forte ou moderada na primeira imagem e na imagem seguinte seja verificado tempo bom, é possível que os efeitos da chuva ainda sejam sentidos pelos motoristas, como a perda de visibilidade e pista molhada. Dessa forma, as leituras das imagens consecutivas foram analisadas e foi adotado o critério indicado na Figura 2.3.

Na Figura 2.3 nota-se que quando duas imagens consecutivas apresentam a mesma condição meteorológica, esta leitura foi adotada para todo o intervalo de 15 minutos. Quando duas imagens consecutivas apresentam leituras diferentes foi adotada para as condições da pista a maior intensidade de precipitação, como verificado nas situações $1,2,3,5,6,8,9$ e 12, apresentadas na Tabela 2.3, pois entende-se que a pista está molhada e a baixa visibilidade ainda influenciam o comportamento dos motoristas.

Nas situações 7, 10 e 11 foi adotada uma intensidade de chuva intermediária entre as sucessivas condições verificadas. E na situação 4, quando ocorre uma leitura de "chuva fraca" e na imagem seguinte é verificada a condição "sem chuva", a condição meteorológica "sem chuva" foi adotada para o intervalo correspondente pois considerou-se que o próprio fluxo veicular é suficiente para secar a pista e fazer com que os efeitos da chuva não impactem na direção dos motoristas. 
Com as considerações feitas e os critérios adotados, é possível agregar o banco de dados de precipitação ao banco de dados de tráfego nos intervalos correspondentes de 15 minutos.

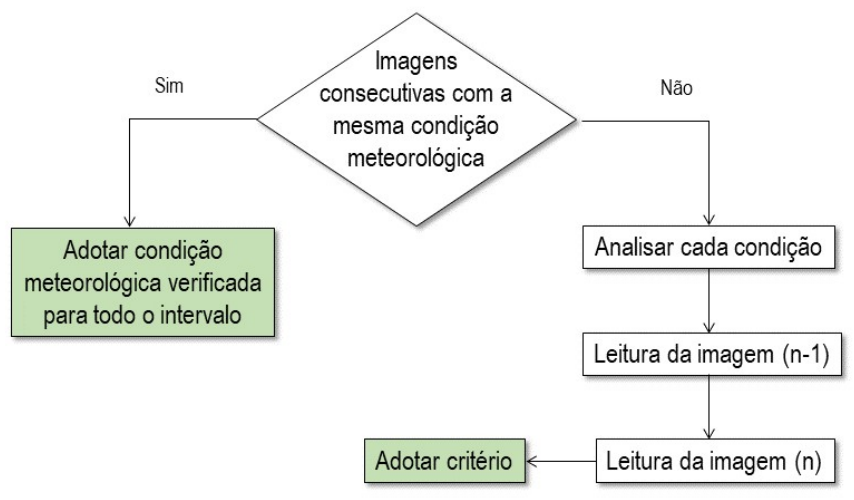

Figura 2.3: Fluxograma com o critério adotado para a leitura de imagens consecutivas

Tabela 2.3: Critério adotado quando as imagens consecutivas apresentam leituras diferentes

\begin{tabular}{lll}
\hline Leitura da imagem $(\mathbf{n}-\mathbf{1})$ & Leitura da imagem $(\mathbf{n})$ & Intensidade adotada para o período \\
\hline \multirow{3}{*}{ Sem chuva } & Chuva fraca & 1. Chuva fraca \\
& Chuva moderada & 2. Chuva moderada \\
& Chuva forte & 3. Chuva forte \\
\hline \multirow{3}{*}{ Chuva fraca } & Sem chuva & 4. Sem chuva \\
& Chuva moderada & 5. Chuva moderada \\
& Chuva Forte & 6. Chuva forte \\
Chuva moderada & Sem chuva & 7. Chuva fraca \\
& Chuva fraca & 8. Chuva moderada \\
& Chuva forte & 9. Chuva forte \\
\hline \multirow{3}{*}{ Chuva forte } & Sem chuva & 10. Chuva moderada \\
& Chuva fraca & 11. Chuva moderada \\
& Chuva moderada & 12. Chuva forte \\
\hline
\end{tabular}

\subsection{Criação do banco de dados para o estudo}

Com os dois bancos de dados agregados pela informação concomitante da data e hora em que as imagens e os dados de tráfego foram gerados, obteve-se o banco de dados utilizado neste estudo.

Neste banco de dados final foram estabelecidos os fatores de conversão dos veículos pesados para carros de passeio equivalentes (cpe) usando-se o fator de equivalência estabelecido pela ARTESP para cada trecho. Em seguida, a densidade da corrente foi estimada através da equação fundamental do tráfego $(k=q / v)$, de tal modo que, para cada intervalo de observação têmse a taxa de fluxo de tráfego $q$, em cpe/(h.faixa), a velocidade média da corrente de tráfego $v$ $(\mathrm{km} / \mathrm{h})$, a densidade da corrente $k$, em cpe/(km.faixa), a condição meteorológica (sem chuva, chuva fraca, chuva moderada ou chuva forte) e o período do dia (diurno ou noturno). 


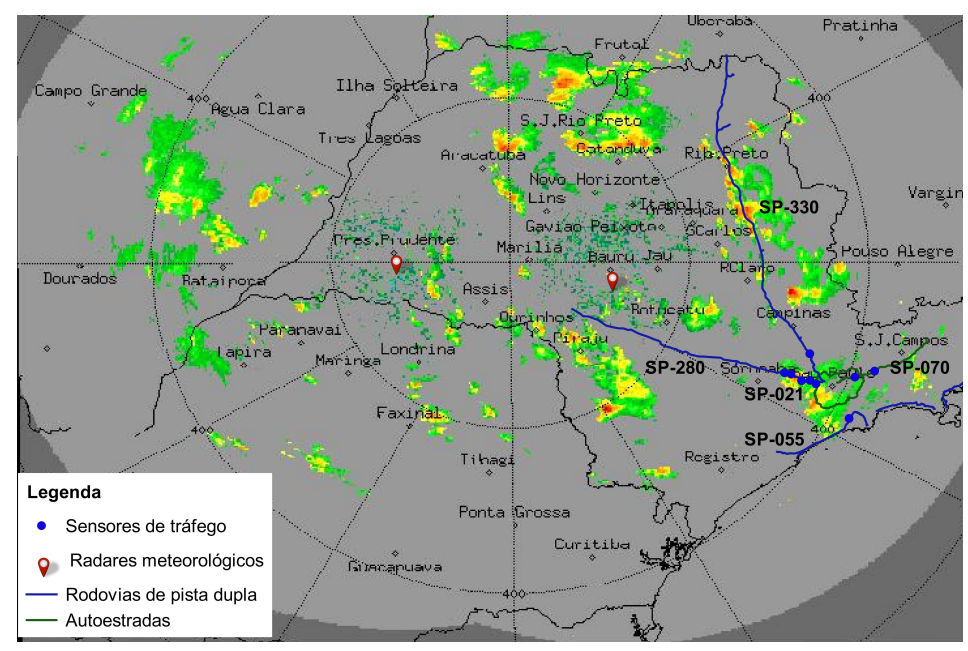

Figura 2.4: Área de cobertura dos radares meteorológicos e localização das estações de monitoramento de tráfego usadas neste estudo [Adaptado de imagem fornecida pelo IPMet/UNESP]

Verificou-se que da quantidade de sensores iniciais, alguns não apresentavam ou apresentavam poucos dados na região congestionada, outros sensores apresentavam dados na região de fluxo livre que não se aproximavam da capacidade e outros sensores apresentavam dados claramente manipulados. Estes sensores foram excluídos do banco de dados e o ajustamento do modelo não foi realizado.

Dos sensores restantes, segregou-se os dados em condições chuvosas e não chuvosas e verificou-se que alguns sensores não apresentavam muitos dados com chuva na região congestionada, o que também interferia no ajuste e, consequentemente, na análise da influência da precipitação na operação das rodovias. Estes sensores também foram excluídos do banco de dados.

Após a exclusão de todos estes sensores, a análise foi realizada utilizando os dados registrados em 12 SATs provenientes de cinco concessionárias: CCR AutoBAn, CCR ViaOeste, CCR RodoAnel Oeste, Ecovias e Ecopistas. Estes sensores estão instalados em trechos onde o acesso é controlado e estão fora da área de influência de dispositivos de acesso da via. Os trechos estudados também apresentam pavimentação e sinalização em boas condições. A Figura 2.4 mostra a localização dos sensores e a Tabela 2.4 apresenta algumas características destes pontos de monitoramento.

Na Tabela 2.5 é apresentado o número de observações para cada um dos 12 sensores utilizados nesta pesquisa. As colunas "Tráfego" e "Meteorologia" apresentam, respectivamente, a quantidade de observações válidas de tráfego e de chuva durante o período de 1/9/2011 a 31/12/2017 e a coluna "Fusão de dados" apresenta a quantidade total de observações existentes combinadas de tráfego com a condição meteorológica. No entanto, foram usados somente os dados de tráfego registrados entre $5 \mathrm{~h}$ e $22 \mathrm{~h}$, pois se considerou que o fluxo durante as madrugadas não é representativo da operação das rodovias devido ao baixo número de veículos e à elevada porcentagem de veículos pesados. 
Tabela 2.4: Características dos pontos de monitoramento do tráfego

\begin{tabular}{|c|c|c|c|c|c|c|c|c|}
\hline \multirow[b]{2}{*}{ Id } & \multirow[b]{2}{*}{ Rodovia } & \multirow[b]{2}{*}{ km } & \multirow[b]{2}{*}{ Sentido } & \multicolumn{2}{|c|}{ Limite de velocidade } & \multirow{2}{*}{$\begin{array}{l}\text { Número } \\
\text { de } \\
\text { faixas }\end{array}$} & \multirow[b]{2}{*}{ Tipo de via } & \multirow{2}{*}{$\begin{array}{l}\text { Ocupação } \\
\text { lindeira }\end{array}$} \\
\hline & & & & Leves & Pesados & & & \\
\hline 1 & SP-021 & 18,3 & Externo & 100 & 80 & 4 & Autoestrada & Urbano \\
\hline 2 & SP-021 & 18,3 & Interno & 100 & 80 & 5 & Autoestrada & Urbano \\
\hline 3 & SP-280 & 26,9 & Oeste & 100 & 90 & 3 & Rodovia de pista dupla & Urbano \\
\hline 4 & SP-280 & 26,9 & Leste & 100 & 90 & 3 & Rodovia de pista dupla & Urbano \\
\hline 5 & SP-330 & 55,2 & Norte & 100 & 80 & 2 & Rodovia de pista dupla & Urbano \\
\hline 6 & SP-330 & 55,2 & Sul & 100 & 80 & 2 & Rodovia de pista dupla & Urbano \\
\hline 7 & SP-055 & 276,9 & Oeste & 110 & 90 & 3 & Rodovia de pista dupla & Rural \\
\hline 8 & SP-070 & 30,0 & Oeste & 110 & 90 & 4 & Autoestrada & Urbano \\
\hline 9 & SP-070 & 54,1 & Oeste & 120 & 90 & 2 & Autoestrada & Rural \\
\hline 10 & SP-280 & 37,0 & Leste & 120 & 90 & 3 & Rodovia de pista dupla & Rural \\
\hline 11 & SP-280 & 51,9 & Oeste & 120 & 90 & 3 & Rodovia de pista dupla & Rural \\
\hline 12 & SP-280 & 59,6 & Leste & 120 & 90 & 3 & Rodovia de pista dupla & Rural \\
\hline
\end{tabular}

Tabela 2.5: Número de observações correspondendo a intervalos de 15 min em cada SAT

\begin{tabular}{|c|c|c|c|c|c|c|c|c|c|}
\hline \multirow[b]{2}{*}{ Id } & \multicolumn{2}{|c|}{ Banco de dados } & \multirow{2}{*}{ Fusão de dados } & \multicolumn{6}{|c|}{ Dados das $5 \mathrm{~h}$ às $22 \mathrm{~h}$} \\
\hline & Tráfego & Meteorologia & & Total & $\begin{array}{l}\text { Sem } \\
\text { chuva }\end{array}$ & $\begin{array}{l}\text { Chuva } \\
\text { fraca }\end{array}$ & $\begin{array}{l}\text { Chuva mo- } \\
\text { derada }\end{array}$ & $\begin{array}{l}\text { Chuva } \\
\text { forte }\end{array}$ & $\begin{array}{l}\text { Total com } \\
\text { chuva }\end{array}$ \\
\hline 1 & 153.804 & 173.391 & 116.725 & 82.571 & 79.778 & 1.509 & 1.270 & 14 & 2.793 \\
\hline 2 & 154.257 & 173.391 & 117.301 & 82.967 & 80.155 & 1.526 & 1.272 & 14 & 2.812 \\
\hline 3 & 118.226 & 107.690 & 91.059 & 66.827 & 64.280 & 1.432 & 1.113 & 2 & 2.547 \\
\hline 4 & 126.436 & 107.690 & 92.724 & 65.698 & 63.152 & 1.458 & 1.086 & 2 & 2.546 \\
\hline 5 & 131.986 & 107.692 & 100.319 & 71.050 & 67.895 & 1.840 & 1.307 & 8 & 3.155 \\
\hline 6 & 130.499 & 107.692 & 99.251 & 70.272 & 67.128 & 1.831 & 1.305 & 8 & 3.144 \\
\hline 7 & 161.403 & 164.529 & 126.451 & 89.533 & 87.535 & 519 & 1.479 & 0 & 1.998 \\
\hline 8 & 198.361 & 173.403 & 148.517 & 105.277 & 102.251 & 1.116 & 1.905 & 5 & 3.026 \\
\hline 9 & 208.423 & 173.399 & 162.412 & 114.913 & 112.081 & 855 & 1.975 & 2 & 2.832 \\
\hline 10 & 128.391 & 107.686 & 97.380 & 68.948 & 66.191 & 1.560 & 1.195 & 2 & 2.757 \\
\hline 11 & 130.594 & 107.684 & 99.975 & 70.727 & 67.527 & 1.907 & 1.289 & 4 & 3.200 \\
\hline 12 & 128.283 & 107.692 & 98.293 & 69.633 & 66.599 & 1.822 & 1.211 & 1 & 3.034 \\
\hline Total & 1.770 .663 & 1.611 .939 & 1.350 .407 & 958.416 & 924.572 & 17.375 & 16.407 & 62 & 33.844 \\
\hline
\end{tabular}

Inicialmente, os dados foram segregados de acordo com a intensidade da precipitação (sem chuva, chuva fraca, chuva moderada e chuva forte). Observando-se os dados da Tabela 2.5, é possível perceber que a quantidade de dados para períodos chuvosos é muito menor que o número para períodos de tempo bom; além disso, o volume de dados para chuva forte é muito pequeno, o que reduz a qualidade de ajuste dos modelos fluxo-velocidade-densidade. Dessa forma, para a análise da influência da precipitação considerou-se somente a segregação em condições sem chuva (coluna 6) e com chuva (coluna 10), apresentadas na Tabela 2.5.

Mesmo após a eliminação de dados devido ao mau funcionamento dos sensores de tráfego e eliminação devido aos problemas em relação aos dados meteorológicos, é possível que ainda existam muitas observações espúrias. Durante o período de coleta dos dados, podem ter ocorrido obras, acidentes, interdições de faixas e demais incidentes que afetam o comportamento do fluxo de tráfego e não representam o comportamento normal da via. As ocorrências destes incidentes não foram fornecidas pela ARTESP e são ruídos que podem afetar o ajuste dos 
modelos de fluxo de tráfego. Dessa forma, surgiu a necessidade de propor um método para eliminar estes dados com ruídos e realizar o ajuste de modelos fluxo-velocidade-densidade quando se dispõe de uma base de dados muito grande (very large database - VLDB). O método proposto é apresentado no Capítulo 3. 


\section{Capítulo}

\section{Ajuste de modelos de fluxo de tráfego com base em VLDB}

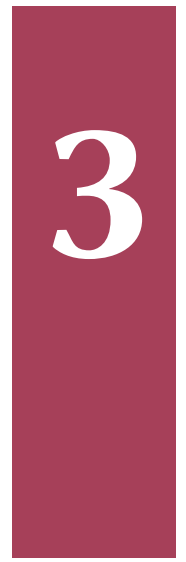

Em análises de correntes de tráfego, corriqueiramente são utilizados dados coletados por sensores automáticos de tráfego (SAT) que, funcionando continuamente, podem acumular uma enorme quantidade de observações. No entanto, estes dados incluem ruídos que podem enviesar os modelos. Obras, acidentes, intempéries, defeitos nos sensores e incidentes que afetam o comportamento do fluxo de tráfego são condições anômalas que não representam a operação normal da via. Pode-se esperar que, numa base de dados muito grande (VLDB, de very large database), cobrindo um período de vários anos, uma parcela não desprezível das observações inclui ruído.

Neste capítulo ${ }^{1}$ propõe-se um processo para ajuste de modelos fluxo-velocidade-densidade a partir de uma VLDB. O modelo escolhido para este estudo foi o proposto por Van Aerde (RAKHA, 2009), por ser um modelo bastante disseminado e as técnicas de otimização testadas foram o algoritmo hill climbing (AHC) e o algoritmo genético (AG).

\subsection{Revisão da literatura}

Um modelo de tráfego descreve as relações macroscópicas entre fluxo $(q)$, velocidade $(u)$ e densidade $(k)$ (MAY, 1990), num sistema de equações consistindo de uma equação de continuidade $\partial q / \partial x+\partial k / \partial t=0$, uma equação de estado $q=u \cdot k$ e uma relação entre a velocidade e a densidade $u=f(k)$ (LU et al., 2010). A hipótese fundamental para a definição de um modelo é que, para cada local específico, existe uma relação única entre $u, k$, e $q$, denominada diagrama fundamental, no qual residem todas as soluções para um modelo steady-state para essa corrente de tráfego (KERNER, 2004). As relações de tráfego são alvo de constantes estudos dado

\footnotetext{
${ }^{1}$ Este capítulo é baseado num trabalho apresentado no 33 Congresso de Pesquisa e Ensino em Transportes, realizado em Camboriú, SC, em novembro de 2019 e publicado nos seus anais (CARDOSO; ASSIRATI; SETTI, 2019).
} 
sua capacidade informacional quanto às características das vias e dos condutores.

Tais relações têm sido estudadas desde 1933, com a publicação do modelo de Greenshields (KÜHNE, 2011). Desde então foram desenvolvidos diversos outros modelos entre os quais os propostos por Greenberg (1959), Underwood (MAY, 1990), Drake (LU et al., 2010), Pipes (RAKHA; CROWTHER, 2003) e, mais recentemente, o modelo de Van Aerde (RAKHA, 2009) e o intelligentdriver model (TREIBER; HENNECKE; HELBING, 2000), além do modelo usado no HCM (TRB, 2016). O modelo de Greenshields é conhecido por seu caráter pioneiro; neste modelo, a relação entre a densidade e a velocidade é linear.

O ajuste das funções que compõem o modelo de tráfego é feito a partir de dados coletados por sensores automáticos de tráfego, que fornecem medidas independentes de fluxo, velocidade e ocupância (da qual pode ser estimada a densidade), às quais está sempre associado um erro. Sabe-se que a regressão de uma variável dependente $y$ em função de uma variável independente $x$ tal que $y=f_{1}(x)$ não produz a mesma relação que a regressão de $x$ em função de $y$ (DRAPER; SMITH, 1980). Para evitar esse problema, numa regressão, deve-se definir claramente quais as variáveis independentes e quais as variáveis dependentes, uma vez que supõe-se que apenas a variável dependente contém um erro de medida - ou seja, a regressão $u=f(k)$, em que se admite que a densidade $k$ é a variável explanatória (independente) e que a velocidade $u$ é a variável dependente, a regressão minimiza apenas o erro ligado à estimativa da velocidade. Rakha e Arafeh (2010) demonstram que esse não é o caso dos modelos de tráfego, uma vez que não é possível definir claramente qual a variável independente, já que, dependendo da situação, qualquer uma das três variáveis pode ser o fator determinante para o comportamento do tráfego, e que as três variáveis trazem inerentemente um erro de medida.

Para evitar isso, Rakha e Arafeh (2010) propõem que o ajuste seja baseado numa regressão neutra, na qual se dispensa a determinação da variável dependente e o ajuste procura minimizar o erro quadrático ortogonal normalizado do diagrama fundamental do modelo escolhido, de tal forma que o modelo de otimização pode ser descrito como:

$$
\operatorname{minimizar} E=\sum_{i}\left\{\left(\frac{u_{i}-\hat{u}_{i}}{\tilde{u}}\right)^{2}+\left(\frac{q_{i}-\hat{q}_{i}}{\tilde{q}}\right)^{2}+\left(\frac{k_{i}-\hat{k}_{i}}{\tilde{k}}\right)^{2}\right\}
$$

sujeito à

$$
\begin{aligned}
\hat{u}_{i} & =f\left(\hat{k}_{i}\right) \quad \forall i, \\
\hat{q}_{i} & =\hat{k}_{i} \times \hat{u}_{i} \quad \forall i, \\
\hat{q}_{i}, \hat{k}_{i}, \hat{u}_{i} & \geq 0 \quad \forall i,
\end{aligned}
$$

em que $E$ é o erro quadrático ortogonal estimado; $u_{i}, q_{i}$ e $k_{i}$ valores observados de velocidade, fluxo e densidade para um evento $i ; \hat{u}_{i}, \hat{q}_{i}$ e $\hat{k}_{i}$ são os valores estimados para velocidade, fluxo e densidade para um evento $i$; e $\tilde{u}, \tilde{q}$ e $\tilde{k}$ são os valores máximos observados para velocidade, fluxo e densidade. Esta abordagem pode ser aplicada a qualquer modelo de tráfego (RAKHA; ARAFEH, 2010). 
O modelo de Van Aerde combina os modelos de Pipes e Greenberg (LU et al., 2010) e é capaz de representar os fluxos livre e congestionado através de uma única função matemática, sem que seja necessário estabelecer breakpoints que separem esses dois regimes (RAKHA, 2009). Em função da sua estrutura matemática, foi demonstrado que esse modelo é capaz de representar adequadamente o comportamento da corrente de tráfego tanto em freeways como em rodovias de pista dupla ou mesmo em arteriais urbanas (RAKHA; CROWTHER, 2003). Por sua versatilidade, o modelo de Van Aerde foi adotado pelo manual de capacidade alemão HBS - Handbuch für die Bemessung von Straßenverkehrsanlagen (FGSV, 2015).

O modelo para as relações entre fluxo $(q)$, velocidade $(u)$ e densidade $(k)$ de Van Aerde é baseado em quatro parâmetros: a velocidade livre (também chamada de velocidade de fluxo livre) $u_{f}$, a velocidade na capacidade $u_{c}$, a capacidade $q_{c}$, e a densidade de congestionamento $k_{j}$ (RAKHA, 2009). Matematicamente, o modelo é expresso por:

$$
\begin{aligned}
& q=u \cdot k \\
& k=\frac{1}{c_{1}+\frac{c_{2}}{u_{f}-u}+c_{3} u}
\end{aligned}
$$

em que $c_{1}(\mathrm{~km}) ; c_{2}\left(\mathrm{~km}^{2} / \mathrm{h}\right)$; e $c_{3}(\mathrm{~h})$ são constantes calculadas por (DEMARCHI, 2003):

$$
\begin{aligned}
& c_{1}=\frac{u_{f}}{k_{j} u_{c}^{2}}\left(2 u_{c}-u_{f}\right) \\
& c_{2}=\frac{u_{f}}{k_{j} u_{c}^{2}}\left(u_{f}-u_{c}\right)^{2} \mathrm{e} \\
& c_{3}=\frac{1}{q_{j}}-\frac{u_{f}}{k_{j} u_{c}^{2}} .
\end{aligned}
$$

Van Aerde e Rakha (1995) propuseram que o ajuste do modelo fosse feito através da minimização dos erros quadráticos ortogonais utilizando um algoritmo hill climbing (AHC) (uma técnica de otimização matemática que envolve um processo iterativo) para ajustar os parâmetros do modelo: $u_{f}, u_{c}, k_{j}$, e $q_{c}$. Rakha e Arafeh (2010) revisaram a abordagem de Van Aerde e Rakha (1995), propondo um ajuste multiestágio, não mais baseado num AHC.

Diversos estudos (HRANAC et al., 2006; RAKHA et al., 2008; BILLOT; EL FAOUZI; VUYST, 2009; DHALIWAL et al., 2017) analisaram o efeito das condições meteorológicas sobre a corrente de tráfego por meio do ajuste do modelo de Van Aerde para as condições chuvosas e sem chuva. Este modelo pode ser calibrado a partir de dados de sensores automáticos e, além de ser capaz de representar diferentes tipos de rodovias, tem a vantagem de expressar os regimes de fluxo livre e fluxo congestionado através de uma função contínua, tão bem quanto modelos de regime múltiplo (RAKHA, 2009).

Usualmente os modelos fluxo-velocidade-densidade utilizam dados coletados automaticamente nas estações de monitoramento de tráfego (HALL; HURDLE; BANKS, 1992). Contudo, o 
uso de dados coletados por sensores automáticos para o ajuste desses modelos está ligado a uma série de problemas (KNOOP; DAAMEN, 2017): (a) corrente de tráfego pode não estar em equilíbrio durante o período de observação; (b) o tráfego é heterogêneo; (c) os detectores não são capazes de detectar veículos parados; (d) o número de veículos medido durante um intervalo é sempre inteiro; e (e) a velocidade média registrada pelo sensor é a velocidade média no tempo, e não a velocidade média no espaço.

O ajuste desses modelos com bases de dados muito grandes (VLDBs), que contém dados coletados durante vários meses ou anos, está associada a um outro problema, que é o ruído nos dados. Durante a operação das rodovias podem ocorrer diversos incidentes (obras, interdições de faixas, acidentes, intempéries, defeitos nos sensores, etc.) que fazem com que os dados coletados apresentem ruídos (dados espúrios) que podem viciar o ajuste dos modelos.

Alguns estudos têm analisado a influência destes incidentes na operação do tráfego. Lu e Elefteriadou (2013) desenvolveram um modelo de previsão da redução da capacidade quando ocorre incidentes. Smith, Qin e Venkatanarayana (2003) caracterizaram a redução na capacidade resultante dos acidentes de tráfego e verificaram que em vias de três faixas, quando uma faixa é bloqueada, uma redução de $63 \%$ na capacidade é verificada; e reduções de $77 \%$ são observadas quando duas faixas são bloqueadas. O que indica quantitativamente o impacto que um incidente causa na operação das rodovias. O HCM-6 apresenta fatores de ajuste da influência dos incidentes na capacidade considerando o número de faixas bloqueadas (TRB, 2016, p. 11-44).

$\mathrm{Na}$ falta de informações confiáveis sobre esses incidentes, é indispensável definir um método capaz de lidar com os ruídos para modelar de maneira satisfatória a corrente de tráfego de uma rodovia, de modo semelhante ao usado para detectar incidentes em freeways, que integram lógica fuzzy, wavelets e redes neurais para melhorar a confiabilidade do método e eliminar ruídos e dados espúrios (KARIM; ADELI, 2002). Estes trabalhos, especialmente os que lidam com VLDBs, mostram as dificuldades em filtrar os dados brutos para que as interferências causadas pelos ruídos sejam minimizadas.

VLDBs exigem que o ajuste do modelo seja feito de modo automático o que pode levar a distorções nos resultados, se o conjunto de dados não for depurado e preparado para o processo. A visualização de uma grande quantidade de dados se torna um desafio computacional e para o caso específico da calibração dos modelos fluxo-velocidade-densidade, a grande quantidade de dados com baixas densidades pode enviesar o modelo, já que a curva calibrada tende a passar próxima destas observações. Wickham (2013) apresenta um método para visualização de uma grande quantidade de dados com base na segregação em intervalos (bins). Dessa forma, a informação é resumida, suavizada e ainda representa os dados originais.

Em trabalhos que utilizam VLDBs, costuma-se segregar os dados em pequenos intervalos de densidade e, para cada intervalo, calcula-se a média ou diferentes percentis da velocidade. Dessa forma, o fluxo é estabelecido em função da densidade e da velocidade, por meio da 

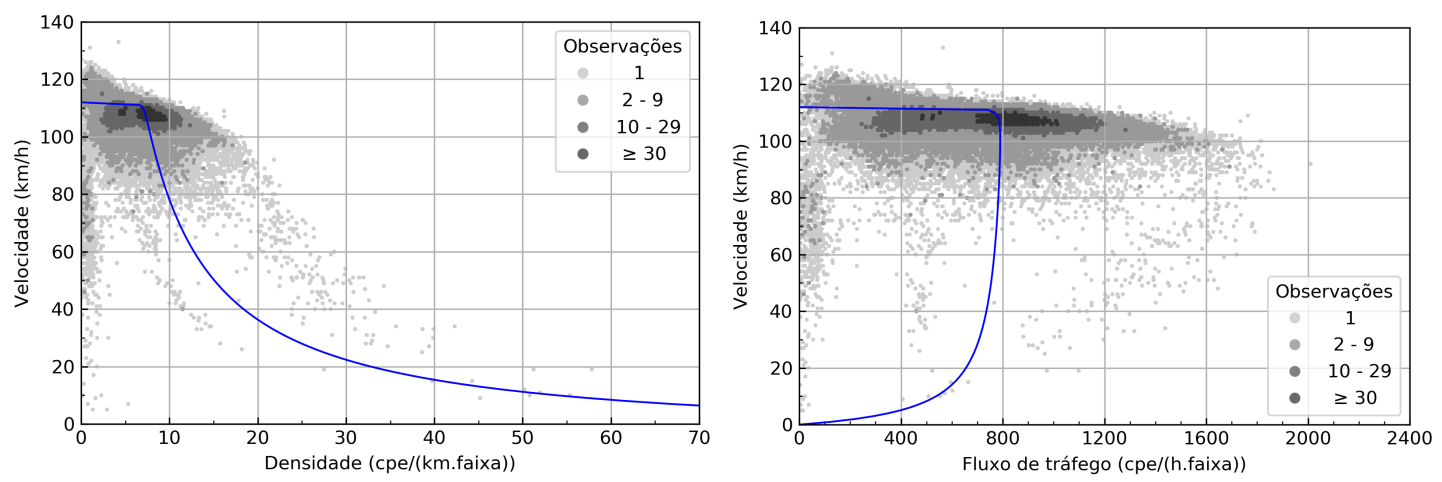

Figura 3.1: Modelo de Van Aerde ajustado para todas as observações do SAT do km 39,5L da SP-070. O grande número de registros com densidade entre 5 e $10 \mathrm{cpe} /(\mathrm{km}$.faixa) enviesa o modelo, resultando numa capacidade muito menor do que os fluxos máximos observados.

relação $q=u \cdot k$, e obtem-se um único valor fluxo-velocidade-densidade para cada intervalo, representando os dados originais. Rakha e Arafeh (2010) utilizaram a média, Chow et al. (2008) e Dervisoglu et al. (2009) basearam-se no 75ํ percentil e Pompigna e Rupi (2015) utilizaram o 85 을 percentil.

\subsection{Método proposto}

A abordagem adotada visa ajustar as relações entre fluxo, velocidade e densidade do modelo de Van Aerde usando uma base de dados muito grande (VLDB) automaticamente, por meio de um programa escrito em Python. Os passos para isso estão descritos a seguir.

\subsubsection{Redução e filtragem inicial dos dados de tráfego}

O modelo proposto por Van Aerde e Rakha (1995) deve ser ajustado utilizando observações dos regimes de fluxo livre e de fluxo congestionado. O sucesso do ajuste está condicionado a uma boa quantidade de dados em ambos os regimes. Porém, há dois problemas que interferem no ajuste do modelo usando dados brutos do SAT: (1) o ruído (condições anormais de tráfego); e (2) a menor quantidade de períodos congestionados.

A Figura 3.1 mostra o efeito desses dois problemas. Uma parte do ruído é aparente no gráfico que mostra a relação entre $u$ e $k$. O grande número de observações em que a densidade é baixa, inferior a $k<5 \mathrm{cpe} /(\mathrm{km}$.faixa), e a velocidade também é baixa, menor que $u<80 \mathrm{~km} / \mathrm{h}$, representam uma operação anômala da rodovia, em que veículos com espaçamento superior a $200 \mathrm{~m}$ viajam em velocidade muito abaixo do limite de velocidade, que é $120 \mathrm{~km} / \mathrm{h}$. O segundo aspecto pode ser visto pela grande concentração de observações em certas regiões dos gráficos, como indica a escala de cinza. Isso pode enviesar o ajuste, já que o modelo ajustado tende a passar mais próximo dessas regiões, visto que elas terão maior peso no cálculo do erro do modelo, resultando num modelo distorcido, como mostram as curvas em azul na Figura 3.1. Por isso, o processo de ajustamento deve incluir um filtro para eliminar o ruído e uma forma 
de reduzir os dados repetidos, para que todas as faixas de densidade tenham o mesmo peso na calibração do modelo (RAKHA; ARAFEH, 2010).

Para isso, os dados de tráfego foram segregados em faixas de densidade de $0,25 \mathrm{cpe} /(\mathrm{km}$. faixa) de largura. Para cada faixa, calcularam-se a média, a mediana e diferentes percentis $\left(70^{\circ}, 75^{\circ}\right.$, $80^{\circ}$ e $85^{\circ}$ ) da velocidade e da densidade. Assim, somente uma observação fluxo-velocidade representa cada faixa de densidade, garantindo uma distribuição uniforme dos dados para o ajuste. A redução dos dados em suas respectivas médias, medianas e $85^{\circ}$ percentil é apresentada na Figura 3.2. Os pontos correspondentes ao $85^{\circ}$ percentil foram escolhidos para o ajuste porque se considerou que este valor representaria melhor a velocidade média dos automóveis, uma vez que o valor fornecido é a média da velocidade de todos os veículos que passam pelo intervalo (veículos leves e pesados). Neste local, o limite de velocidade dos veículos leves é maior que o limite de velocidade dos veículos pesados. Como os veículos pesados foram transformados em carros de passeio equivalentes usando-se o fator de conversão adotado pela ARTESP para o local $\left(E_{T}=2,5\right)$, optou-se por usar o $85^{\circ}$ percentil da velocidade para transformar a velocidade dos veículos pesados em velocidade de veículos equivalentes. Este procedimento foi adotado para os demais locais estudados.
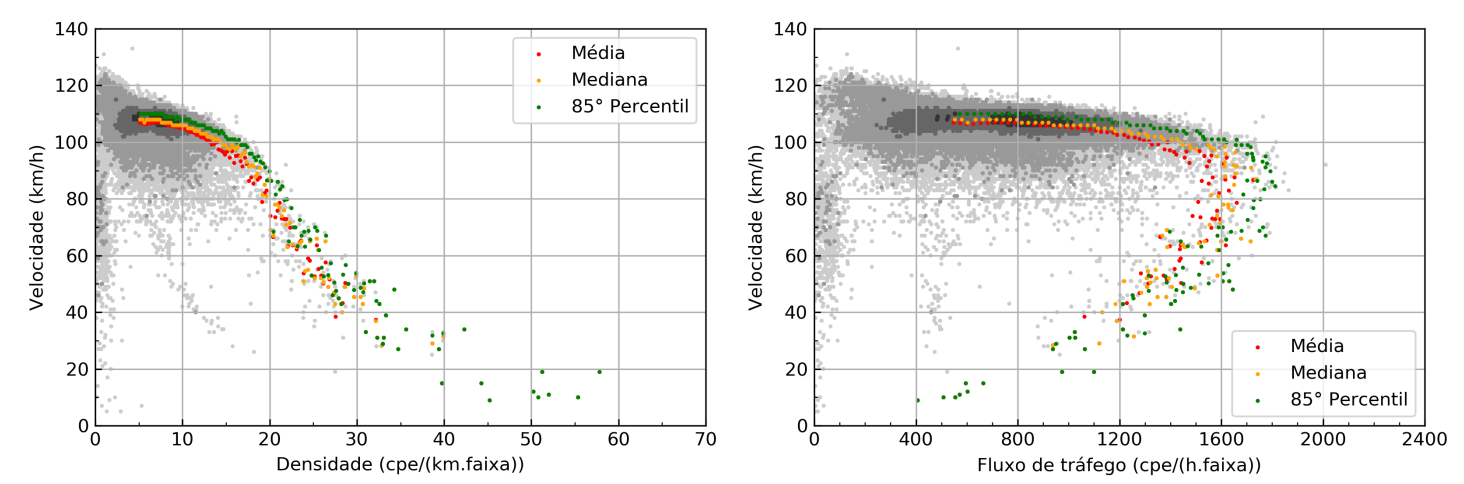

Figura 3.2: Redução dos dados de tráfego para o SAT da SP-070 - km 39,5 Leste

Para evitar o ruído associado às observações com baixa densidade, que pode distorcer e enviesar o ajuste do modelo, foram excluídas as observações em que $k<5 \mathrm{cpe} /(\mathrm{km}$.faixa), uma vez que dentro deste limite não há uma relação clara entre a densidade e a velocidade. É importante ressaltar que a filtragem e o ajuste da curva devem ser feitos a partir dos dados de velocidade e densidade, visto que a relação entre esses dois parâmetros é inequívoca: a velocidade nunca pode aumentar com o aumento da densidade, isto é, densidades baixas implicam em velocidades altas e vice-versa.

O ajuste do modelo foi realizado a partir dos dados de velocidade e densidade reduzidos pelo $85^{\circ}$ percentil, com a densidade da $i$-ésima observação tendo sido calculada por $k_{i}=q_{i} / u_{i}$. Além de eliminar discrepâncias das observações em seu estado bruto, a redução em faixas de densidade fez com que cada valor da relação fluxo-velocidade-densidade tivesse igual influência na calibração do modelo, permitindo um melhor ajuste das curvas fluxo-velocidade e densidade- 
velocidade. No final desta etapa, havia 126 observações de densidade e velocidade para ajustar o modelo.

\subsubsection{Ajuste do modelo de Van Aerde através do algoritmo hill climbing}

Para ajustar o modelo, inicialmente decidiu-se adotar a mesma estratégia usada por Van Aerde e Rakha (1995), ou seja, usar um AHC para encontrar os valores de $u_{f}, u_{c}, q_{c}$ e $k_{j}$ que resultem no melhor ajuste possível do modelo. O fluxograma da Figura 3.3 mostra a estrutura do algoritmo usado, que foi codificado em Python v. 3.7.0. Normalizando-se os valores do fluxo, densidade e velocidade, o problema de otimização pode ser expresso por Rakha e Arafeh (2010):

$$
\operatorname{minimizar} E=\sum_{i}\left\{\left(\frac{u_{i}-\hat{u}_{i}}{\tilde{u}}\right)^{2}+\left(\frac{q_{i}-\hat{q}_{i}}{\tilde{q}}\right)^{2}+\left(\frac{k_{i}-\hat{k}_{i}}{\tilde{k}}\right)^{2}\right\}
$$

sujeito a restrições específicas para esta aplicação, que são:

$$
\begin{aligned}
u_{c} & \leq 0,9 u_{f} \mathrm{~km} / \mathrm{h}, \\
u_{f} & \in\left[\left(0,9 \times u_{\text {lim }}\right),\left(1,1 \times u_{\text {lim }}\right)\right] \mathrm{km} / \mathrm{h}, \\
u_{c} & \in[50,105] \mathrm{km} / \mathrm{h}, \\
q_{c} & \in[1000,3000] \text { veic/(h.faixa }), \mathrm{e} \\
k_{j} & \in[75,125] \text { veic/(km.faixa) }
\end{aligned}
$$

em que $u_{\text {lim }}$ é a velocidade máxima regulamentada para a via e as demais variáveis já foram definidas no texto. As perturbações usadas no AHC foram unitárias.

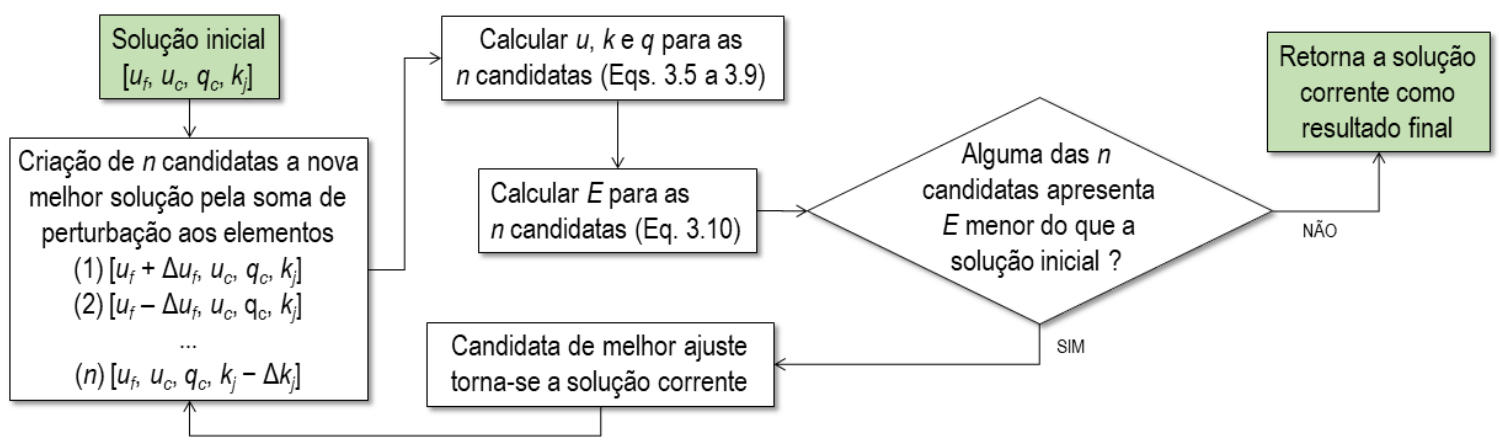

Figura 3.3: Fluxograma do AHC usado para ajuste do modelo de Van Aerde.

Os resultados deste estágio inicial do ajuste do modelo, que é a aplicação do método proposto por Van Aerde e Rakha (1995) sem nenhuma modificação, são mostrados na Figura 3.4. Os pontos coloridos no gráfico mostram os dados usados para o ajuste do modelo. Foi observado na função $u=f(k)$ que diversos pontos (marcados em vermelho) ficavam muito distantes da função ajustada (linha pontilhada) - ou seja, $\left|\hat{u}_{i}\left(k_{i}\right)-u_{i}\left(k_{i}\right)\right| \geq T \mathrm{~km} / \mathrm{h}$ : a diferença absoluta entre a velocidade estimada e a velocidade observada para aquela densidade era maior 

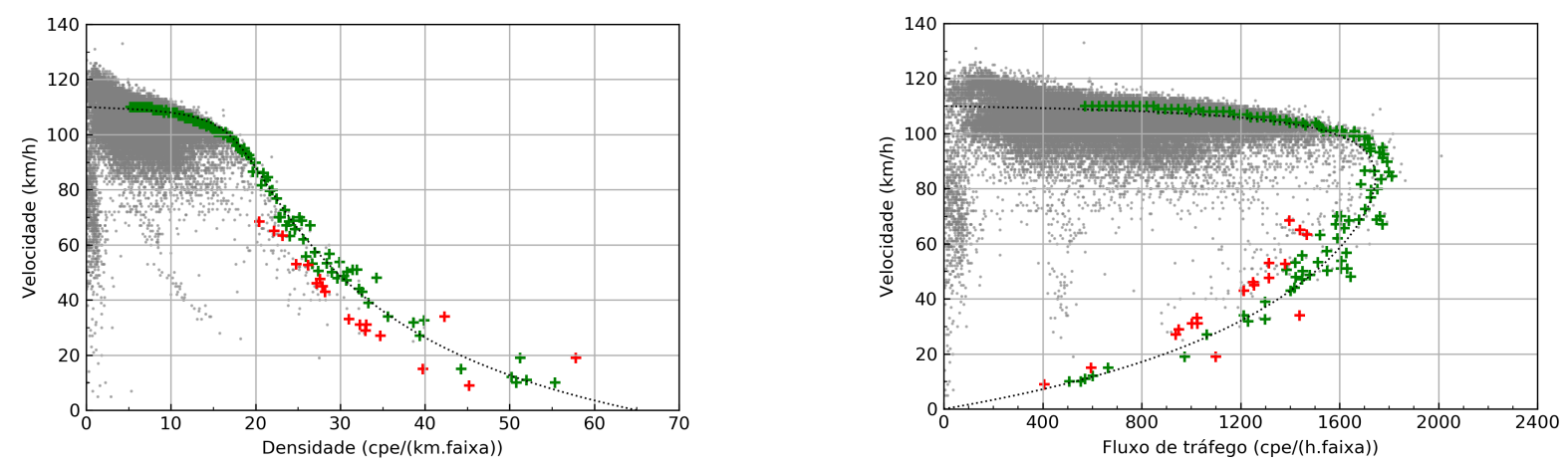

Figura 3.4: Ajuste do modelo pelo AHC: primeira etapa. Os outliers estão em vermelho e os pontos em verde são usados na segunda etapa do ajuste. Os gráficos mostram o modelo ajustado com dados do SAT do $\mathrm{km} 39,5 \mathrm{~L}$ da SP-070.

que a tolerância $T$. Esses outliers foram considerados ruído (observações feitas sob condições anômalas).

Para eliminar estes outliers, decidiu-se modificar o método de ajustamento proposto originalmente, adicionando-se uma segunda etapa consistindo de uma nova triagem dos dados seguido por um novo ajuste do modelo. A partir da primeira função ajustada, uma tolerância $T= \pm 10 \mathrm{~km} / \mathrm{h}$ foi estabelecida para os valores de velocidade observados. Assim, quaisquer observações com velocidades fora do intervalo de tolerância $\hat{u}_{i}\left(k_{i}\right) \pm T$ foram suprimidas pelo programa antes de uma nova rodada do AHC. Isso implicou na eliminação de 18 observações do conjunto de 126 observações usadas inicialmente. O resultado da segunda etapa de ajuste é apresentado na Figura 3.5.
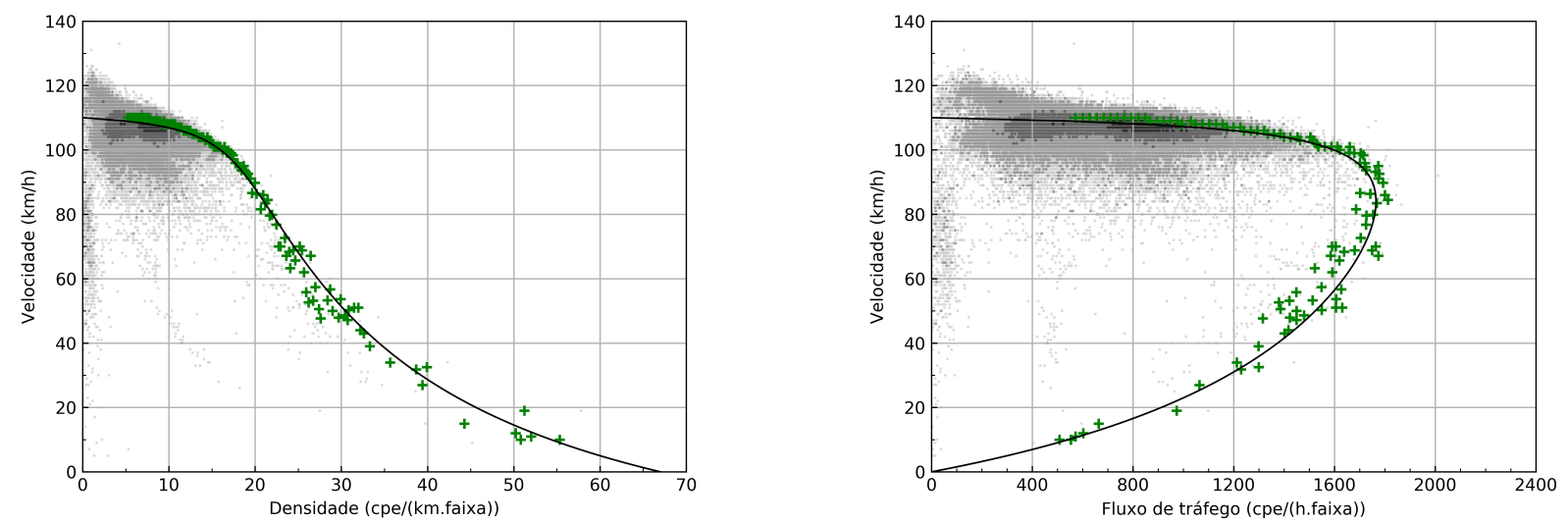

Figura 3.5: Resultado final do ajuste pelo AHC, após eliminação automática de outliers para o modelo ajustado com dados do SAT do km 39,5L da SP-070

O método de otimização hill climbing é um algoritmo heurístico que produz uma solução que não é necessariamente a ótima, mas que é razoavelmente boa para a maioria dos casos; isto é, o algoritmo pode incorrer em um máximo local. Ainda que o AHC tenha produzido bons resultados no ajuste dos modelos, optou-se pela implementação de um algoritmo genético (AG), que permite uma melhor exploração do espaço de soluções, sendo menos suscetível em 
incorrer em máximos locais.

\subsubsection{Ajuste do modelo de Van Aerde através do algoritmo genético}

Os AGs estabelecem uma analogia com a teoria da seleção natural, em que os indivíduos mais bem adaptados ao meio ambiente (as melhores soluções para o problema) têm maior chance de sobrevivência. Nos AGs, a adaptação ao meio ambiente é medida por meio de uma função de adaptação denominada função fitness (GOLDBERG, 1989, p. 9).

A evolução destes indivíduos dá-se através dos operadores genéticos elitismo, seleção, cruzamento, mutação e predação. O processo se inicia com uma população inicial em que são selecionados indivíduos que darão origem a uma nova geração. De tempos em tempos, ocorrem mutações para aumentar a variabilidade da população e predações para eliminar indivíduos mal adaptados (SRINIVAS; PATNAIK, 1994). O processo de evolução continua através das diferentes gerações até que o número máximo de gerações seja atingido ou que o valor fitness se estabilize. O indivíduo mais bem adaptado ao ambiente desta geração representa a melhor solução. O fluxograma da Figura 3.6 demonstra o processo de ajuste adotado.

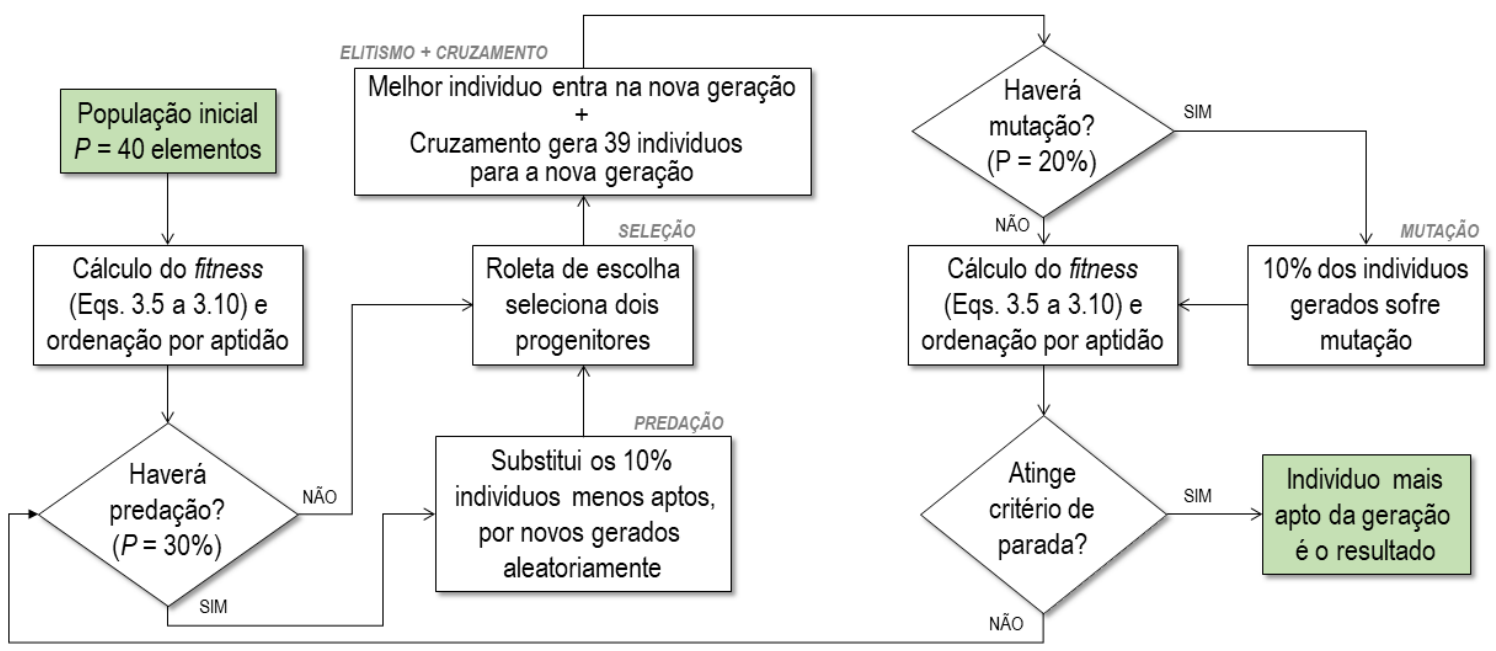

Figura 3.6: Estrutura do AG usado para ajustar o modelo de Van Aerde.

O processo inicia-se com a redução dos dados do SAT utilizando o 85\% percentil e, a seguir, executa-se o AG. Gera-se uma população inicial $P$ com 40 indivíduos, sendo que cada indivíduo é composto por um conjunto, randomicamente criado, das quatro características (genes) a serem calibradas: velocidade de fluxo livre $u_{f}$, velocidade na capacidade $u_{c}$, fluxo na capacidade $q_{c}$, e densidade de congestionamento $k_{j}$.

O tamanho $P$ da população inicial é um fator crítico, pois exerce grande influência no custo computacional da otimização. Caso $P$ seja um valor muito pequeno, o algoritmo poderá convergir precocemente, enquanto $P$ demasiadamente grande poderá exigir um grande número de iterações para que ocorra alguma melhora no resultado (ARABAS; MICHALEWICZ; MULAWKA, 
1994). Devido às particularidades de cada problema, não há uma regra geral para definir a população $P$ (DIAZ-GOMEZ; HOUGEN, 2007). Assim sendo, optou-se por uma abordagem clássica que define $P$ pela regra $P=10 \times D$, sendo $D=4$ características para este estudo (STORN, 1996).

Estabelecida a população inicial deve-se encontrar os indivíduos mais aptos, isto é, ordenamse os indivíduos, de maneira decrescente pelo valor do erro quadrático ortogonal $E$, a função fitness usada neste AG. Com este fim, para cada indivíduo aplicam-se as Eqs. 3.5 a 3.9 e calculase o seu fitness E (Eq. 3.10). Os indivíduos mais aptos (com os menores valores de E) ocupam as primeiras posições da lista.

A cada geração, há uma chance de ocorrer predação. Em caso positivo, os menos aptos são excluídos e substituídos por novos indivíduos, gerados aleatoriamente e, possivelmente, mais aptos. Neste estudo, a predação elimina os piores indivíduos a uma taxa $t_{p}=10 \%$, com probabilidade de ocorrência de $P_{p}=30 \%$ a cada iteração (SIVANANDAM; DEEPA, 2007).

A nova geração é criada por meio dos operadores elitismo, seleção e cruzamento. Através do elitismo, o indivíduo mais apto de uma geração é selecionado para a próxima geração, garantindo que uma boa solução não será descartada por acaso durante o processo de seleção de indivíduos para produzir a geração seguinte. Os $(P-1)$ demais indivíduos da nova geração são criados através do cruzamento de dois progenitores selecionados pelo método da roleta de escolha (CHAMBERS, 2000), em que os progenitores são escolhidos de tal forma que indivíduos mais aptos têm maior chance de se reproduzirem. Para tanto, realiza-se o somatório $S$ de todos os erros $E_{i}$ de modo que a probabilidade $p_{i}$ de escolha de um indivíduo seja inversamente proporcional a sua contribuição para $S$. Escolhidos os dois progenitores por esse método, sorteia-se com igual probabilidade de ocorrência se um, dois, três ou quatro genes virão de um progenitor, com o complemento vindo do outro progenitor. Essa combinação de genes cria um novo indivíduo para a próxima geração. O processo é repetido até que tenham sido criados os indivíduos necessários para completar a população da próxima geração.

Por fim, têm-se o operador mutação, que é aplicado de maneira semelhante à predação, ocorrendo a uma taxa constante $t_{m}=10 \%$ da população com uma probabilidade de ocorrência randômica $P_{m}=20 \%$ por iteração. A mutação permite escapar de cenários em que já não ocorre grande variabilidade na população e, portanto, os descendentes tendem a ser réplicas exatas dos pais. Nesses casos, a mutação é uma oportunidade de gerar um novo e melhor indivíduo a partir de uma população estagnada (COLEY, 1999).

O processo do AG ocorre até a milésima geração, para que seja possível explorar o maior número de soluções que atendam à função objetivo. Esse número de iterações, talvez exagerado, foi determinado devido ao baixo custo computacional para atingir esse patamar, cerca de 10 minutos, e também pelo fato de um número maior de gerações não ter resultado em soluções melhores nos testes realizados.

A redução dos dados empíricos em faixas de densidade e o cálculo do respectivo 85º percen- 

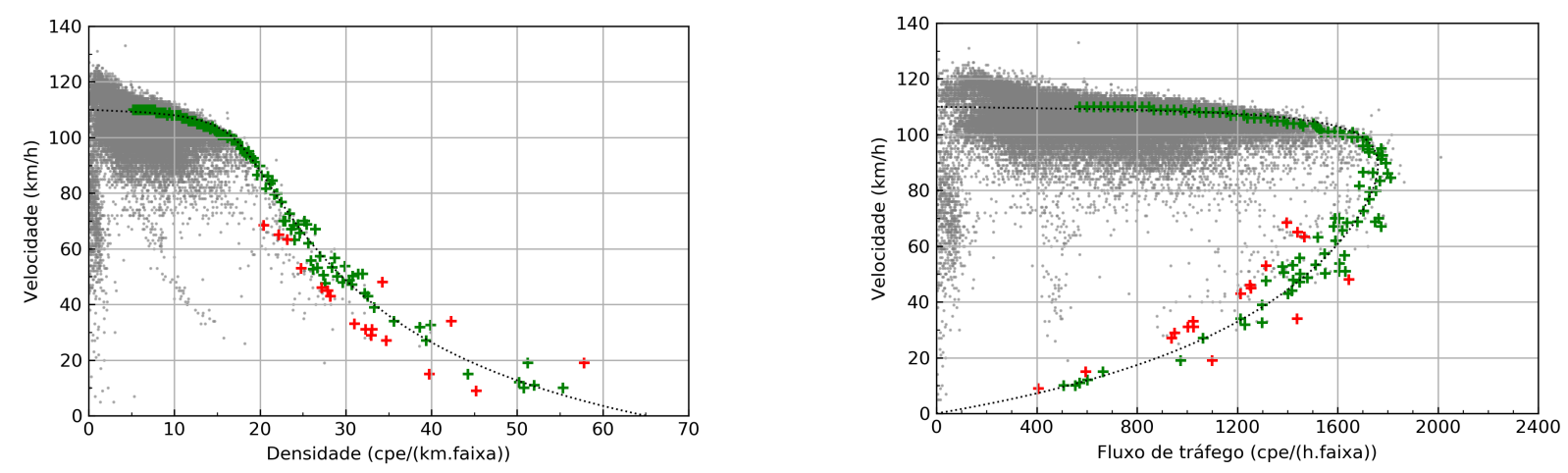

Figura 3.7: Resultado da primeira etapa do ajuste do modelo de Van Aerde por AG para os dados do SAT do km 39,5L da SP-070. Os outliers estão em vermelho e os pontos em verde são usados na segunda etapa do ajuste da curva.

til eliminou anomalias do espaço amostral, permitindo um melhor ajuste das funções fluxovelocidade-densidade. O problema de otimização é o mesmo expresso pelas Eqs. 3.5 a 3.15. Novamente o artifício de duas execuções foi utilizado para garantir a remoção dos ruídos sobreviventes ao primeiro tratamento. A Figura 3.7 apresenta o resultado da primeira etapa do ajuste do modelo para os dados do SAT do km 39,5L da SP-070; os 17 outliers definidos pela tolerância $T= \pm 10 \mathrm{~km} / \mathrm{h}$ estão mostrados em vermelho. A Figura 3.8 mostra o resultado final do modelo ajustado após a segunda etapa do ajuste da curva.
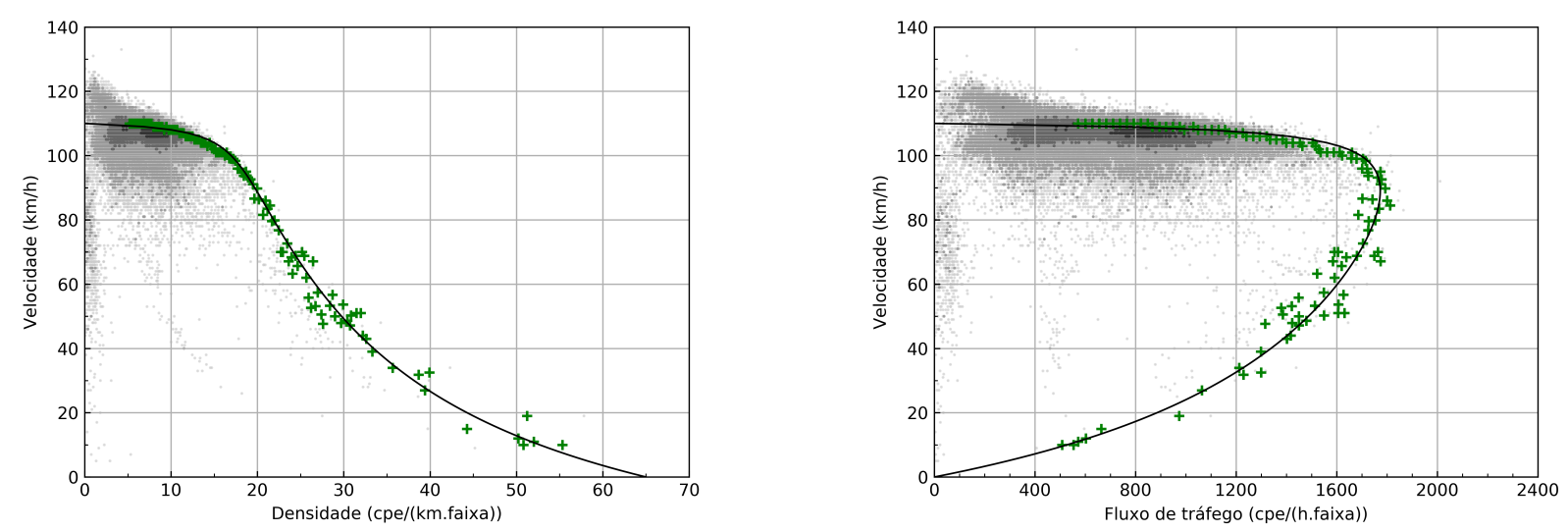

Figura 3.8: Resultado final da aplicação do AG para ajuste do modelo de Van Aerde, após a eliminação dos outliers, para os dados do SAT do km 39,5L da SP-070.

\subsection{Análise dos resultados}

Para a avaliação dos resultados do ajuste, usou-se uma métrica $Q$ definida como:

$$
Q_{i}=\alpha \cdot \exp \left(-\beta \cdot E_{i} / \gamma\right)
$$

em que $E_{i}$ é o erro quadrático ortogonal da melhor solução da geração (ou iteração) $i$, definido pela Eq. 3.10; e $\alpha, \beta$ e $\gamma$ são fatores de escala, cujos valores foram arbitrariamente escolhidos 

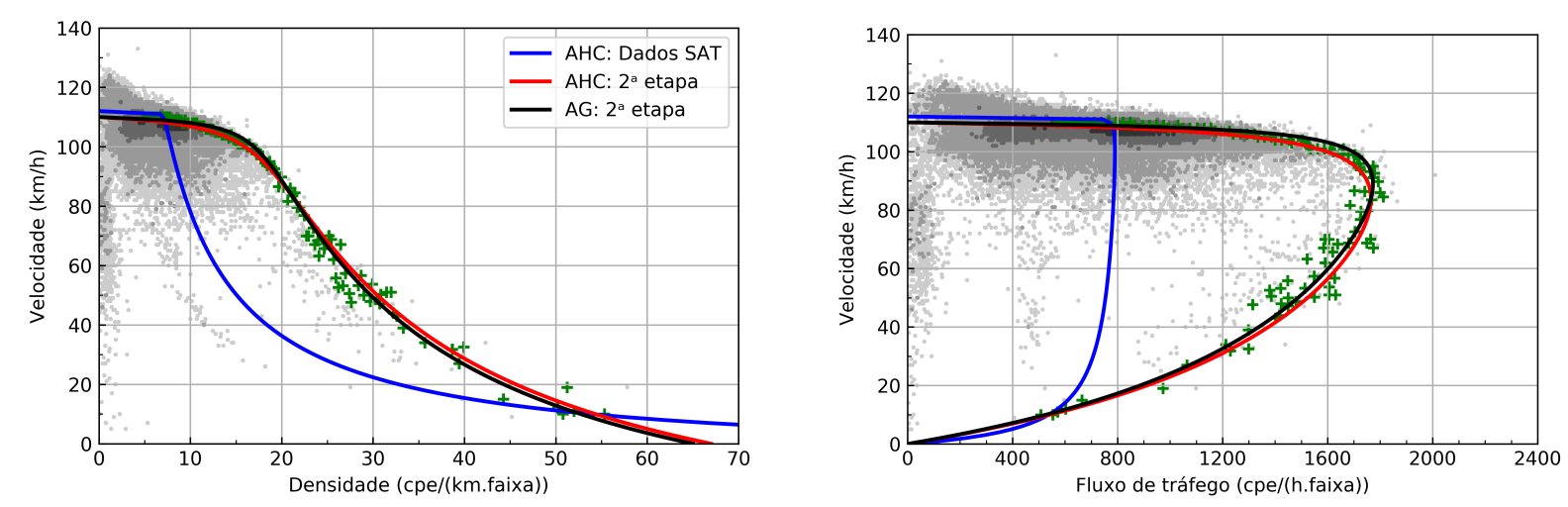

Figura 3.9: Comparação do resultado final do ajuste dos modelos para os dados do SAT do km 39,5L da SP-070: a função azul corresponde ao modelo ajustado com as 104 mil observações; as funções vermelha e preta são os modelos ajustados pela abordagem proposta para a redução e filtragem dos dados.

como sendo $\alpha=100, \beta=5$ e $\gamma=1$. A Eq. 3.16 mostra que $0<Q_{i} \leq 100$; ou seja, quanto maior o erro quadrático ortogonal $E_{i}$, menor o valor de $Q_{i}$ e se $E_{i}=0 \Rightarrow Q_{i}=100$.

Os gráficos da Figura 3.9 mostram o resultado final do ajuste dos modelos com as três estratégias testadas. As funções em azul, se referem ao modelo ajustado sem redução nem filtragem dos dados do SAT pelo AHC, correspondem à aplicação direta do método usado por Van Aerde e Rakha (1995). Pode-se notar que esta estratégia é gravemente afetada pela concentração de observações na região que compreende fluxos entre 400 e $1200 \mathrm{cpe} /($ h.faixa). As funções em vermelho e preto representam o resultado da calibração usando a estratégia da redução de dados e duas etapas de otimização ( $1^{\text {a }}$ etapa: ajuste inicial + eliminação dos outliers e $2^{\text {a }}$ etapa: ajuste final) com o AHC (vermelho) e o AG (preto). Nota-se que a abordagem proposta consegue resultados que representam melhor a corrente de tráfego. Além disso, percebe-se que os dois algoritmos produzem resultados similares, já que as funções estão praticamente superpostas.

A Figura 3.10 permite comparar a evolução da qualidade do ajuste $Q_{i}$ em função do número de soluções testadas para o modelo ajustado com dados do SAT do km 39,5L da SP-070. Cada iteração do AHC implica em testar 8 soluções (2 variações para cada um dos 4 parâmetros de calibração), ao passo que cada geração do AG implica em testar pelo menos 39 soluções (mais, se os operadores predação e mutação forem aplicados naquela geração).

Para esses dados, a aplicação direta do método de Van Aerde e Rakha (1995) (baseada num AHC) aos dados brutos do SAT apresentou uma qualidade de ajuste máxima de 8,2 após 1448 soluções testadas. A baixa qualidade de ajuste é explicada pela quantidade excessiva de observações com valores baixos de fluxo de tráfego, o que justifica a necessidade da aplicação do tratamento proposto.

O ajuste do modelo de Van Aerde por hill climbing aplicado aos dados reduzidos apresentou, em sua primeira etapa, uma qualidade de ajuste de 89,8 após 1280 soluções testadas. Vale 
ressaltar que a redução dos dados empíricos em faixas de densidade auxiliou no bom resultado apresentado por este modelo por minimizar os ruídos existentes nos dados brutos ponderando a relação fluxo-velocidade-densidade mais precisamente. Na segunda etapa, após a exclusão dos outliers, o modelo melhorou sua qualidade de ajuste para 91,5, necessitando testar 1232 soluções para chegar neste resultado.

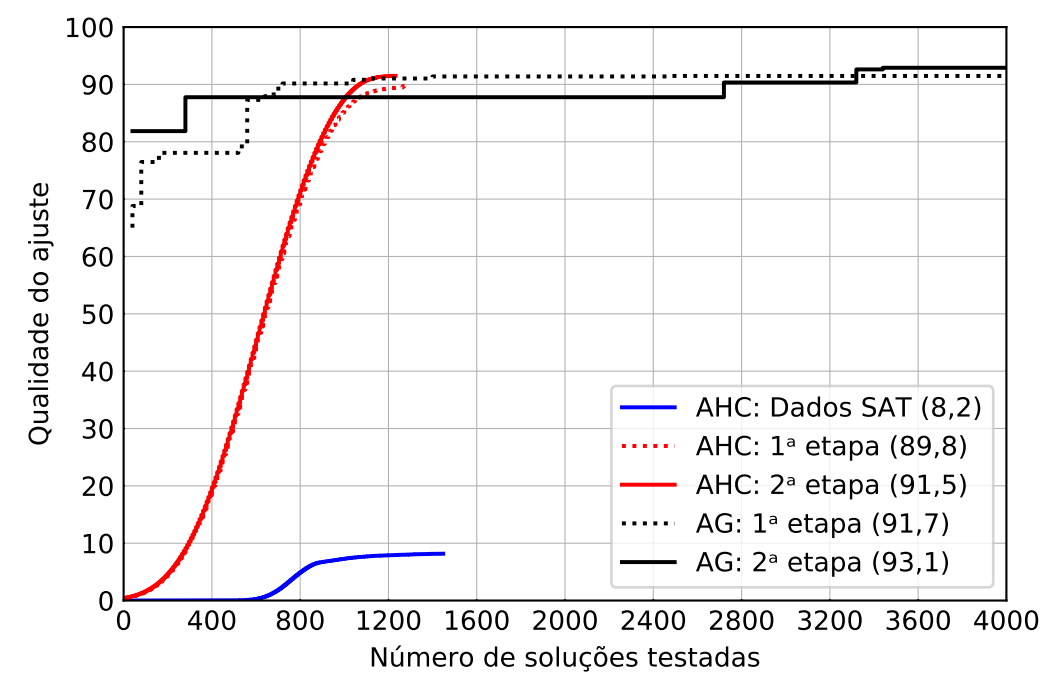

Figura 3.10: Evolução da qualidade do ajuste em função do número de gerações, para os dados do SAT do km 39,5L da SP-070.

Na abordagem utilizando AG, o processo de criação estabeleceu uma população inicial com $P=40$ indivíduos aleatoriamente criados; no AHC, o processo se inicia a partir de uma única solução inicial, em que todos os parâmetros de calibração recebem o valor mínimo admissível. Fica claro, portanto, que o AG estará muito mais propenso à se beneficiar de uma boa solução desde as primeiras soluções testadas, como pode ser observado na Figura 3.10, em que as funções ajustadas via $A G$ iniciam com qualidade de ajuste nitidamente superior às funções obtidas via AHC. Além disso, na primeira etapa do AG, testadas 1400 soluções, a qualidade do ajuste já é superior ao resultado final via AHC, sugerindo que o método via AG é capaz de melhor explorar o espaço de soluções. Na segunda etapa do ajuste via AG, após a exclusão dos outliers, atinge-se uma qualidade de ajuste de 93,1 após 3400 soluções testadas, atestando que a abordagem proposta (tratamento dos dados brutos + ajuste inicial via AG + aplicação de um filtro adicional para outliers + ajuste final via $A G$ ) converge mais rapidamente para os melhores resultados. Finalmente, deve-se ressaltar que apenas 30 gerações no AG (que correspondem grosseiramente a 1200 soluções testadas) bastariam para atingir a mesma qualidade de ajuste que foi obtida com o AHC.

\subsection{Considerações finais}

A aplicação direta do método proposto por Van Aerde e Rakha (1995) à uma VLDB não forneceu um bom ajuste das relações entre fluxo, velocidade e densidade. A VLDB contém cerca de 
104 mil observações, que incluem ruídos que interferem no ajustamento do modelo. Além disso, a grande quantidade de observações no regime de fluxo livre faz com que a capacidade estimada pelo modelo ajustado seja subestimada. Com o intuito de solucionar estes problemas foi proposta a redução dos dados brutos em faixas de densidade para que cada conjunto de dados fluxo-velocidade-densidade tivesse igual influência no ajuste do modelo e o ruído fosse minimizado. Esta abordagem foi essencial para que o modelo ajustado melhor representasse o comportamento do tráfego.

As duas técnicas de otimização empregadas apresentaram resultados similares, como é possível perceber pelas curvas superpostas na Figura 3.9. No entanto, a implementação de um algoritmo genético otimizou a busca por soluções ótimas ao invés de soluções subótimas, recorrentemente encontradas na modelagem tradicional.

O próximo capítulo usa os modelos de fluxo de tráfego ajustados para cada local estudado para analisar os efeitos das condições do tempo e de luminosidade sobre as correntes de tráfego. 


\section{Capítulo}

\section{Influência das condições adversas na operação do tráfego}

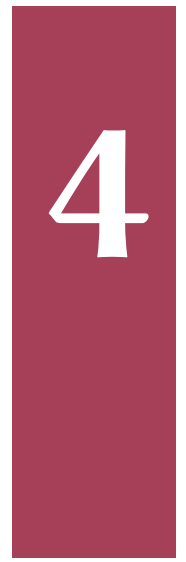

Este capítulo aborda a influência das condições adversas do tempo e da luminosidade na operação do tráfego. Apresenta-se uma revisão da literatura com destaque para os trabalhos que abordam os impactos na velocidade de fluxo livre, na velocidade na capacidade e na capacidade em condições chuvosas em relação às condições ideais. Estes estudos, em sua maioria, foram desenvolvidos no hemisfério norte e seus resultados indicam a necessidade de se estudar a influência da precipitação considerando as condições meteorológicas particulares de cada local.

Dessa forma, são apresentados os resultados do ajuste do modelo de Van Aerde considerando as condições meteorológicas e a luminosidade em cada local estudado.

\subsection{Revisão da literatura}

Diversos estudos têm analisado a influência das condições meteorológicas no tráfego rodoviário. Em uma análise microscópica, a chuva, a neve e a perda de visibilidade afetam a velocidade que os motoristas desenvolvem nas vias, pois interferem na percepção e sensação de segurança, o que acaba por fazer com que os motoristas reduzam a velocidade para aumentar a distância de segurança entre os veículos (GOODWIN, 2002). Em uma análise macroscópica, esse comportamento faz com que ocorra a diminuição da velocidade de fluxo livre, a redução da velocidade na capacidade e a redução da capacidade (EL FAOUZI et al., 2010).

A perda de visibilidade causada pelas condições climáticas adversas é um importante fator para que os motoristas diminuam suas velocidades: Edwards (1999) observou uma diminuição nas velocidades desenvolvidas com uma pequena redução na visibilidade, enquanto Hawkins (1988) e Kyte et al. (2001) constataram que as velocidades desenvolvidas pelos motoristas diminuem significativamente quando a visibilidade é reduzida para $300 \mathrm{~m}$ de distância. O HCM 
2000 (TRB, 2000, p. 22-8) sugere que a principal razão para que os motoristas diminuam suas velocidades em condições adversas é a perda de visibilidade, causada pela intensidade da precipitação. Por isso, alguns estudos segregam os efeitos da chuva em precipitações fracas e fortes (IBRAHIM; HALL, 1994; CAMACHO; GARCÍA; BELDA, 2010).

$\mathrm{Na}$ Espanha, observou-se uma redução na velocidade de fluxo livre de $5,5 \mathrm{~km} / \mathrm{h}$ sob chuva fraca e de $7 \mathrm{~km} / \mathrm{h}$ sob chuva forte (CAMACHO; GARCÍA; BELDA, 2010); no Canadá, foi observada uma redução de $2 \mathrm{~km} / \mathrm{h}$ na velocidade sob chuva fraca e reduções que variam entre 5 e $10 \mathrm{~km} / \mathrm{h}$ sob chuva forte (IBRAHIM; HALL, 1994). Em outro estudo realizado no Canadá, a influência da precipitação e da luminosidade foram avaliadas. Durante o dia, uma redução de $8 \mathrm{~km} / \mathrm{h}$ foi observada no fluxo não congestionado sob chuva fraca em relação ao tempo bom; durante a noite, foi verificada uma redução de 2,5 km/h (UNRAU; ANDREY, 2006).

Nas autoestradas alemãs, constatou-se uma redução nas velocidades de $10 \mathrm{~km} / \mathrm{h}$ sob tempo chuvoso em relação ao tempo bom. Quando analisou-se a influência da luminosidade, constatouse uma redução de $5 \mathrm{~km} / \mathrm{h}$ nas velocidades desenvolvidas à noite em relação às velocidades desenvolvidas durante o período diurno (BRILON; PONZLET, 1996).

Estudos mostram que a chuva também causa redução na velocidade desenvolvida na capacidade. Hranac et al. (2006) e Rakha et al. (2008) analisaram o efeito das condições adversas em três regiões metropolitanas dos Estados Unidos. O modelo de Van Aerde foi ajustado com dados dos sensores de tráfego e foram observadas reduções na velocidade na capacidade da ordem de 8 a $10 \%$ para chuva fraca e de 8 a $14 \%$ para chuva forte.

Em condições adversas, os motoristas tendem a diminuir suas velocidades e aumentar a distância entre os veículos. Hall e Barrow (1988) constataram que durante uma tempestade a corrente de tráfego passa do regime não congestionado para o congestionado em taxas de ocupação mais baixas, implicando na redução da capacidade. Hranac et al. (2006) nos Estados Unidos e Tu et al. (2010) na Holanda observaram uma redução na capacidade de, respectivamente, $11 \%$ e $14 \%$, nas condições com chuva comparado ao tempo bom e, nestes estudos, a redução não é influenciada pela intensidade da precipitação. Resultado diferente dos observados em Minnesota e na Virgínia, Estados Unidos. No primeiro estudo, constatou-se uma redução média de $7 \%$ na capacidade da via com chuva fraca e $14 \%$ com chuva forte (MAZE; AGARWAL; BURCHETT, 2006); na Virgínia, observou-se uma redução entre 4 e $10 \%$ sob chuva fraca e entre 25 e $30 \%$ sob chuva forte, um indicativo que, nestes locais, as reduções estão relacionadas à intensidade da precipitação (SMITH et al., 2004).

No HCM-6 (TRB, 2016, p. 11-43) apresentam-se os fatores de ajuste dos impactos das condições adversas na capacidade e na velocidade de fluxo livre, de acordo com a velocidade desenvolvida pelos motoristas em diferentes situações climáticas dos Estados Unidos. No entanto, deve-se ressaltar que se realizem estudos que correlacionem as condições de tráfego ao clima local, para se obter resultados mais acurados, condizentes com a realidade observada em cada estudo. 
No Brasil, os estudos sobre a influência das condições meteorológicas no tráfego apresentam um enfoque diferente. Moreira, Costa e Cunto (2017) avaliaram o impacto da chuva na velocidade de fluxo livre e no fluxo de saturação no ambiente urbano, realizando um estudo de caso para a cidade de Fortaleza. Os autores constataram uma redução na velocidade de fluxo livre na condição chuvosa em relação ao tempo bom e não houve influência da intensidade da precipitação. Em Porto Alegre, Caleffi et al. (2016) estudaram se há correlação entre as condições meteorológicas e os acidentes de trânsito e Zechin et al. (2018) verificaram a probabilidade de breakdown da corrente de tráfego na BR-290.

Os estudos sobre a influência das condições meteorológicas na operação das rodovias utilizam dados históricos e dados em tempo real. Nestes estudos, a precipitação, a intensidade da precipitação e/ou visibilidade foram consideradas. Hranac et al. (2006) e Rakha et al. (2008) consideraram a intensidade da precipitação e a visibilidade como parâmetros do fator de ajuste das condições meteorológicas. Este fator apresentou coeficientes distintos de acordo com as localidades e os parâmetros estudados (velocidade de fluxo livre, velocidade na capacidade e capacidade). Em outros estudos, a visibilidade é uma variável independente que influencia a velocidade desenvolvida pelos motoristas (KYTE et al., 2001; CAMACHO; GARCÍA; BELDA, 2010).

Hooper, Chapman e Quinn (2014a) utilizaram a regressão polinomial no ajuste do modelo proposto. No entanto, a regressão polinomial mostrou não ser o método mais apropriado para se estudar os impactos no fluxo congestionado, mesmo resultado obtido por Unrau e Andrey (2006). Os autores utilizaram um modelo de regressão polinomial quadrático para o fluxo não congestionado e um modelo de comportamento exponencial na região de fluxo congestionado. A Tabela 4.1 apresenta um resumo dos métodos de análise utilizados e os modelos desenvolvidos.

\subsection{Efeito das condições meteorológicas sobre o comportamento do tráfego}

Após a realização de todas as etapas para organização e tratamento dos dados meteorológicos e de tráfego, o modelo de Van Aerde foi ajustado utilizando o método proposto quando se dispõe de uma base de dados muito grande empregando o algoritmo genético como técnica de otimização, conforme apresentado no Capítulo 3. A Tabela 4.2 mostra o número de observações iniciais e a quantidade de dados utilizados para ajustar o modelo após a redução pelo 85 percentil e exclusão dos outliers.

A Figura 4.1 ilustra o resultado da calibração do modelo de Van Aerde para um sensor localizado na SP-280, km 26,9 sentido Leste (Id4). Os pontos cinzas correspondem às observações para os períodos sem chuva; os pontos azuis representam as observações sob tempo chuvoso.

A Tabela 4.3 exibe os resultados dos parâmetros calibrados pelo modelo de Van Aerde para os 12 locais, considerando as condições chuvosas e sem chuva. As funções calibradas dos 12 
Tabela 4.1: Métodos utilizados na análise dos efeitos da precipitação

\begin{tabular}{|c|c|}
\hline Autores & Método \\
\hline Ibrahim e Hall (1994) & 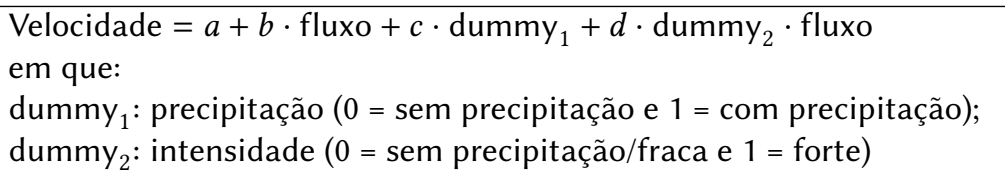 \\
\hline Hranac et al. (2006) e Rakha et al. (2008) & $\begin{array}{l}\text { Ajuste do modelo de Van Aerde e análise de regressão stepwise } \\
F=c_{1}+c_{2} i+c_{3} i^{2}+c_{4} v+c_{5} v^{2}+c_{6} i v \\
\text { em que: } \\
\text { F: fator de ajuste meteorológico; } \\
\text { i: intensidade da precipitação }(\mathrm{cm} / \mathrm{h}) \\
\text { v: visibilidade }(\mathrm{km})\end{array}$ \\
\hline Camacho, García e Belda (2010) & $\begin{array}{l}V=a+b \cdot I_{t}+c \cdot \log \frac{\mathrm{vis}}{2000}+d \cdot V_{w}+\frac{f}{e^{I_{p}}} \\
\text { em que: } \\
V: \text { velocidade; } \\
I_{t}: \text { porcentagem de caminhões }(\%) ; \\
\text { vis: visibilidade }(\mathrm{m}), \text { variando de } 0 \text { à } 2000 \mathrm{~m} ; \\
V_{w}: \text { velocidade do vento }(\mathrm{m} / \mathrm{s}) ; \\
I_{p}: \text { intensidade da precipitação }(\mathrm{mm} / \mathrm{h})\end{array}$ \\
\hline Brilon e Ponzlet (1996) e Holdener (1998) & Análise de variância \\
\hline Kyte et al. (2001) & $\begin{array}{l}\text { Regressão linear múltipla com velocidade como variável dependente } \\
\text { e variáveis independentes: neve, pavimento molhado, visibilidade, } \\
\text { ventos }\end{array}$ \\
\hline Unrau e Andrey (2006) & $\begin{array}{l}\text { Regressão polinomial quadrática para o fluxo não congestionado } \\
\text { e regressão exponencial para o fluxo congestionado, com a velocidade } \\
\text { como variável dependente e o fluxo como variável independente }\end{array}$ \\
\hline Hooper, Chapman e Quinn (2014a) & Regressão polinomial com o fluxo como variável independente \\
\hline Caleffi et al. (2016) & Cluster $K$-médias \\
\hline Dhaliwal et al. (2017) & $\begin{array}{l}\text { Ajuste do modelo de Van Aerde, teste de Mann-Whitney, } \\
\text { Kolmogorov-Smirnov e análise de variância }\end{array}$ \\
\hline
\end{tabular}

Tabela 4.2: Número de observações utilizadas no ajuste do modelo de Van Aerde

\begin{tabular}{rrrrrrrr}
\hline & \multicolumn{3}{c}{ Sem chuva } & & \multicolumn{3}{c}{ Com chuva } \\
\cline { 2 - 5 } \cline { 6 - 7 } Id & N. Obs. & $\mathbf{1}^{\mathbf{a}}$ etapa & $\mathbf{2}^{\mathbf{a}}$ etapa & & N. Obs. & $\mathbf{1}^{\mathbf{a}}$ etapa & $\mathbf{2}^{\mathbf{a}}$ etapa \\
\hline 1 & 79.778 & 196 & 193 & 2.793 & 155 & 150 \\
2 & 80.155 & 182 & 177 & 2.812 & 126 & 117 \\
3 & 64.280 & 216 & 216 & 2.547 & 143 & 136 \\
4 & 63.152 & 244 & 201 & 2.546 & 172 & 154 \\
5 & 67.895 & 191 & 185 & 3.155 & 108 & 94 \\
6 & 67.128 & 173 & 167 & 3.144 & 80 & 76 \\
7 & 87.535 & 282 & 243 & 1.998 & 103 & 90 \\
8 & 102.251 & 253 & 251 & 3.026 & 117 & 106 \\
9 & 112.081 & 180 & 180 & 2.832 & 60 & 54 \\
10 & 66.191 & 146 & 134 & 2.757 & 83 & 78 \\
11 & 67.527 & 158 & 146 & 3.200 & 67 & 63 \\
12 & 66.599 & 167 & 167 & 3.034 & 98 & 93 \\
\hline
\end{tabular}


SATs encontram-se no Apêndice B.
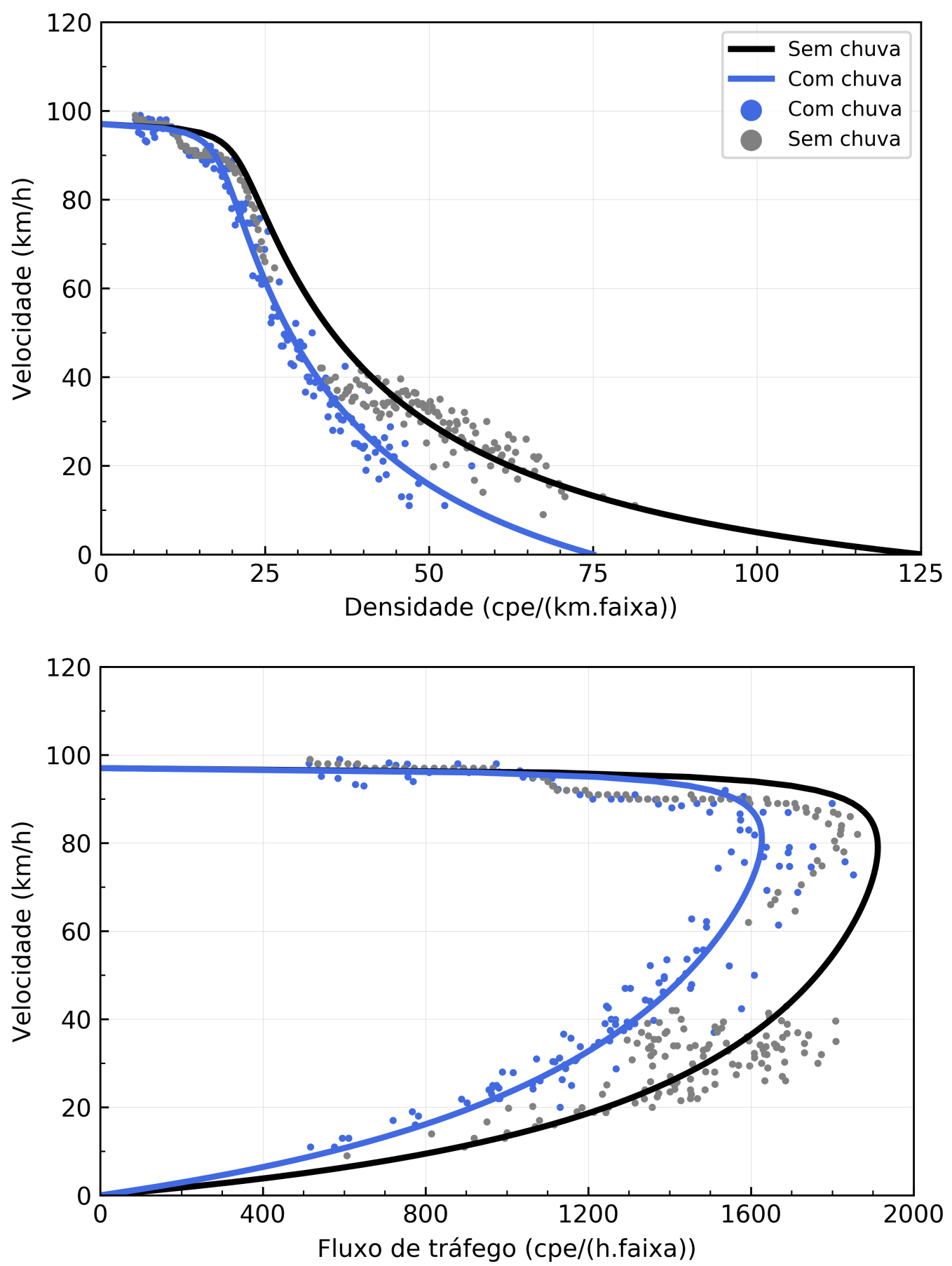

Figura 4.1: Efeito da precipitação atmosférica sobre a corrente de tráfego, medido através do modelo fluxo-velocidade-densidade de Van Aerde, para os dados do SAT da SP-280, km 26,9 Leste

Nota-se na Tabela 4.3 que a capacidade foi o parâmetro que sofreu maior influência da precipitação. Todos os locais analisados apresentaram redução na capacidade com tempo chuvoso. A densidade na capacidade também apresentou redução em todos os locais estudados, acompanhando o comportamento da capacidade, pois estes parâmetros estão altamente corre- 
lacionados $\left(k_{c}=q_{c} / u_{c}\right)$, apesar da velocidade na capacidade $u_{c}$ não ter apresentado reduções significativas.

A densidade de congestionamento $k_{j}$ apresentou uma grande variabilidade. Isso pode ser explicado pelo pequeno número de observações de congestionamentos severos concomitantemente com chuva no conjunto de dados. A raridade desses casos pode ser vista na Figura 4.1, pela escassez de pontos na região em que a velocidade é inferior a $20 \mathrm{~km} / \mathrm{h}$ e a taxa de fluxo é menor que $800 \mathrm{cpe} /($ h.faixa). A falta de informação sobre essa região faz com que o AG encontre valores bastante dispersos para a densidade de congestionamento.

Não foram verificadas reduções significativas na velocidade de fluxo livre desenvolvida pelos motoristas. Este fato pode ser explicado pela velocidade de fluxo livre representar a velocidade de desejo que os motoristas querem trafegar quando o fluxo está baixo. Com o fluxo veicular baixo, a chuva não interfere na sensação de segurança e os motoristas não reduzem suas velocidades de forma significativa.

Tabela 4.3: Análise comparativa entre tempo chuvoso e tempo bom por meio do modelo de Van Aerde

\begin{tabular}{|c|c|c|c|c|c|c|c|c|c|c|c|c|c|c|c|}
\hline \multirow[b]{2}{*}{ Id } & \multicolumn{5}{|c|}{ Tempo bom } & \multicolumn{5}{|c|}{ Tempo chuvoso } & \multicolumn{5}{|c|}{ Diferença (tempo bom - tempo chuvoso) } \\
\hline & $u_{f}$ & $u_{c}$ & $q_{c}$ & $k_{j}$ & $k_{c}$ & $u_{f}$ & $u_{c}$ & $q_{c}$ & $k_{j}$ & $k_{c}$ & $\Delta u_{f}$ & $\Delta u_{c}$ & $\Delta q_{c}$ & $\Delta k_{j}$ & $\Delta k_{c}$ \\
\hline & \multicolumn{15}{|c|}{ Limite de velocidade de $100 \mathrm{~km} / \mathrm{h}$} \\
\hline 1 & 95 & 64 & 1861 & 75 & 29,1 & 92 & 68 & 1770 & 75 & 26,0 & $-3 \%$ & $6 \%$ & $-5 \%$ & $0 \%$ & $-10 \%$ \\
\hline 2 & 94 & 78 & 1918 & 75 & 24,6 & 93 & 84 & 1646 & 113 & 19,6 & $-1 \%$ & $8 \%$ & $-14 \%$ & $51 \%$ & $-20 \%$ \\
\hline 3 & 95 & 76 & 1978 & 88 & 26,0 & 95 & 77 & 1829 & 81 & 23,8 & $0 \%$ & $1 \%$ & $-8 \%$ & $-8 \%$ & $-9 \%$ \\
\hline 4 & 97 & 79 & 1912 & 125 & 24,2 & 97 & 81 & 1627 & 75 & 20,1 & $0 \%$ & $3 \%$ & $-15 \%$ & $-40 \%$ & $-17 \%$ \\
\hline 5 & 98 & 84 & 1640 & 76 & 19,5 & 97 & 87 & 1566 & 78 & 18,0 & $-1 \%$ & $4 \%$ & $-5 \%$ & $3 \%$ & $-8 \%$ \\
\hline \multirow[t]{2}{*}{6} & 99 & 81 & 1797 & 92 & 22,2 & 99 & 86 & 1617 & 78 & 18,8 & $0 \%$ & $6 \%$ & $-10 \%$ & $-15 \%$ & $-15 \%$ \\
\hline & \multicolumn{15}{|c|}{ Limite de velocidade de $110 \mathrm{~km} / \mathrm{h}$} \\
\hline 7 & 99 & 53 & 1561 & 108 & 29,5 & 99 & 53 & 1527 & 75 & 28,8 & $0 \%$ & $0 \%$ & $-2 \%$ & $-31 \%$ & $-2 \%$ \\
\hline \multirow[t]{2}{*}{8} & 105 & 86 & 1685 & 125 & 19,6 & 104 & 85 & 1537 & 125 & 18,1 & $-1 \%$ & $-1 \%$ & $-9 \%$ & $0 \%$ & $-8 \%$ \\
\hline & \multicolumn{15}{|c|}{ Limite de velocidade de $120 \mathrm{~km} / \mathrm{h}$} \\
\hline 9 & 112 & 89 & 1824 & 82 & 20,5 & 111 & 93 & 1517 & 82 & 16,3 & $-1 \%$ & $4 \%$ & $-17 \%$ & $0 \%$ & $-20 \%$ \\
\hline 10 & 108 & 80 & 1575 & 108 & 19,7 & 109 & 76 & 1491 & 75 & 19,6 & $1 \%$ & $-5 \%$ & $-5 \%$ & $-31 \%$ & $0 \%$ \\
\hline 11 & 108 & 70 & 1661 & 75 & 23,7 & 108 & 69 & 1381 & 75 & 20,0 & $0 \%$ & $-1 \%$ & $-17 \%$ & $0 \%$ & $-16 \%$ \\
\hline \multirow[t]{2}{*}{12} & 110 & 85 & 1574 & 75 & 18,5 & 108 & 86 & 1433 & 83 & 16,7 & $-2 \%$ & $1 \%$ & $-9 \%$ & $11 \%$ & $-10 \%$ \\
\hline & & & & & & & & & & Média & $-1 \%$ & $2 \%$ & $-10 \%$ & $-5 \%$ & $-11 \%$ \\
\hline
\end{tabular}

Com o intuito de verificar se as diferenças encontradas entre os modelos ajustados sob condições chuvosas e sob tempo bom são estatisticamente significativas realizou-se o teste de Wilcoxon para amostras relacionadas. O teste de Wilcoxon é um teste não-paramétrico correspondente ao teste $t$-Student (paramétrico)(MARÔCO, 2014, p. 412). Os pressupostos para a aplicação do teste $t$-Student (número de amostras maior que 30, amostra com distribuição normal e homogeneidade da variância) não são satisfeitos para os parâmetros dos modelos ajustados. Por este motivo, optou-se pela realização do teste de Wilcoxon. A Tabela 4.4 apresenta os resultados do teste.

O teste de Wilcoxon mostrou que há uma diferença estatisticamente significativa entre os valores encontrados para a capacidade sob tempo chuvoso e os valores de capacidade sob 
Tabela 4.4: Estatísticas do teste de Wilcoxon $(\alpha=0,05)$ para a determinação do efeito da chuva sobre a corrente de tráfego, através do modelo de Van Aerde.

\begin{tabular}{rrrrrr}
\hline & \multicolumn{1}{c}{$u_{f}$} & \multicolumn{1}{c}{$u_{c}$} & \multicolumn{1}{c}{$q_{c}$} & \multicolumn{1}{c}{$k_{j}$} & \multicolumn{1}{c}{$k_{c}$} \\
\hline$Z$ & $-1,930$ & $-1,791$ & $-3,059$ & $-0,981$ & $-3,059$ \\
$p$ & 0,054 & 0,073 & $\mathbf{0 , 0 0 2}$ & 0,326 & $\mathbf{0 , 0 0 2}$ \\
\hline
\end{tabular}

tempo bom $(Z=-3,059 ; p<0,05)$. Pode-se afirmar que o mesmo ocorre com a densidade na capacidade pois estes parâmetros são altamente correlacionados $(Z=-3,059 ; p<0,05)$. Os demais parâmetros não apresentaram diferenças estatisticamente significativas, $\operatorname{com} \alpha=5 \%$.

Portanto, pode-se afirmar que, dos parâmetros estudados, a capacidade e a densidade na capacidade sofrem uma influência estatisticamente significativa da chuva. A capacidade apresentou uma redução média de $10 \%$ e a densidade na capacidade apresentou uma redução média de $11 \%$, em relação aos valores observados sob tempo bom.

\subsection{Efeito combinado da precipitação com a luminosidade}

Para a análise do efeito combinado da luminosidade com as condições meteorológicas na operação das rodovias paulistas, os dados de tráfego foram segregados em condições diurnas e noturnas, com tempo bom e tempo chuvoso.

A Tabela 4.5 apresenta a quantidade de observações registradas entre $5 \mathrm{~h}$ e $22 \mathrm{~h}$ em cada local para cada uma das quatro configurações analisadas: (1) condição diurna sem chuva, (2) condição diurna com chuva, (3) condição noturna sem chuva e (4) condição noturna com chuva. O período diurno corresponde às observações entre o nascer e o pôr do sol e o período noturno corresponde às demais observações, conforme explicado na seção 2.4 do Capítulo 2.

Tabela 4.5: Número de observações em condições diurnas e noturnas

\begin{tabular}{|c|c|c|c|c|c|c|c|}
\hline \multirow{2}{*}{ Id } & \multicolumn{3}{|c|}{ Dia } & \multicolumn{3}{|c|}{ Noite } & \multirow{2}{*}{ Total } \\
\hline & Sem chuva & Com chuva & Total & Sem chuva & Com chuva & Total & \\
\hline 1 & 56.054 & 2.093 & 58.147 & 23.724 & 700 & 24.424 & 82.571 \\
\hline 2 & 56.451 & 2.108 & 58.559 & 23.704 & 704 & 24.408 & 82.967 \\
\hline 3 & 47.546 & 1.923 & 49.469 & 16.734 & 624 & 17.358 & 66.827 \\
\hline 4 & 45.215 & 1.862 & 47.077 & 17.937 & 684 & 18.621 & 65.698 \\
\hline 5 & 48.295 & 2.296 & 50.591 & 19.600 & 859 & 20.459 & 71.050 \\
\hline 6 & 47.787 & 2.292 & 50.079 & 19.341 & 852 & 20.193 & 70.272 \\
\hline 7 & 61.507 & 1.491 & 62.998 & 26.028 & 507 & 26.535 & 89.533 \\
\hline 8 & 72.777 & 2.364 & 75.141 & 29.474 & 662 & 30.136 & 105.277 \\
\hline 9 & 79.627 & 2.179 & 81.806 & 32.454 & 653 & 33.107 & 114.913 \\
\hline 10 & 47.057 & 2.046 & 49.103 & 19.134 & 711 & 19.845 & 68.948 \\
\hline 11 & 48.102 & 2.283 & 50.385 & 19.425 & 917 & 20.342 & 70.727 \\
\hline 12 & 47.500 & 2.149 & 49.649 & 19.099 & 885 & 19.984 & 69.633 \\
\hline Total & 657.918 & 25.086 & 683.004 & 266.654 & 8.758 & 275.412 & 958.416 \\
\hline
\end{tabular}


É possível notar que a quantidade de observações com chuva é bem inferior à quantidade de observações com tempo bom, assim como o número de observações noturnas em relação às diurnas. Dessa forma, a combinação dessas duas características, condição noturna com chuva, apresenta um número ainda mais reduzido de observações, o que pode interferir no ajuste dos modelos. A Tabela 4.6 apresenta o número de observações iniciais de cada configuração e o número de observações utilizadas no ajuste dos modelos, após a redução pelo 85ำ percentil e exclusão dos outliers.

Tabela 4.6: Número de observações utilizadas para ajustar o modelo de Van Aerde, considerando a precipitação e a luminosidade

\begin{tabular}{|c|c|c|c|c|c|c|c|c|c|c|c|c|}
\hline \multirow{2}{*}{ Id } & \multicolumn{3}{|c|}{ Dia - Sem chuva } & \multicolumn{3}{|c|}{ Dia-Com chuva } & \multicolumn{3}{|c|}{ Noite - Sem chuva } & \multicolumn{3}{|c|}{ Noite - Com chuva } \\
\hline & N. Obs. & $1^{a}$ etapa & $2^{a}$ etapa & N. Obs. & $1^{a}$ etapa & $2^{a}$ etapa & N. Obs. & $1^{\mathbf{a}}$ etapa & $2^{a}$ etapa & N. Obs. & $1^{a}$ etapa & $2^{a}$ etapa \\
\hline 1 & 56.054 & 189 & 187 & 2.093 & 148 & 141 & 23.724 & 185 & 182 & 700 & 115 & 104 \\
\hline 2 & 56.451 & 179 & 174 & 2.108 & 126 & 118 & 23.704 & 136 & 112 & 704 & 48 & 41 \\
\hline 3 & 47.546 & 210 & 209 & 1.923 & 138 & 130 & 16.734 & 189 & 189 & 624 & 101 & 99 \\
\hline 4 & 45.215 & 230 & 186 & 1.862 & 161 & 147 & 17.937 & 217 & 177 & 684 & 116 & 98 \\
\hline 5 & 48.295 & 168 & 159 & 2.296 & 98 & 87 & 19.600 & 156 & 147 & 859 & 73 & 71 \\
\hline 6 & 47.787 & 137 & 127 & 2.292 & 75 & 72 & 19.341 & 160 & 157 & 852 & 67 & 66 \\
\hline 7 & 61.507 & 243 & 218 & 1.491 & 83 & 73 & 26.028 & 195 & 168 & 507 & 71 & 57 \\
\hline 8 & 72.777 & 210 & 205 & 2.364 & 83 & 76 & 29.474 & 249 & 249 & 662 & 83 & 76 \\
\hline 9 & 79.627 & 158 & 149 & 2.179 & 49 & 46 & 32.454 & 153 & 149 & 653 & 45 & 41 \\
\hline 10 & 47.057 & 109 & 94 & 2.046 & 64 & 60 & 19.134 & 136 & 130 & 711 & 74 & 65 \\
\hline 11 & 48.102 & 158 & 147 & 2.283 & 64 & 58 & 19.425 & 59 & 57 & 917 & 46 & 45 \\
\hline 12 & 47.500 & 128 & 127 & 2.149 & 80 & 77 & 19.099 & 160 & 159 & 885 & 71 & 64 \\
\hline
\end{tabular}

A Figura 4.2 apresenta o modelo ajustado com dados coletados na SP-280, km 26,9 Leste (Id4), com a segregação nas quatro configurações analisadas. Optou-se por traçar estas quatro curvas em um mesmo gráfico para facilitar a análise comparativa visual. Os pontos azuis correspondem aos pontos do $85^{\circ}$ percentil utilizados no ajuste e representam os dados com chuva durante o dia (azul claro) e com chuva durante à noite (azul escuro); os pontos cinzas correspondem aos períodos diurnos sem chuva e os pontos pretos aos períodos noturnos sem chuva. Os modelos ajustados para os dados dos demais sensores encontram-se no Apêndice C.

As Tabelas 4.7 e 4.8 apresentam os resultados comparativos dos modelos ajustados de acordo com as condições meteorológicas e de luminosidade. As análises foram feitas a cada duas configurações. A primeira tabela apresenta a influência da luminosidade sob as mesmas condições meteorológicas e a segunda apresenta a influência da chuva, com os resultados dos modelos ajustados sob as mesmas condições de luminosidade.

\subsubsection{Análise dos efeitos da luminosidade}

A Tabela 4.7 apresenta os parâmetros dos modelos ajustados para condições de tempo bom durante o dia e tempo bom durante a noite. Nota-se que, em seis dos doze locais estudados, a velocidade de fluxo livre para os modelos ajustados com dados noturnos é menor que nos modelos ajustados com dados diurnos, indicando um possível efeito da luminosidade sobre a velocidade de fluxo livre. 

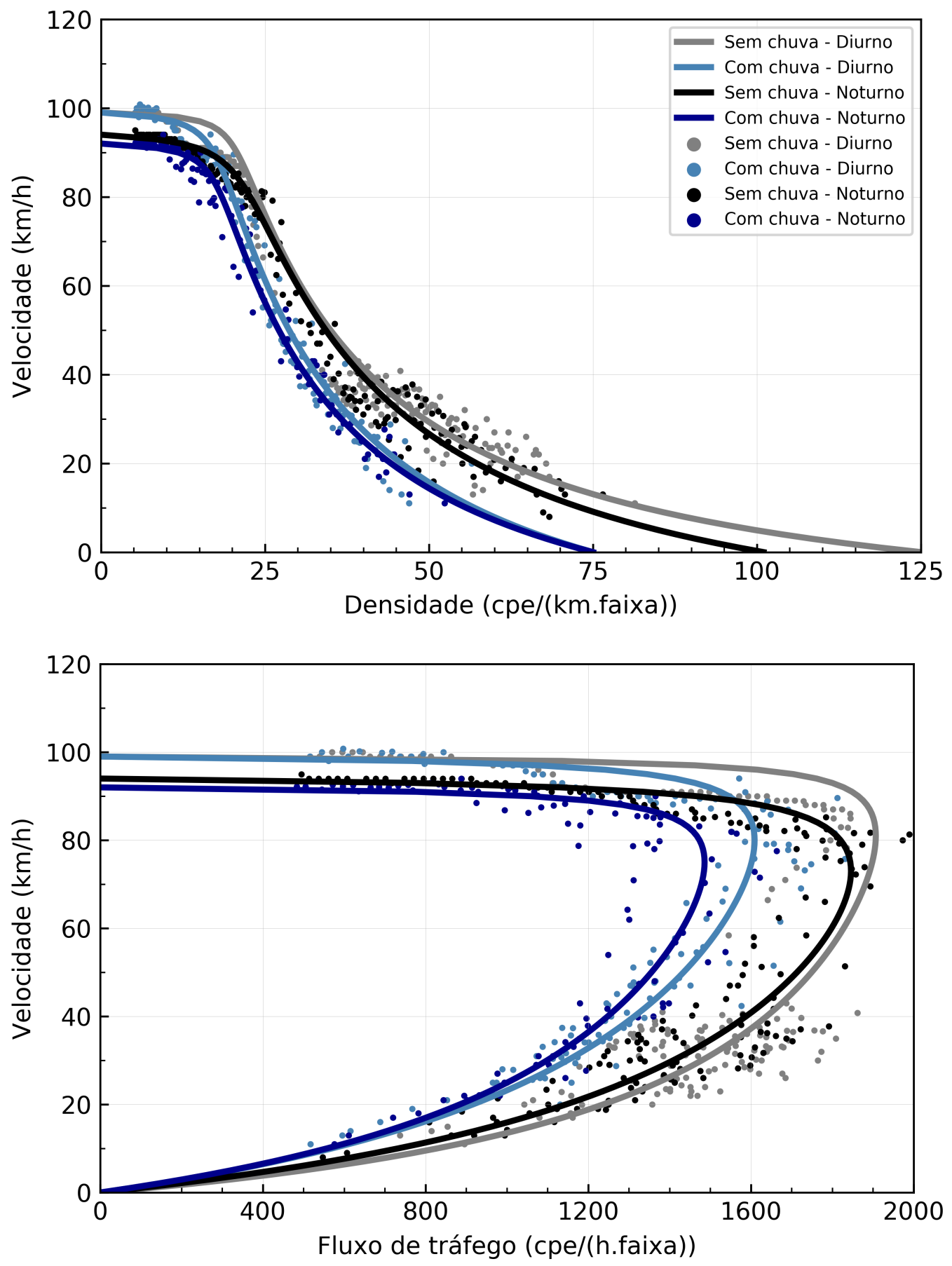

Figura 4.2: Resultados do ajuste do modelo fluxo-velocidade-densidade de Van Aerde estudando os efeitos combinados da precipitação com luminosidade, SP-280, km 26,9 Leste 
No entanto, o efeito mais significativo da luminosidade foi sobre os valores encontrados para a velocidade na capacidade. Em onze locais, houve redução entre os valores dos modelos para as condições noturnas em relação aos valores para os modelos ajustados para condições diurnas, com uma redução média de $9 \%$, indicando que a luminosidade pode afetar esse parâmetro do modelo.

O fluxo na capacidade apresentou redução sob condições noturnas em relação ao valores encontrados para o ajuste dos modelos sob condições diurnas em onze locais, com uma redução média de 4\%. Dentre todas as análises comparativas realizadas (tempo bom de dia e de noite; tempo chuvoso de dia e de noite; condição diurna com e sem chuva e; condição noturna com e sem chuva) esta redução de $4 \%$ foi a menor redução verificada na capacidade. Ainda assim, a redução foi estatisticamente significativa $(Z=-2,982 ; p=0,003)$ de acordo com o teste de Wilcoxon.

A velocidade na capacidade e a capacidade sob condições noturnas apresentaram reduções em relação ao valores encontrados para o ajuste dos modelos sob condições diurnas. No entanto, as reduções verificadas na velocidade na capacidade apresentaram maiores magnitudes, fazendo com que a densidade na capacidade $\left(k_{c}=q_{c} / u_{c}\right)$ apresentasse, em média, um aumento de $6 \%$ em condições noturnas em relação aos valores encontrados sob condições diurnas.

O parâmetro densidade de congestionamento apresentou grande variabilidade de valores devido ao pequeno número de observações na região de fluxo congestionado. Dessa forma, não é possível tecer conclusões sobre os impactos da luminosidade neste parâmetro.

A segunda parte da Tabela 4.7 apresenta uma análise do efeito da combinação de chuva com a luminosidade, comparando modelos ajustados para tempo chuvoso diurno e tempo chuvoso noturno. Em sete dos doze pontos estudados os valores da velocidade de fluxo livre obtidos para condições chuvosas noturnas foram inferiores aos obtidos para os modelos para condições chuvosas diurnas, sugerindo um pequeno efeito combinado da chuva e luminosidade sobre este parâmetro do modelo.

Em dez pontos os valores encontrados para o parâmetro velocidade na capacidade, para os modelos ajustados sob chuva noturna foram inferiores aos valores encontrados para os modelos ajustados para chuva diurna, com uma redução média de $9 \%$, sugerindo um efeito mais significativo que o detectado para a velocidade de fluxo livre. Um efeito semelhante foi encontrado para o parâmetro capacidade: em onze dos doze locais, houve redução nos valores dos parâmetros ajustados para chuva noturna, com redução média igual a 9\%, o que sugere um efeito digno de nota.

Apesar de os parâmetros capacidade e velocidade na capacidade apresentarem reduções estatísticas significativas entre os modelos ajustados para as condições noturnas com chuva em relação aos modelos ajustados para os períodos diurnos chuvosos, a densidade na capacidade não apresentou diferença estatisticamente significativa $(Z=-0,235 ; p=0,814)$, indicando que 
Tabela 4.7: Análise do efeito da luminosidade

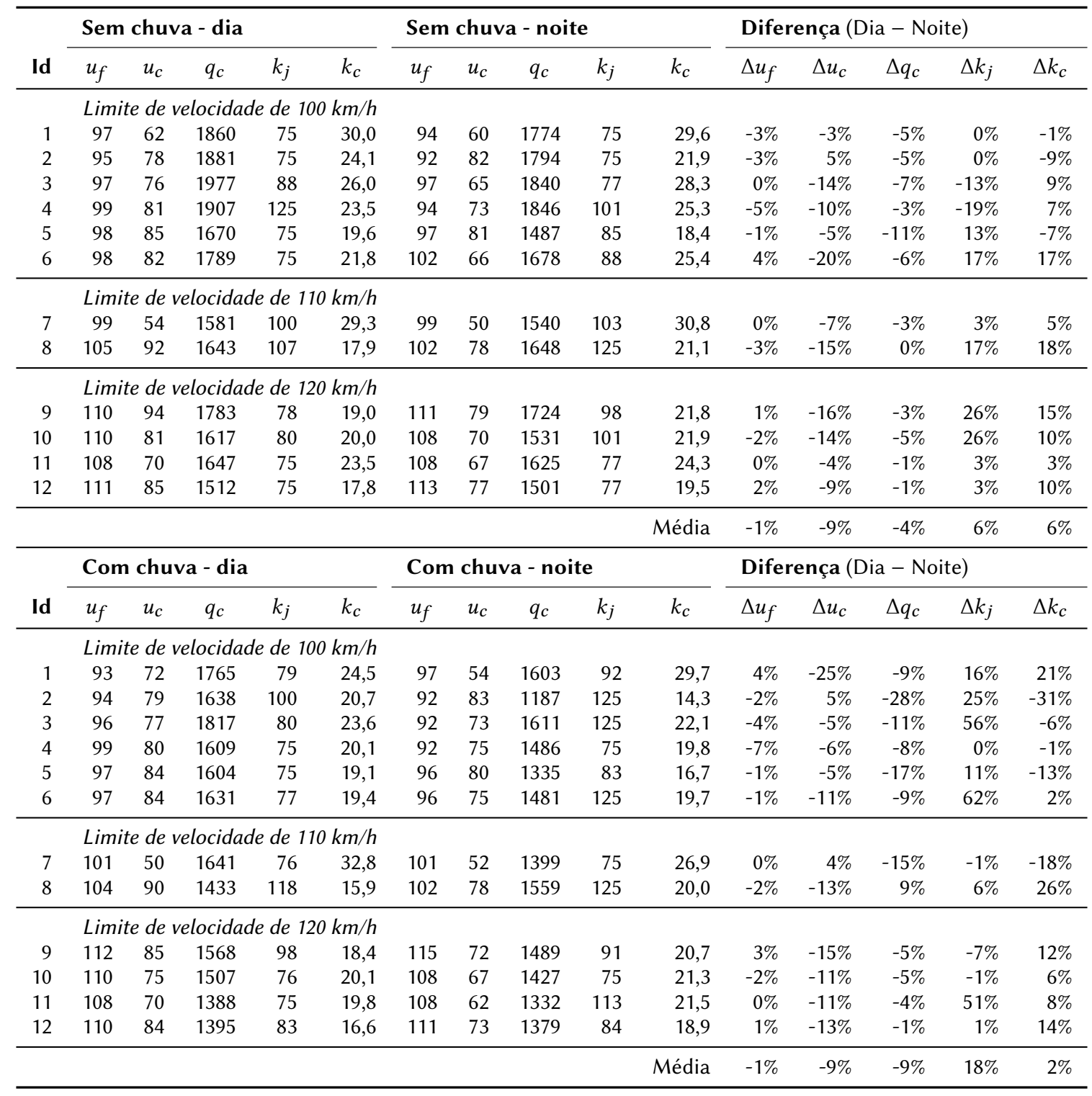

a luminosidade não afeta este parâmetro.

Os valores encontrados para o parâmetro densidade de congestionamento apresentaram diferenças estatisticamente significativas $(Z=-2,184 ; p=0,029)$, de acordo com o teste de Wilcoxon para amostras pareadas. No entanto, deve-se ressaltar que o número de observações na região de fluxo congestionado, durante a noite e com chuva é muito pequeno devido à baixa probabilidade de ocorrência destas situações, o que pode comprometer a análise.

\subsubsection{Análise dos efeitos da precipitação}

A Tabela 4.8 apresenta os valores dos parâmetros dos modelos ajustados com base nas observações feitas em períodos diurnos com e sem chuva. Em três dos locais estudados, os valores encontrados para a velocidade de fluxo livre se mantiveram constantes, ao passo que sete locais, a velocidade apresentou redução sob tempo chuvoso, indicando um possível efeito da 
chuva sobre este parâmetro.

Os valores obtidos para a velocidade na capacidade apresentaram uma tendência de redução sob tempo chuvoso. Entretanto, estas reduções não foram significativas, indicando que a chuva não interfere neste parâmetro do modelo.

O fluxo na capacidade foi o parâmetro mais influenciado pela chuva: os valores encontrados para os modelos ajustados com dados de períodos chuvosos diurnos são, em média, $9 \%$ inferiores aos valores encontrados para os modelos ajustados com dados de períodos diurnos sem chuva. A densidade na capacidade também apresentou redução significativa, com os parâmetros dos modelos ajustados com dados de períodos com chuva durante o dia sendo, em média, $8 \%$ inferiores aos valores dos modelos ajustados para períodos diurnos sem chuva.

Tabela 4.8: Análise do efeito da precipitação

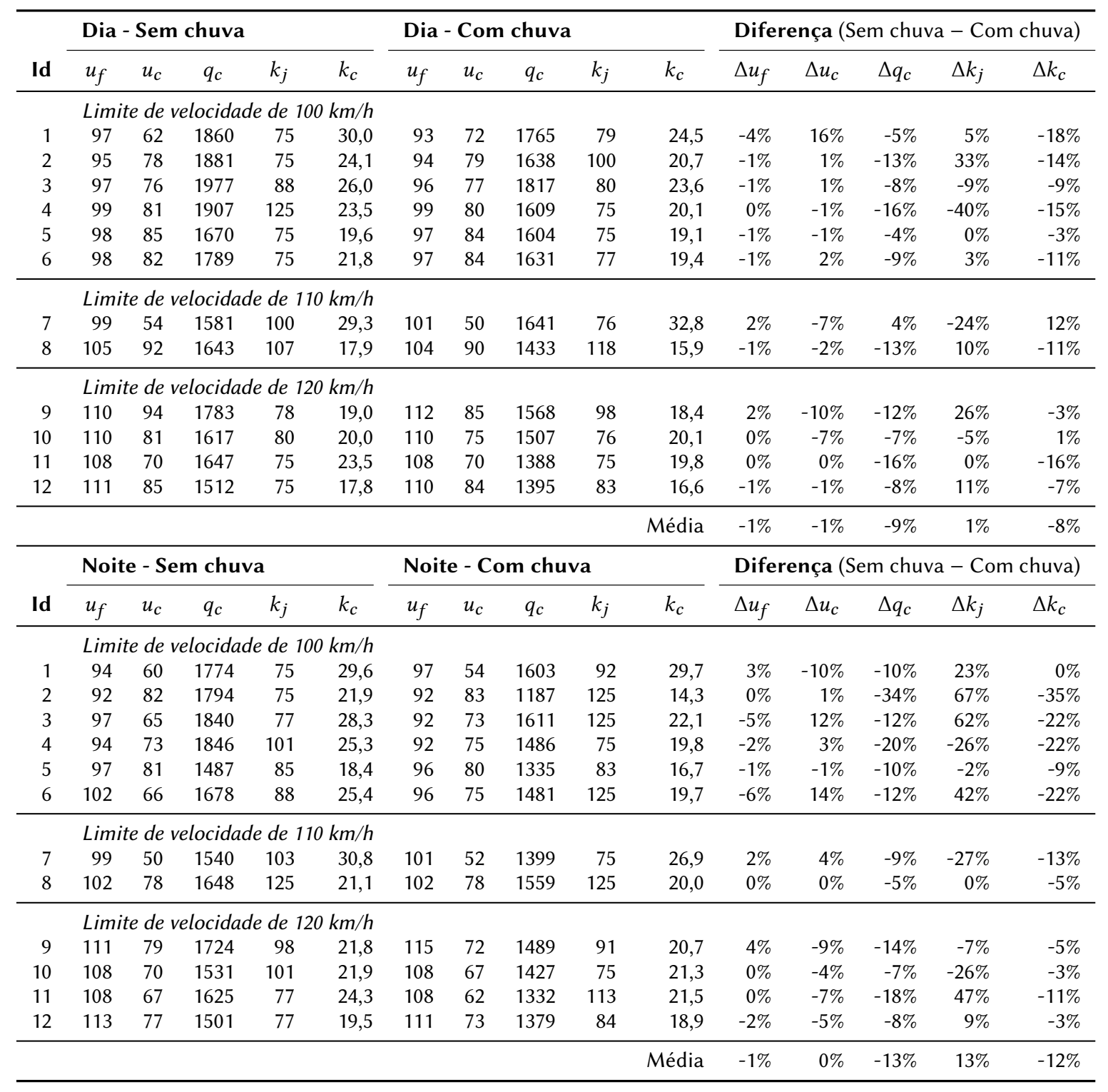

A Tabela 4.8 apresenta a análise da influência da chuva durante o período noturno, através dos valores dos parâmetros dos modelos ajustados com base nas observações feitas em 
períodos noturnos com e sem chuva.

Não é possível perceber uma influência clara da chuva sobre os parâmetros velocidade de fluxo livre e velocidade na capacidade. No entanto, a redução encontrada nos parâmetros fluxo na capacidade e densidade na capacidade nos modelos ajustados com dados de períodos noturnos com chuva, em relação aos valores dos modelos ajustados com dados de períodos sem chuva, sugere a existência de um efeito da chuva.

Nos doze locais estudados houve redução entre os valores encontrados para a capacidade sob condições chuvosas em relação ao tempo bom, com uma redução média de $13 \%$. Também é possível verificar que a chuva impacta a densidade na capacidade. Os resultados do ajuste dos modelos indicam uma redução média de $12 \%$ na densidade na capacidade sob chuva. Uma possível explicação é que em condições chuvosas, os motoristas tendem a aumentar a distância de segurança entre os veículos, fazendo com que a densidade na capacidade se reduza. Como a densidade na capacidade e a capacidade estão altamente relacionadas $\left(k_{c}=q_{c} / u_{c}\right)$, a capacidade também sofre redução.

Nota-se que os resultados encontrados para o fluxo e para a densidade na capacidade sofrem reduções maiores durante o período noturno em comparação às reduções verificadas durante o período diurno, sugerindo que a combinação entre luminosidade e meteorologia exerce maior influência quando as rodovias estão operando próximas à capacidade.

O teste de Wilcoxon foi aplicado para as quatro análises mostradas na Tabela 4.9. Primeiro, analisou-se a influência da luminosidade, comparando os resultados dos modelos ajustados sob as mesmas condições meteorológicas (análises 1 e 2). Posteriormente, realizou-se o teste estatístico para analisar a influência das condições meteorológicas, comparando os resultados dos parâmetros entre o tempo bom e o tempo chuvoso obtidos sob os mesmos períodos do dia (análises 3 e 4). Os resultados dos testes encontram-se na Tabela 4.9.

Tabela 4.9: Estatísticas do teste de Wilcoxon $(\alpha=0,05)$ para a determinação do efeito da luminosidade e da chuva sobre a corrente de tráfego, através do modelo de Van Aerde.

\begin{tabular}{|c|c|c|c|c|c|c|c|c|c|c|}
\hline \multirow[b]{2}{*}{ Análise } & \multicolumn{2}{|c|}{$u_{f}$} & \multicolumn{2}{|c|}{$u_{c}$} & \multicolumn{2}{|c|}{$q_{c}$} & \multicolumn{2}{|c|}{$k_{j}$} & \multicolumn{2}{|c|}{$k_{c}$} \\
\hline & $Z$ & $p$ & $Z$ & $p$ & $Z$ & $p$ & $Z$ & $p$ & $Z$ & $p$ \\
\hline 1. Sem chuva (noite - dia) & $-1,131$ & 0,258 & $-2,752$ & 0,006 & $-2,982$ & 0,003 & $-1,275$ & 0,202 & $-2,118$ & 0,034 \\
\hline 2. Com chuva (noite - dia) & $-1,025$ & 0,305 & $-2,751$ & 0,006 & $-2,589$ & 0,010 & $-2,184$ & 0,029 & $-0,235$ & 0,814 \\
\hline 3. Dia (chuva - sem chuva) & $-0,918$ & 0,359 & $-0,854$ & 0,393 & $-2,981$ & 0,003 & $-0,255$ & 0,799 & $-2,197$ & 0,028 \\
\hline 4. Noite (chuva - sem chuva) & $-0,563$ & 0,574 & $-0,311$ & 0,755 & $-3,059$ & 0,002 & $-1,023$ & 0,306 & $-2,981$ & 0,003 \\
\hline
\end{tabular}

Analisando-se os resultados dos modelos ajustados com dados dos períodos com tempo bom, durante os períodos noturnos em relação aos períodos diurnos, o teste de Wilcoxon mostra que há diferenças estatisticamente significativas nos parâmetros velocidade na capacidade, fluxo na capacidade e densidade na capacidade (ver Tabela 4.9), o que indica a existência de um efeito da luminosidade sobre o comportamento do tráfego. 
Observando-se a segunda linha da Tabela 4.9, pode-se perceber que este efeito da luminosidade também existe sob chuva, pois o teste de Wilcoxon mostra que há diferenças estatisticamente significativas nos valores da velocidade na capacidade, fluxo na capacidade e densidade de congestionamento verificadas à noite em relação ao período diurno. No entanto, deve-se ressaltar que o número de observações na região de fluxo congestionado, durante a noite e com chuva é pequeno devido à baixa probabilidade de ocorrência simultânea destas situações, o que pode comprometer a análise do parâmetro $k_{j}$.

A análise do efeito da chuva pode ser feita através dos resultados do teste de Wilcoxon mostrados nas linhas 3 e 4 da Tabela 4.9. Pode-se notar que há um efeito estatisticamente significativo da chuva sobre os parâmetros capacidade e densidade na capacidade, tanto para os modelos ajustados para períodos diurnos quanto noturnos. No entanto, deve-se ressaltar que a densidade na capacidade é um parâmetro fortemente correlacionado com o fluxo na capacidade e, por conseguinte, é compreenssível que apresentem características bastante similares.

Com base nos resultados dos testes estatísticos mostrados na Tabela 4.9, é possível afirmar que a velocidade na capacidade, o fluxo na capacidade e a densidade na capacidade sofrem influência das condições adversas de precipitação e luminosidade. Para verificar se os efeitos combinados da precipitação com a luminosidade, de fato, impactam estes parâmetros, o teste de Friedman foi aplicado.

\subsubsection{Teste de Friedman}

Com o intuito de verificar se há um efeito combinado da luminosidade e da chuva, o teste de Friedman foi aplicado para as quatro configurações: (1) condição diurna sem chuva, (2) condição diurna com chuva, (3) condição noturna sem chuva e (4) condição noturna com chuva.

O teste de Friedman é uma alternativa não paramétrica para o teste de experimentos na ANOVA, utilizado para comparar duas ou mais populações com amostras emparelhadas. Neste teste, a hipótese nula é de que todas as populações possuem funções de distribuição iguais; a hipótese alternativa de que ao menos uma distribuição difere das demais (MARÔCO, 2014, p. 419). No caso, a hipótese nula é que o valor de cada parâmetro do modelo de Van Aerde tem a mesma distribuição nas quatro configurações apresentadas. A Tabela 4.10 resume os resultados do teste.

Tabela 4.10: Resumo dos resultados do teste de Friedman para o efeito combinado da precipitação e luminosidade

\begin{tabular}{lrrl}
\hline Hipótese nula & \multicolumn{1}{c}{$p$} & \multicolumn{1}{c}{$\chi^{2}$} & Significado \\
\hline A distribuição de $u_{f}$ é a mesma para as quatro configurações & 0,208 & 4,545 & a hipótese nula não pode ser rejeitada \\
A distribuição de $u_{c}$ é a mesma para as quatro configurações & $<\mathbf{0 , 0 0 1}$ & 18,077 & rejeitar a hipótese nula \\
A distribuição de $q_{c}$ é a mesma para as quatro configurações & $<\mathbf{0 , 0 0 1}$ & 29,300 & rejeitar a hipótese nula \\
A distribuição de $k_{j}$ é a mesma para as quatro configurações & 0,120 & 5,841 & a hipótese nula não pode ser rejeitada \\
A distribuição de $k_{c}$ é a mesma para as quatro configurações & $\mathbf{0 , 0 0 4}$ & 13,500 & rejeitar a hipótese nula \\
\hline
\end{tabular}


O teste de hipótese mostra que dentre os parâmetros estudados, deve-se rejeitar a hipótese nula de que a velocidade na capacidade, o fluxo na capacidade e a densidade na capacidade apresentam funções de distribuição semelhantes entre as quatro configurações analisadasou seja, pode-se considerar que há um efeito combinado da luminosidade e da chuva sobre a velocidade na capacidade, capacidade e densidade na capacidade, mas não sobre os demais parâmetros do modelo de fluxo de tráfego escolhido.

Após a aplicação do teste de hipótese, foi realizada uma comparação de pares entre as quatro configurações adotadas: (1) condição diurna sem chuva, (2) condição diurna com chuva, (3) condição noturna sem chuva e (4) condição noturna com chuva para os três parâmetros que apresentaram diferenças. A Tabela 4.11 apresenta a comparação entre pares do teste de Friedman para os resultados obtidos.

Tabela 4.11: Resultados do teste de Friedman para a comparação entre pares para os parâmetros velocidade na capacidade $u_{c}$, fluxo na capacidade $q_{c}$ e densidade na capacidade $k_{c}$

\begin{tabular}{|c|c|c|c|c|}
\hline Análise & $\chi^{2}$ & $\sigma$ & Erro estat. do teste & Sig. Aj. \\
\hline \multicolumn{5}{|c|}{ Velocidade na capacidade } \\
\hline$(4)-(1)$ & 1,750 & 0,527 & 3,320 & 0,005 \\
\hline (3) $-(1)$ & 1,708 & 0,527 & 3,241 & 0,007 \\
\hline$(4)-(2)$ & 1,375 & 0,527 & 2,609 & 0,055 \\
\hline (3) $-(2)$ & 1,333 & 0,527 & 2,530 & 0,068 \\
\hline$(2)-(1)$ & 0,375 & 0,527 & 0,712 & 1,000 \\
\hline$(4)-(3)$ & 0,042 & 0,527 & 0,079 & 1,000 \\
\hline \multicolumn{5}{|c|}{ Fluxo na capacidade } \\
\hline$(4)-(1)$ & 2,750 & 0,527 & 5,218 & $<0,001$ \\
\hline$(4)-(3)$ & 1,833 & 0,527 & 3,479 & 0,003 \\
\hline (2) $-(1)$ & 1,667 & 0,527 & 3,162 & 0,009 \\
\hline$(4)-(2)$ & 1,083 & 0,527 & 2,055 & 0,239 \\
\hline$(3)-(1)$ & 0,917 & 0,527 & 1,739 & 0,492 \\
\hline$(2)-(3)$ & $-0,750$ & 0,527 & $-1,423$ & 0,928 \\
\hline \multicolumn{5}{|c|}{ Densidade na capacidade } \\
\hline$(2)-(3)$ & $-1,750$ & 0,527 & $-3,320$ & 0,005 \\
\hline$(4)-(3)$ & 1,500 & 0,527 & 2,846 & 0,027 \\
\hline$(2)-(1)$ & 1,000 & 0,527 & 1,897 & 0,347 \\
\hline (4) $-(1)$ & 0,750 & 0,527 & 1,423 & 0,928 \\
\hline$(1)-(3)$ & $-0,750$ & 0,527 & $-1,423$ & 0,928 \\
\hline$(2)-(4)$ & $-0,250$ & 0,527 & $-0,474$ & 1,000 \\
\hline
\end{tabular}

O teste de Friedman mostrou que há efeito da configuração (4) condição noturna com chuva em relação à configuração (1) condição diurna sem chuva sobre os valores obtidos de velocidade na capacidade $\left(\chi^{2}(3)=1,750 ; p=0,005\right)$, com uma redução média verificada de $10 \%$. Neste parâmentro, também há um efeito da configuração (3) condição noturna sem chuva em relação à configuração $(1)$ condição diurna sem chuva $\left(\chi^{2}(3)=1,708 ; p=0,007\right)$, com uma redução média de $9 \%$.

O teste de Friedman também indicou que há efeito da configuração (4) condição noturna com chuva em relação à configuração (1) condição diurna sem chuva sobre os valores obtidos 
de fluxo na capacidade $\left(\chi^{2}(3)=2,750 ; p<0,001\right)$, com uma redução média de $17 \%$. Para este parâmetro, o teste também indicou que há influência da precipitação, nas duas condições de luminosidade analisadas, mostrando que há efeito da configuração (4) condição noturna com chuva em relação à configuração (3) condição noturna sem chuva sobre os valores obtidos de capacidade $\left(\chi^{2}(3)=1,833 ; p=0,003\right)$, com uma redução média verificada de $13 \%$ e há efeito da configuração (2) condição diurna com chuva em relação à configuração (1) condição diurna sem chuva sobre os valores obtidos de capacidade $\left(\chi^{2}(3)=1,667 ; p=0,009\right)$, com uma redução média verificada de $9 \%$.

Em relação à densidade na capacidade, o teste de Friedman indicou que há efeito da configuração (2) condição diurna com chuva em relação à configuração (3) condição noturna sem chuva sobre os valores obtidos de densidade na capacidade $\left(\chi^{2}(3)=-1,750 ; p=0,005\right)$, com uma redução média de $13 \%$. O teste também indicou que há influência da precipitação durante o período noturno sobre a densidade na capacidade, com efeito da configuração (4) condição noturna com chuva em relação à configuração (3) condição noturna sem chuva sobre os valores obtidos de densidade na capacidade $\left(\chi^{2}(3)=1,500 ; p=0,027\right)$, com uma redução média de $12 \%$.

Com base nos resultados das análises pode-se afirmar que há um efeito da precipitação, da luminosidade e um efeito combinado dessas duas condições nos parâmetros velocidade na capacidade, fluxo na capacidade e densidade na capacidade. 


\section{Capítulo}

\section{Conclusões e recomendações}

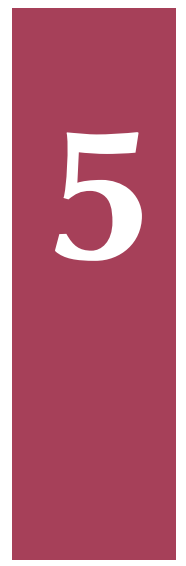

Neste trabalho estudou-se a influência da precipitação, da luminosidade e seus efeitos combinados na operação das rodovias de pista dupla do estado de São Paulo. Todas as etapas para a realização do trabalho foram executadas. Assim, foi possível responder às questões de pesquisa propostas, tecer as conclusões deste trabalho e as recomendações para estudos futuros.

\subsection{Conclusões}

Neste trabalho, foram utilizadas imagens geradas pelos radares meteorológicos do IPMet/UNESP para discretizar a intensidade da precipitação nos locais de coleta dos dados de tráfego. Essas imagens apresentam um fundo preto, com escala de cores discreta para indicar a intensidade da precipitação, o que facilitou a segregação dessas leituras nas quatro classificações adotadas (sem chuva, chuva fraca, chuva moderada e chuva forte).

Após a fusão dos bancos de dados de tráfego e chuva, foi necessário o desenvolvimento de um método para ajustamento de um modelo de fluxo de tráfego usando uma base de dados muito grande (VLDB). O método desenvolvido buscou eliminar as observações com ruído e uniformizar a informação ao longo de toda a gama de volumes observados por meio da segregação em pequenas faixas de densidade. O método proposto garante uma melhor distribuição dos dados de tráfego, fazendo com que as regiões de fluxo livre e de fluxo congestionado exerçam a mesma influência no ajuste do modelo. Duas técnicas de otimização, o algoritmo hill climbing e o algoritmo genético foram testadas para ajustar o modelo. O algoritmo genético apresentou uma qualidade de ajuste marginalmente superior à apresentada pelo hill climbing, por ser capaz de encontrar mínimos globais mais rapidamente.

O estudo da influência da precipitação foi feito comparando-se modelos ajustados para condições chuvosas e não chuvosas. Com base nos resultados das análises conduzidas, é possível 
afirmar que a chuva exerce uma maior influência quando a operação da rodovia se aproxima da capacidade. Sob condições chuvosas, os motoristas tendem a aumentar a distância de segurança entre os veículos, diminuindo a densidade de veículos na capacidade e o fluxo na capacidade. Nos locais estudados, a densidade na capacidade e a capacidade apresentaram uma redução média de 11 e $10 \%$ e estas reduções foram estatísticamente significativas.

Com a segregação dos dados nas quatro configurações: (1) condição diurna sem chuva, (2) condição diurna com chuva, (3) condição noturna sem chuva e (4) condição noturna com chuva, é possível afirmar que a velocidade na capacidade sofre influência da luminosidade, sob tempo bom e sob tempo chuvoso, houve uma redução de $9 \%$ nas velocidades verificadas à noite em relação às velocidades obtidas durante o dia.

A densidade na capacidade sofre influência das condições meteorológicas sob luminosidades distintas. Durante o dia, verifica-se uma redução média de $8 \%$ nos valores de densidade na capacidade sob tempo chuvoso em comparação aos valores de densidade encontrados sob tempo bom; durante a noite estas reduções são maiores, verifica-se uma redução média de $12 \%$ nos valores obtidos sob chuva em relação aos valores obtidos com tempo bom.

A capacidade foi o único parâmetro que apresentou influência das condições adversas em todas as análises realizadas. Os resultados indicam que a capacidade sofre influência da luminosidade, das condições meteorológicas e, também sofre influência do efeito combinado da precipitação com a luminosidade.

$\mathrm{Na}$ análise da influência da luminosidade, sob tempo bom, houve uma redução de $4 \%$ nos valores de capacidade verificados no período noturno em relação aos valores observados durante o período diurno e sob chuva; houve uma redução de $9 \%$ na capacidade verificada à noite em comparação com a capacidade verificada durante o dia.

$\mathrm{Na}$ análise da influência da precipitação, nos locais estudados observou-se uma redução média de $9 \%$ nos valores de capacidade verificados durante o dia com chuva em relação aos valores obtidos sob condições diurnas sem chuva. Durante a noite, essas reduções foram maiores, verificou-se uma redução média de $13 \%$ na capacidade sob tempo chuvoso à noite em comparação à capacidade verificada sob tempo bom.

Nos locais estudados, detectou-se efeitos individuais e um efeito combinado das condições meteorológicas e da luminosidade na operação das rodovias, especialmente na velocidade na capacidade, fluxo na capacidade e na densidade na capacidade.

\subsection{Recomendações}

Este estudo se concentrou na análise da influência das condições meteorológicas e de luminosidade na operação das rodovias de pista dupla do estado de São Paulo. Embora os dados analisados nesta pesquisa abranjam um período de seis anos, não foi possível o estudo do impacto da intensidade da precipitação nestes locais, devido aos poucos dados coletados nas 
condições de chuva moderada e, especialmente, chuva forte. Dessa forma, aconselha-se que a coleta de dados seja ampliada para aumentar o número de observações com diferentes intensidades e que estes dados também estejam no regime de fluxo congestionado, dada a natureza aleatória destes eventos.

Além disso, pode-se correlacionar as condições meteorológicas com outras características dos trechos, como número de faixas da via, inclinação dos trechos e uso do solo, que em estudo anterior se mostrou um importante fator na operação das rodovias (ANDRADE; SETTI, 2014). 


\section{Referências}

AGARWAL, M.; MAZE, T. H.; SOULEYRETTE, R. R. Impacts of weather on urban freeway traffic flow characteristics and facility capacity. Ames, Iowa, USA: CTRE Iowa State University, 2005.

ANDRADE, G. R.; SETTI, J. R. Speed-flow relationship and capacity for expressways in Brazil. Transportation Research Circular, 2014. n. EC190, p. 10-25, 2014.

ARABAS, J.; MICHALEWICZ, Z.; MULAWKA, J. GAVaPS-a genetic algorithm with varying population size. In: Proceedings of the 1st IEEE Conference on Evolutionary Computation, IEEE World Congress on Computational Intelligence. Orlando, FL, USA: IEEE, 1994. p. 73-78.

BILLOT, R.; EL FAOUZI, N.-E.; VUYST, F. D. Multilevel assessment of the impact of rain on drivers' behavior: Standardized methodology and empirical analysis. Transportation Research Record: Journal of the Transportation Research Board, 2009. v. 2107, p. 134-142, 2009.

BRILON, W.; PONZLET, M. Variability of speed-flow relationships on German autobahns. Transportation Research Record: Journal of the Transportation Research Board, 1996. v. 1555, p. 91-98, 1996.

CALEFFI, F. et al. Influência das condições climáticas e de acidentes na caracterização do comportamento do tráfego em rodovias. Transportes, 2016. v. 24, n. 4, p. 57-63, 2016.

CALVETTI, L.; BENETI, C.; ZANDONÁ, C. Sistema integrado de análise e visualização de dados de radar meteorológico Doppler. In: Congresso Brasileiro de Meteorologia. Foz do Iguaçu, PR: SBMET, 2002.

CAMACHO, F. J.; GARCÍA, A.; BELDA, E. Analysis of impact of adverse weather on freeway free-flow speed in Spain. Transportation Research Record: fournal of the Transportation Research Board, 2010. v. 2169, p. 150-159, 2010.

CARDOSO, J. M.; ASSIRATI, L.; SETTI, J. R. Calibração de modelos fluxo-velocidade-densidade a partir de bases de dados muito grandes. In: Anais do XXXIII Congresso Nacional de Pesquisa em Transportes. Balneário Camboriú, SC: ANPET, 2019.

CHAMBERS, L. D. The Practical Handbook of Genetic Algorithms: Applications. Florida, USA: Chapman and Hall/CRC, 2000. 
CHOW, A. et al. TOPL: Tools for operational planning of transportation networks. In: Proceedings of Dynamic Systems and Control Conference. Michigan, USA: American Society of Mechanical Engineers, 2008. p. 1035-1042.

COLEY, D. A. An introduction to genetic algorithms for scientists and engineers. Singapore: World Scientific Publishing, 1999.

DEMARCHI, S. H. Uma nova formulação para o modelo fluxo-velocidade-densidade de Van Aerde. In: CNT/ANPET. Transporte em Transformação. Brasília, DF: LGE, 2003, (7). p. 77-94.

DERVISOGLU, G. et al. Automatic calibration of the fundamental diagram and empirical observations on capacity. In: 88th Annual Meeting of the Transportation Research Board. Washington D.C., USA: Transportation Research Board of the National Academies, 2009.

DHALIWAL, S. S. et al. Effects of rain on freeway traffic in Southern California. Transportation Research Record: Journal of the Transportation Research Board, 2017. v. 2616, n. 1, p. 69-80, 2017.

DIAZ-GOMEZ, P. A.; HOUGEN, D. F. Initial population for genetic algorithms: A metric approach. In: Proceedings of the International Conference on Genetic and Evolutionary Methods. Las Vegas, USA: CSREA Press, 2007. p. 43-49.

DRAPER, N.; SMITH, H. Applied Regression Analysis. 2nd. ed. New York, USA: John Wiley \& Sons, 1980.

EDWARDS, J. B. Speed adjustment of motorway commuter traffic to inclement weather. Transportation Research Part F: Traffic Psychology and Behaviour, 1999. v. 2, n. 1, p. 1-14, 1999.

EL FAOUZI, N.-E. et al. Effects of adverse weather on traffic and safety: State-of-the-art and a European initiative. In: 15th International Road Weather Conference. Quebec City, Canada: [s.n.], 2010. p. 1-7.

FGSV. Handbuch für die Bemessung von Straßenverkehrsanlagen: HBS 2015. Cologne: Forschungsgesellschaft für Straßen-und Verkehrswesen, 2015.

GOLDBERG, D. E. Genetic Algorithms in Search, Optimization and Machine Learning. Boston: Addison-Wesley Longman, 1989. ISBN 0201157675.

GOODWIN, L. C. Weather Impacts on Arterial Traffic Flow. Virginia, USA: Mitretek Systems, 2002. Road Weather Management Program.

GREENBERG, H. An analysis of traffic flow. Operations Research, 1959. v. 7, n. 1, p. 79-85, 1959.

HALL, F.; HURDLE, V. F.; BANKS, J. H. Synthesis of recent work on the nature of speed-flow and flow-occupancy (or density) relationships on freeways. Transportation Research Record, 1992. v. 1365, p. 12-18, 1992.

HALL, F. L.; BARROW, D. Effects of weather and the relationship between flow and occupancy on freeways. Transportation Research Record: Fournal of the Transportation Research Board, 1988. v. 1194, p. 55-63, 1988.

HAWKINS, R. K. Motorway traffic behaviour in reduced visibility conditions. In: Vision in Vehicles II. Proceedings of the Second International Conference on Vision in Vehicles. Nottingham, UK: [s.n.], 1988. p. 9-18. 
HELD, G.; GOMES, A. M.; CALHEIROS, R. V. O Instituto de Pesquisas Meteorológicas (IPMet): serviços para a sociedade no estado de São Paulo. Boletim da Sociedade Brasileira de Meteorologia, 2008. v. 32, n. 1, p. 27-33, 2008.

HOLDENER, D. J. The effects of rainfall on freeway speeds. ITE fournal, 1998. v. 68, n. 11, p. 16, 1998.

HOOPER, E.; CHAPMAN, L.; QUINN, A. The impact of precipitation on speed-flow relationships along a UK motorway corridor. Theoretical and Applied Climatology, 2014. v. 117, n. 1-2, p. 303-316, 2014.

HOOPER, E.; CHAPMAN, L.; QUINN, A. Investigating the impact of precipitation on vehicle speeds on UK motorways. Meteorological Applications, 2014. v. 21, n. 2, p. 194-201, 2014.

HRANAC, R. et al. Empirical Studies on Traffic Flow in Inclement Weather. Washington, D.C., USA, 2006.

IBRAHIM, A. T.; HALL, F. L. Effect of adverse weather conditions on speed-flow-occupancy relationships. Transportation Research Record: Fournal of the Transportation Research Board, 1994. v. 1457, p. 184-191, 1994.

KARIM, A.; ADELI, H. Comparison of fuzzy-wavelet radial basis function neural network freeway incident detection model with California algorithm. Fournal of Transportation Engineering, 2002. v. 128, n. 1, p. 21-30, 2002.

KERNER, B. S. The Physics of Traffic - Empirical Freeway Pattern Features, Engineering Applications, and Theory. Berlin Heidelberg: Springer, 2004.

KNOOP, V. L.; DAAMEN, W. Automatic fitting procedure for the fundamental diagram. Transportmetrica B: Transport Dynamics, 2017. v. 5, n. 2, p. 129-144, 2017.

KÜHNE, R. D. Greenshields' legacy: Highway traffic. In: 75 Years of the Fundamental Diagram for Traffic Flow Theory - Greenshields Symposium. Washington, DC, USA: Transportation Research Board, 2011, (Transportation Research Circular E-C149). p. 3-11.

KYTE, M. et al. Effect of weather on free-flow speed. Transportation Research Record: Fournal of the Transportation Research Board, 2001. v. 1776, p. 60-68, 2001.

LU, C.; ELEFTERIADOU, L. An investigation of freeway capacity before and during incidents. Transportation Letters, 2013. v. 5, n. 3, p. 144-153, 2013.

LU, S. et al. Data mining-based adaptive regression for developing equilibrium speed-density relationships. Canadian Journal of Civil Engineering, 2010. v. 37, n. 3, p. 389-400, 2010.

MARÔCO, J. Análise Estatística com o SPSS Statistics. 6. ed. Pero Pinheiro, Portugal: ReportNumber - Análise e Gestão de Informação, 2014.

MAY, A. D. Traffic Flow Fundamentals. Upper Saddle River, NJ, USA: Prentice Hall, 1990.

MAZE, T.; AGARWAL, M.; BURCHETT, G. Whether weather matters to traffic demand, traffic safety, and traffic operations and flow. Transportation Research Record: Fournal of the Transportation Research Board, 2006. v. 1948, p. 170-176, 2006. 
MOREIRA, R. M.; COSTA, S. L.; CUNTO, F. J. C. Impacto de condições ambientais adversas na velocidade de fluxo livre e de fluxo de saturação em vias urbanas. In: Anais do XXXI Congresso Nacional de Pesquisa em Transportes. Recife: ANPET, 2017. p. 3140-3151.

POMPIGNA, A.; RUPI, F. Differences between HCM procedures and fundamental diagram calibration for operational LOS assessment on Italian freeways. Transportation Research Procedia, 2015. Elsevier, v. 5, p. 103-118, 2015.

RAKHA, H. Validation of Van Aerde's simplified steadystate car-following and traffic stream model. Transportation Letters, 2009. v. 1, n. 3, p. 227-244, 2009.

RAKHA, H.; ARAFEH, M. Calibrating steady-state traffic stream and car-following models using loop detector data. Transportation Science, 2010. v. 44, n. 2, p. 151-168, 2010.

RAKHA, H.; CROWTHER, B. Comparison and calibration of FRESIM and INTEGRATION steady-state car-following behavior. Transportation Research Part A: Policy and Practice, 2003. v. 37, n. 1, p. 1-27, 2003.

RAKHA, H. et al. Inclement weather impacts on freeway traffic stream behavior.

Transportation Research Record: Journal of the Transportation Research Board, 2008. v. 2071, p. 8-18, 2008.

SETTI, J. R. Highway Capacity Manual ou manual de capacidade viária? In: Anais do VI Congresso Brasileiro de Rodovias \& Concessões - CBR\&C. Florianópolis: ABCR, 2009.

SIVANANDAM, S. N.; DEEPA, S. N. Introduction to Genetic Algorithms. Berlin: Springer, 2007.

SMITH, B. et al. An investigation into the impact of rainfall on freeway traffic flow. In: $83 r d$ Annual Meeting of the Transportation Research Board. Washington D.C., USA: Transportation Research Board, 2004.

SMITH, B.; QIN, L.; VENKATANARAYANA, R. Characterization of freeway capacity reduction resulting from traffic accidents. Journal of Transportation Engineering, 2003. v. 129, n. 4, p. 362-368, 2003.

SRINIVAS, M.; PATNAIK, L. Adaptive probabilities of crossover and mutation in genetic algorithms. IEEE Transactions on Systems, Man, and Cybernetics, 1994. v. 24, n. 4, p. 656-667, 1994.

STORN, R. On the usage of differential evolution for function optimization. In: Proceedings of North American Fuzzy Information Processing. Berkeley, CA, USA: IEEE, 1996. p. 519-523.

TRB. Highway Capacity Manual. Washington, D.C., USA: Transportation Research Board, National Research Council, 2000.

TRB. Highway Capacity Manual. Washington, D.C., USA: Transportation Research Board, National Research Council, 2016.

TREIBER, M.; HENNECKE, A.; HELBING, D. Congested traffic states in empirical observations and microscopic simulations. Physical Review E, 2000. v. 62, p. 1805-1824, 2000.

TU, H. et al. Empirical investigation on stochastic dutch freeway capacity. In: 13th ITSC International IEEE Conference on Intelligent Transportation Systems. Ilha da Madeira, Portugal: IEEE, 2010. p. 825-830. 
UNRAU, D.; ANDREY, J. Driver response to rainfall on urban expressways. Transportation Research Record: Journal of the Transportation Research Board, 2006. v. 1980, p. 24-30, 2006.

VAN AERDE, M.; RAKHA, H. Multivariate calibration of single regime speed-flow-density relationships. In: Pacific Rim TransTech Conference. 1995 Vehicle Navigation and Information Systems Conference Proceedings. 6th International VNIS. A Ride into the Future. Seatle, WA, USA: IEEE, 1995. p. $334-341$.

WICKHAM, H. Bin-summarise-smooth: a framework for visualising large data. 2013. Technical Report, disponível em vita.had.co.nz/papers/bigvis.pdf.

WILSON, J. W. et al. Nowcasting thunderstorms: A status report. Bulletin of the American Meteorological Society, 1998. v. 79, n. 10, p. 2079-2099, 1998.

ZECHIN, D. et al. Influência da chuva na probabilidade de breakdown. In: XXXII Congresso Nacional de Pesquisa em Transportes. Gramado: ANPET, 2018. p. 3577-3588. 
Apêndices 


\section{APÊNDICE}

\section{Sensores automáticos de tráfego}

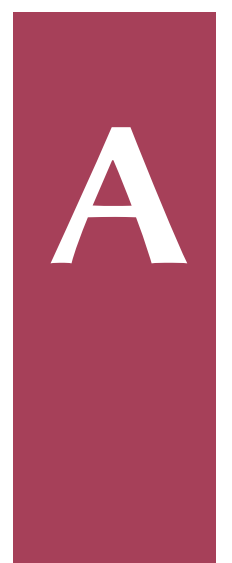

Este apêndice contém os sensores automáticos de tráfego (SATs) inicialmente utilizados neste estudo. 
Tabela A.1: Sensores iniciais estudados

\begin{tabular}{|c|c|c|c|}
\hline Rodovia & $\mathbf{k m}$ & Sentido & Empresa \\
\hline SP-330 & 55,2 & $\mathrm{~N} / \mathrm{S}$ & CCR AutoBAn \\
\hline SP-330 & 79,2 & $\mathrm{~N} / \mathrm{S}$ & CCR AutoBAn \\
\hline SP-330 & 115,9 & $\mathrm{~N} / \mathrm{S}$ & CCR AutoBAn \\
\hline SP-348 & 50,0 & $\mathrm{~N} / \mathrm{S}$ & CCR AutoBAn \\
\hline SP-348 & 65,0 & $\mathrm{~N} / \mathrm{S}$ & CCR AutoBAn \\
\hline SP-348 & 92,0 & $\mathrm{~N} / \mathrm{S}$ & CCR AutoBAn \\
\hline SP-348 & 131,0 & $\mathrm{~S}$ & CCR AutoBAn \\
\hline SP-280 & 26,9 & $\mathrm{~L} / \mathrm{O}$ & CCR ViaOeste \\
\hline SP-280 & 37,0 & LE & CCR ViaOeste \\
\hline SP-280 & 51,9 & $\mathrm{OE}$ & CCR ViaOeste \\
\hline SP-280 & 59,6 & $\mathrm{~L} / \mathrm{OE}$ & CCR ViaOeste \\
\hline SP-280 & 75,0 & $\mathrm{OE}$ & CCR ViaOeste \\
\hline SP-021 & 18,3 & Ext/Int & CCR RodoAnel Oeste \\
\hline SP-021 & 22,3 & Ext & CCR RodoAnel Oeste \\
\hline SP-055 & 276,9 & $\mathrm{~L} / \mathrm{O}$ & Ecovias \\
\hline SP-055 & 288,7 & $\mathrm{O}$ & Ecovias \\
\hline SP-150 & 32,0 & $\mathrm{~L} / \mathrm{O}$ & Ecovias \\
\hline SP-160 & 13,1 & $\mathrm{~L}$ & Ecovias \\
\hline SP-160 & 38,1 & $\mathrm{~L} / \mathrm{O}$ & Ecovias \\
\hline SP-070 & 14,9 & $\mathrm{~L}$ & Ecopistas \\
\hline SP-070 & 17,0 & $\mathrm{O}$ & Ecopistas \\
\hline SP-070 & 21,9 & $\mathrm{~L} / \mathrm{O}$ & Ecopistas \\
\hline SP-070 & 30,0 & $\mathrm{~L} / \mathrm{O}$ & Ecopistas \\
\hline SP-070 & 39,5 & $\mathrm{~L} / \mathrm{O}$ & Ecopistas \\
\hline SP-070 & 54,1 & $\mathrm{~L} / \mathrm{O}$ & Ecopistas \\
\hline SP-070 & 63,8 & $\mathrm{~L} / \mathrm{O}$ & Ecopistas \\
\hline SP-070 & 78,6 & $\mathrm{~L} / \mathrm{O}$ & Ecopistas \\
\hline SP-070 & 87,3 & $\mathrm{~L} / \mathrm{O}$ & Ecopistas \\
\hline SP-065 & 81,5 & $\mathrm{~N} / \mathrm{S}$ & Rota das Bandeiras \\
\hline SP-065 & 96,0 & $\mathrm{~N} / \mathrm{S}$ & Rota das Bandeiras \\
\hline SP-065 & 104,7 & $\mathrm{~N} / \mathrm{S}$ & Rota das Bandeiras \\
\hline SP-065 & 119,7 & $\mathrm{~N} / \mathrm{S}$ & Rota das Bandeiras \\
\hline SP-065 & 124,1 & $\mathrm{~N} / \mathrm{S}$ & Rota das Bandeiras \\
\hline SP-083 & 10,6 & $\mathrm{~N} / \mathrm{S}$ & Rota das Bandeiras \\
\hline
\end{tabular}




\section{APÊNDICE}

\section{Análise do efeito das condições meteorológicas}

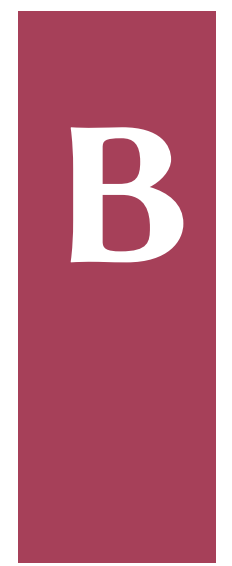

Este apêndice contém os resultados do ajuste do modelo de Van Aerde para os doze locais estudados. Os dados foram segregados em condições chuvosas e sem chuva e os modelos foram ajustados de acordo com as diretrizes apresentadas no Capítulo 3. Os pontos azuis correspondem às observações sob tempo chuvoso e os pontos cinzas às observações com tempo bom.

\section{SP-021, km 18,3 Externo}
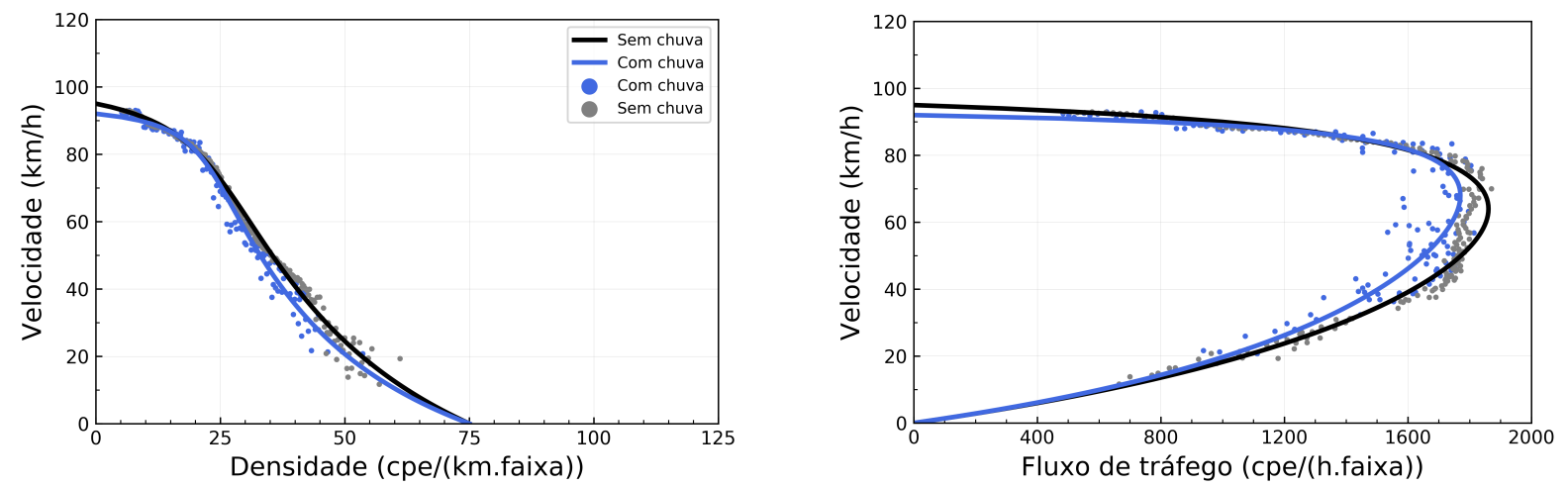

SP-021, km 18,3 Interno
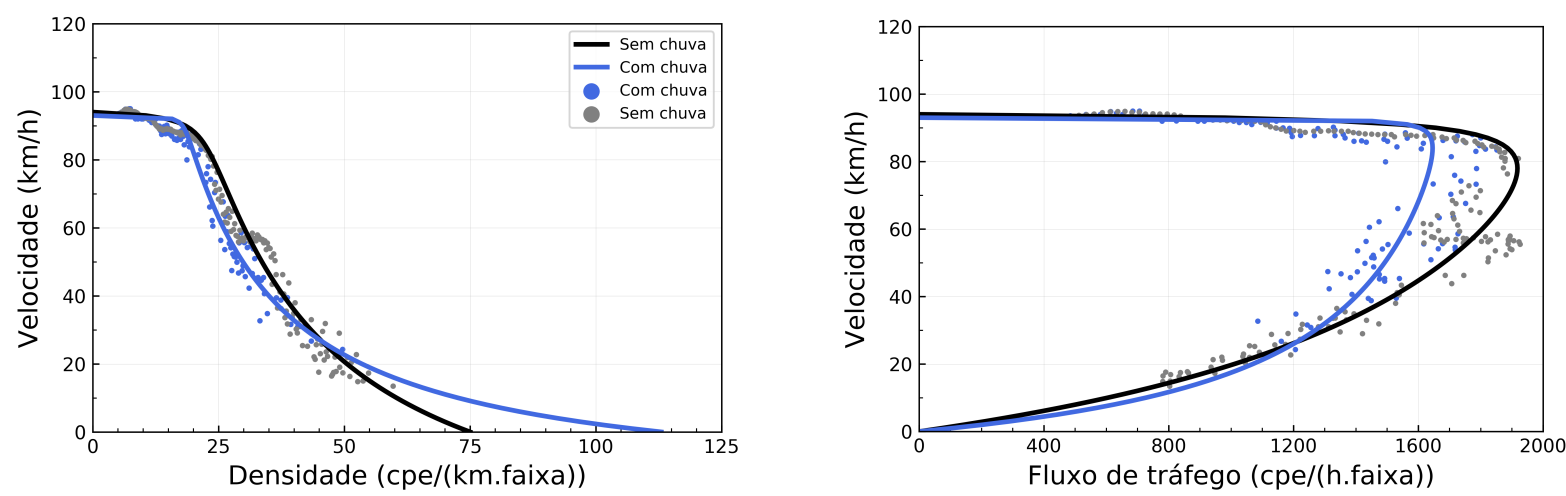
SP-280, km 26,9 Oeste
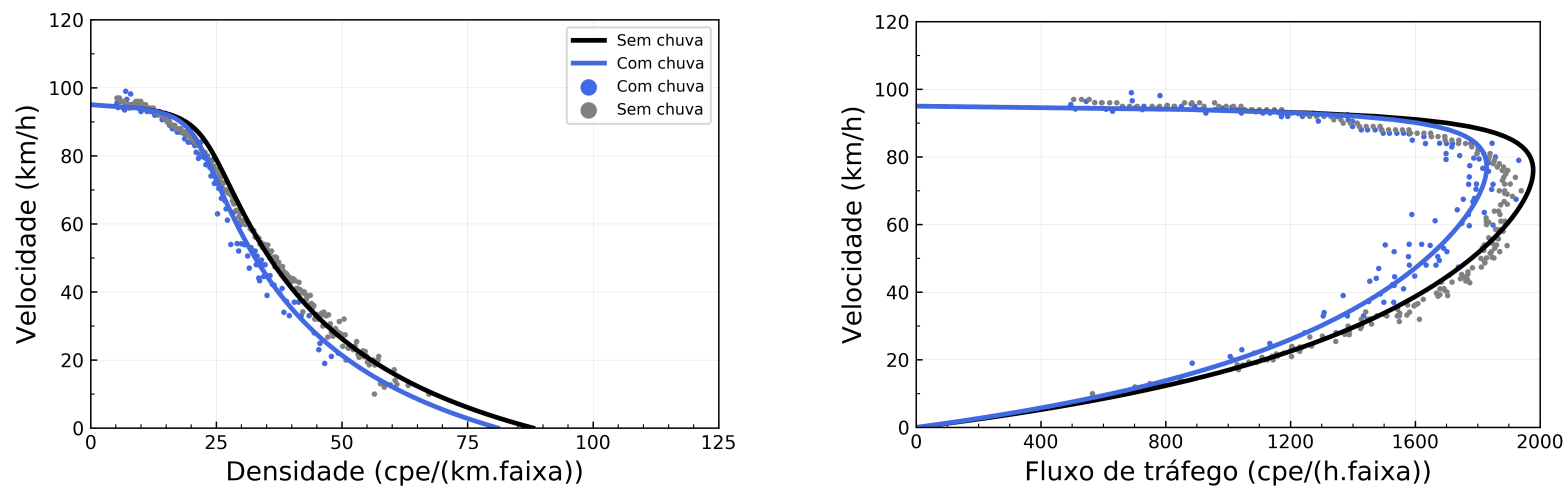

SP-280, km 26,9 Leste
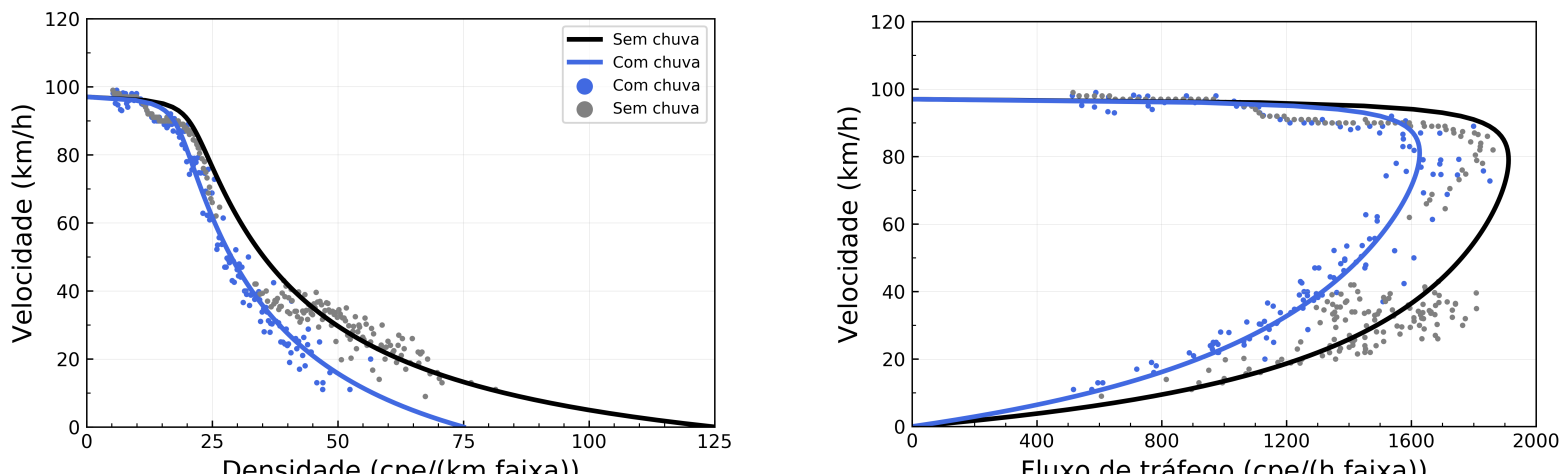

SP-330, km 55,2 Norte
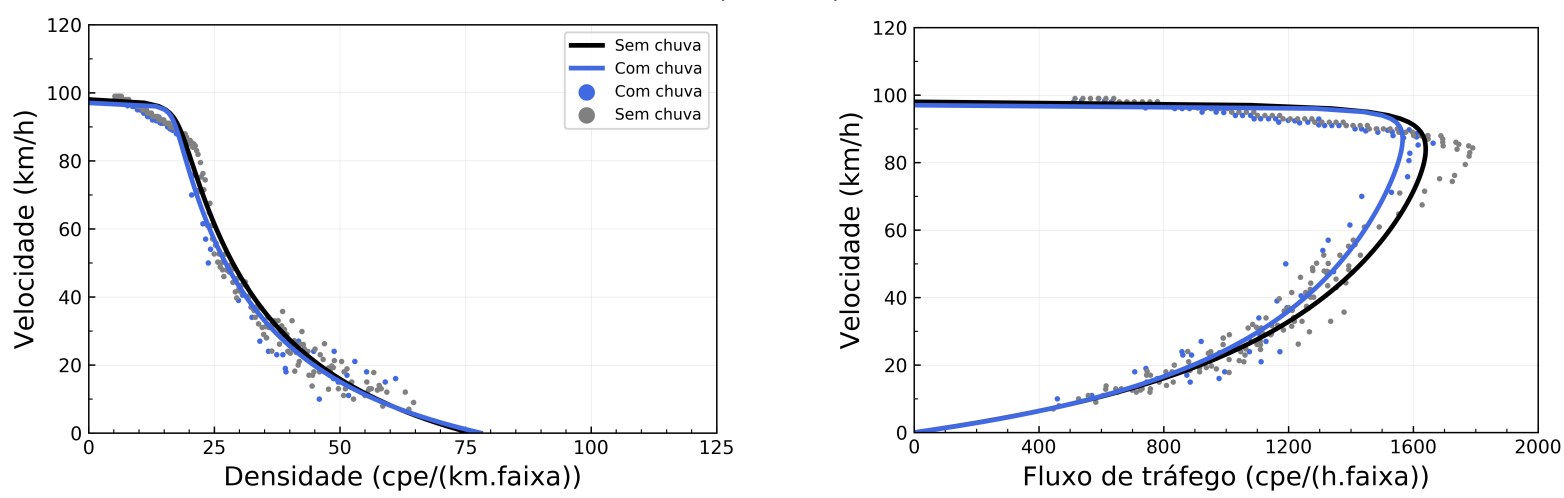

SP-330, km 55,2 Sul
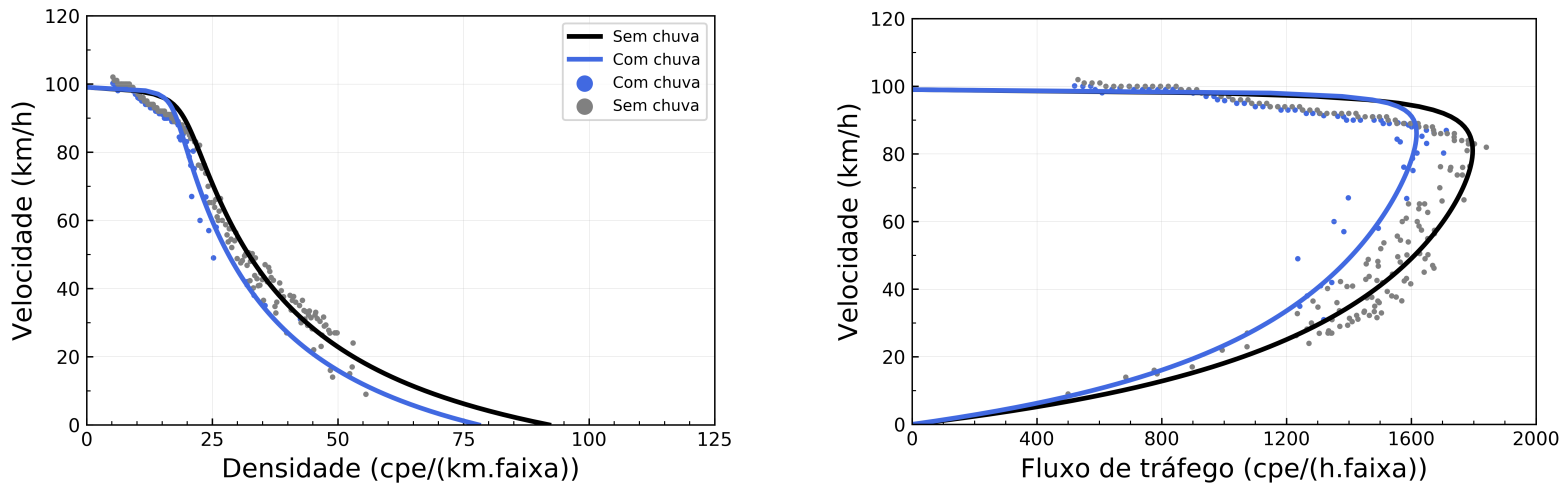

$\begin{array}{lccc}400 & 800 & 1200 & 1600 \\ \text { Fluxo de tráfego (cpe/(h.faixa)) }\end{array}$ 
SP-055, km 276,9 Oeste
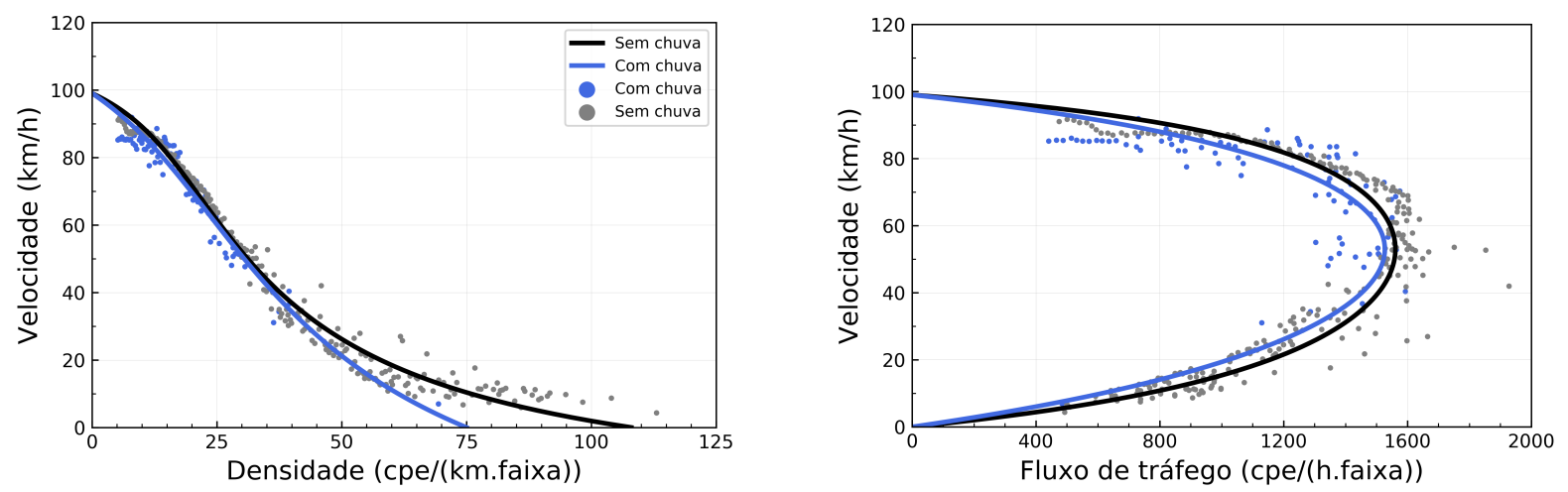

SP-070, km 30,0 Oeste
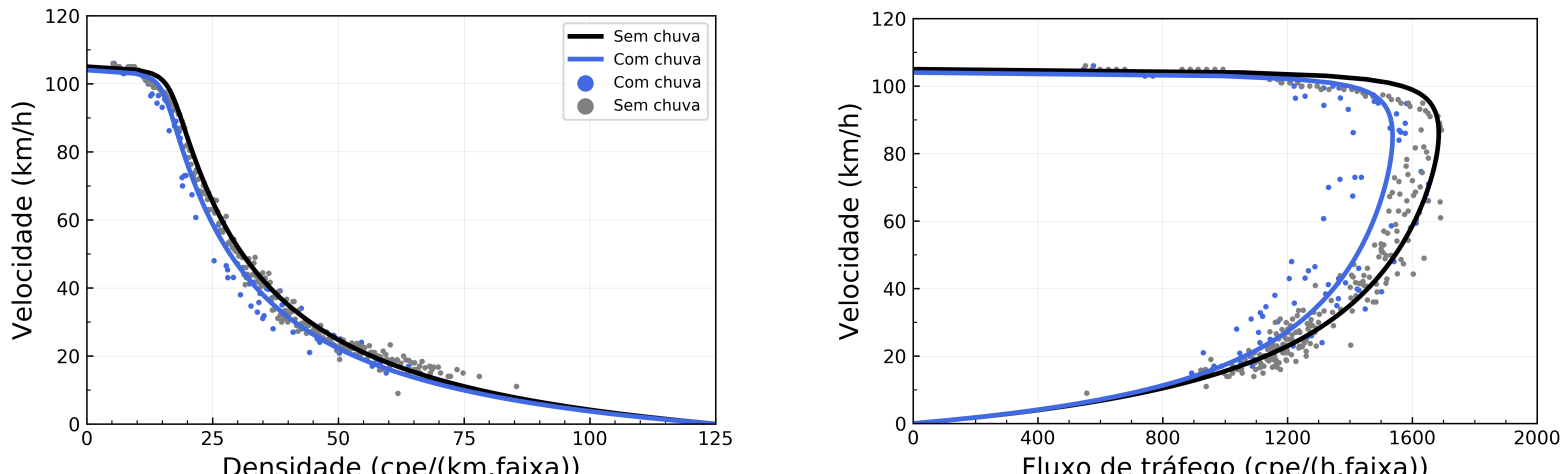

SP-070, km 54,1 Oeste
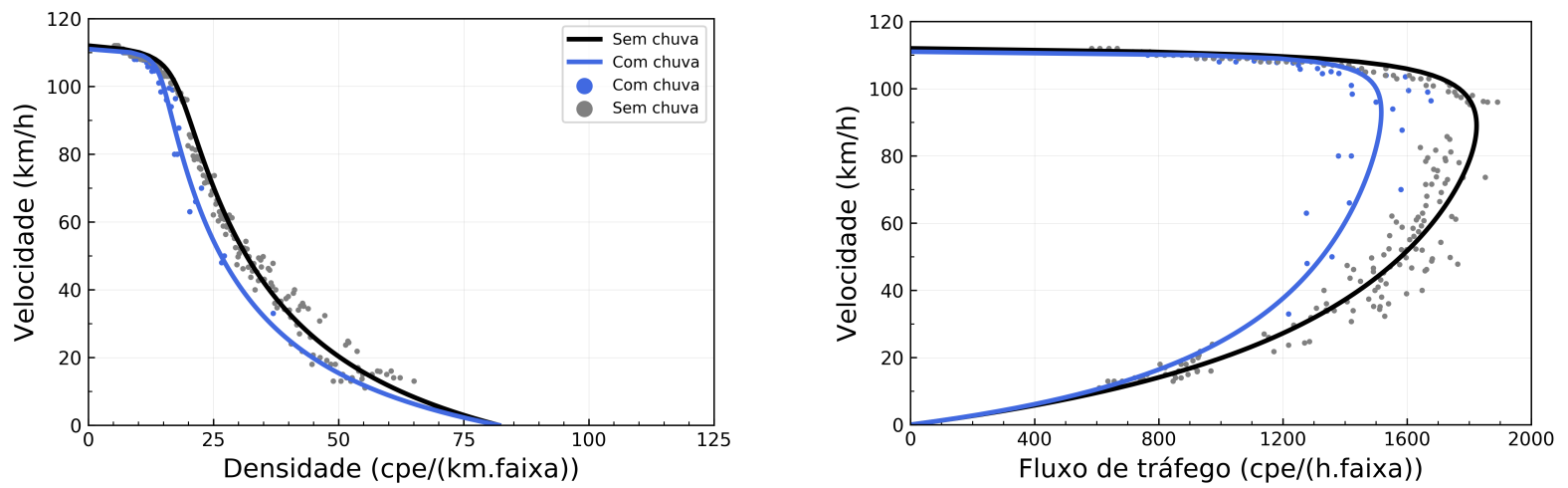

SP-280, km 37,0 Leste
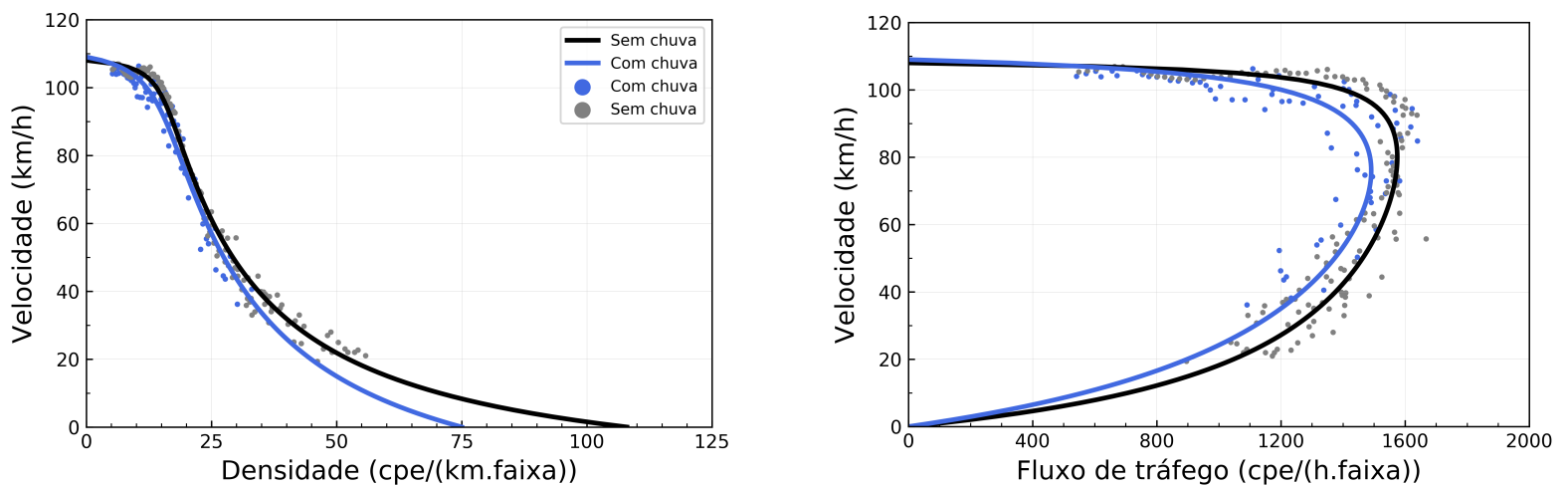

Fluxo de tráfego (cpe/(h.faixa)) 
SP-280, km 51,9 Oeste
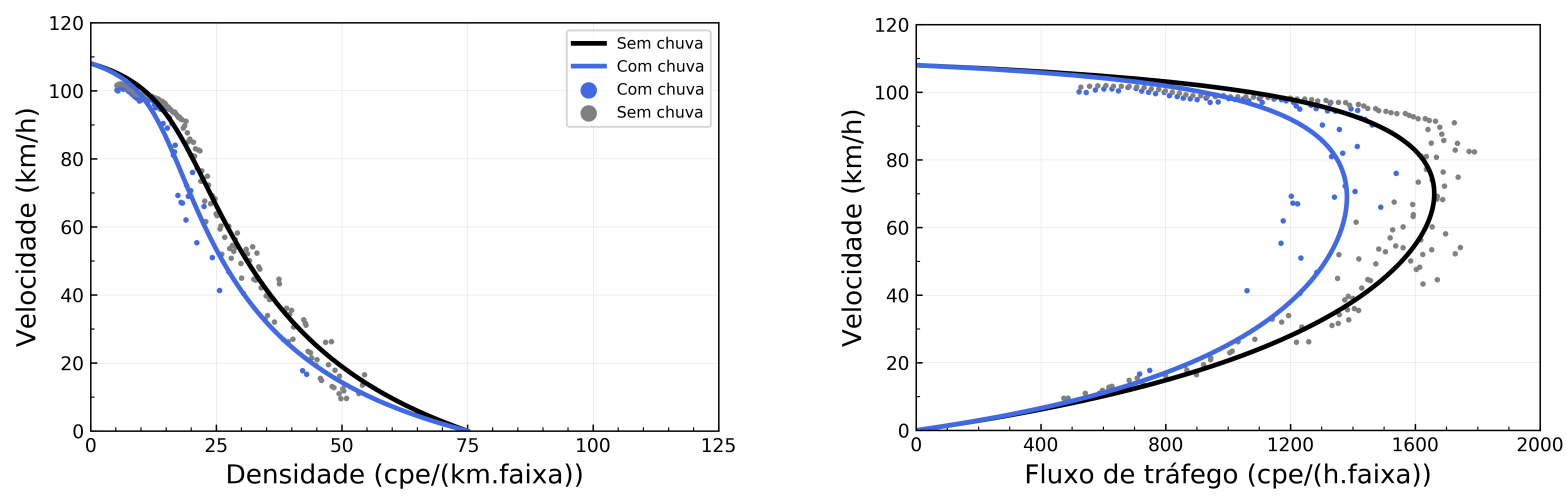

SP-280, km 59,6 Leste
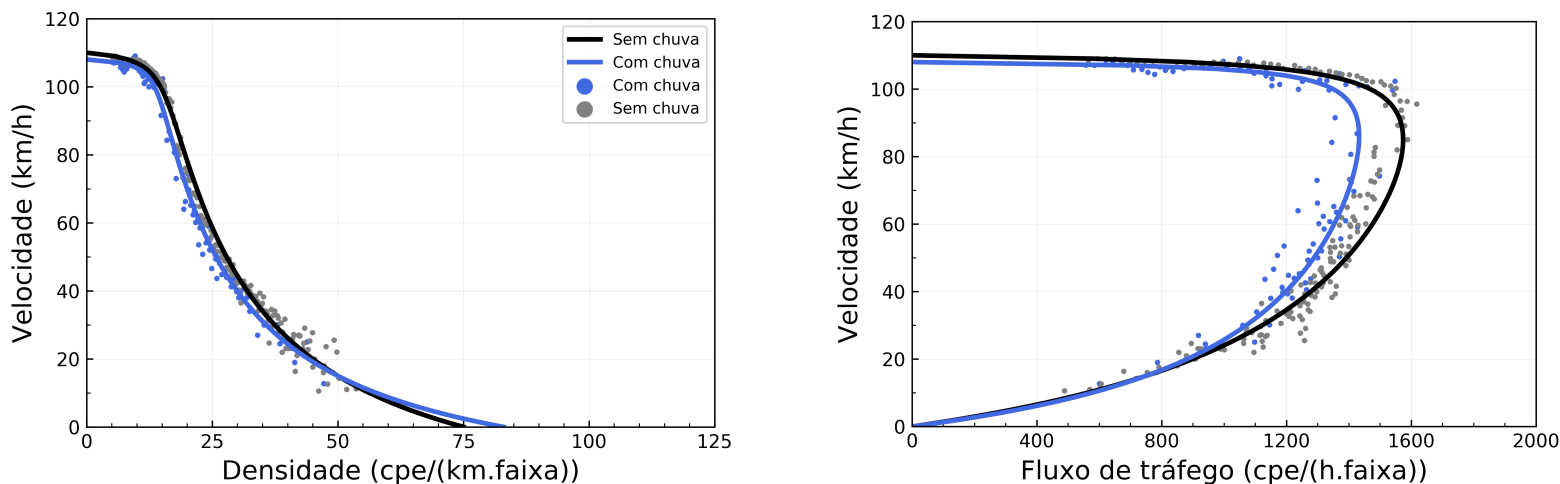

$\begin{array}{lccc}400 & 800 & 1200 & 1600 \\ \text { Fluxo de tráfego (cpe/(h.faixa)) }\end{array}$ 


\section{APÊNDICE}

\section{Análise do efeito combinado da meteorologia com a luminosidade}

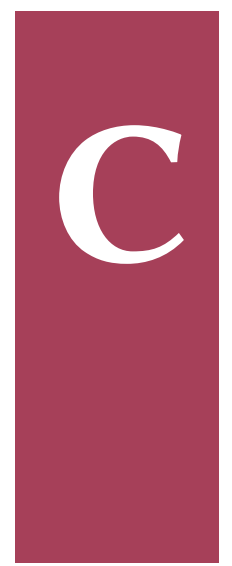

Este apêndice contém os resultados do ajuste do modelo de Van Aerde para os doze locais estudados. Os dados foram segregados em quatro configurações: (1) período diurno sem chuva, (2) período diurno com chuva, (3) período noturno sem chuva e (4) período noturno com chuva; e os modelos foram ajustados de acordo com as diretrizes apresentadas no Capítulo 3. As quatro curvas são apresentadas simultaneamente para facilitar a análise comparativa visual.
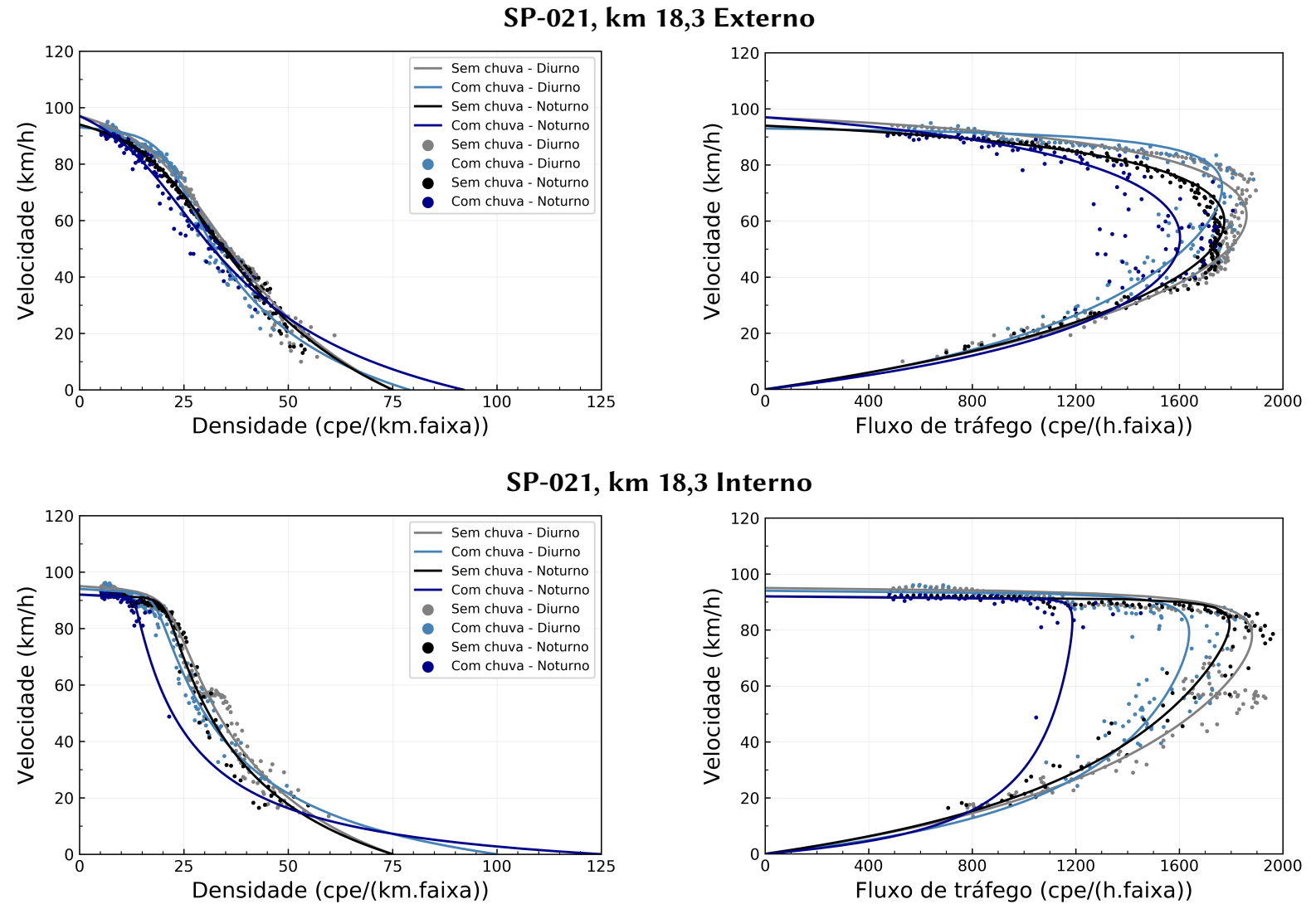
SP-280, km 26,9 Oeste
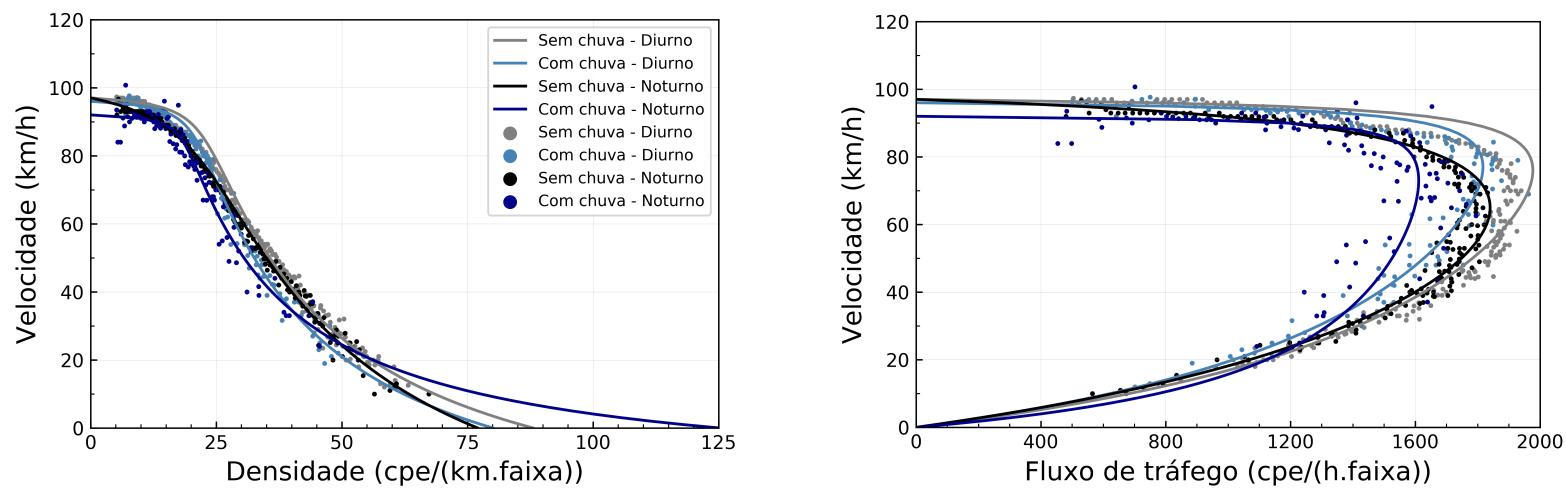

SP-280, km 26,9 Leste
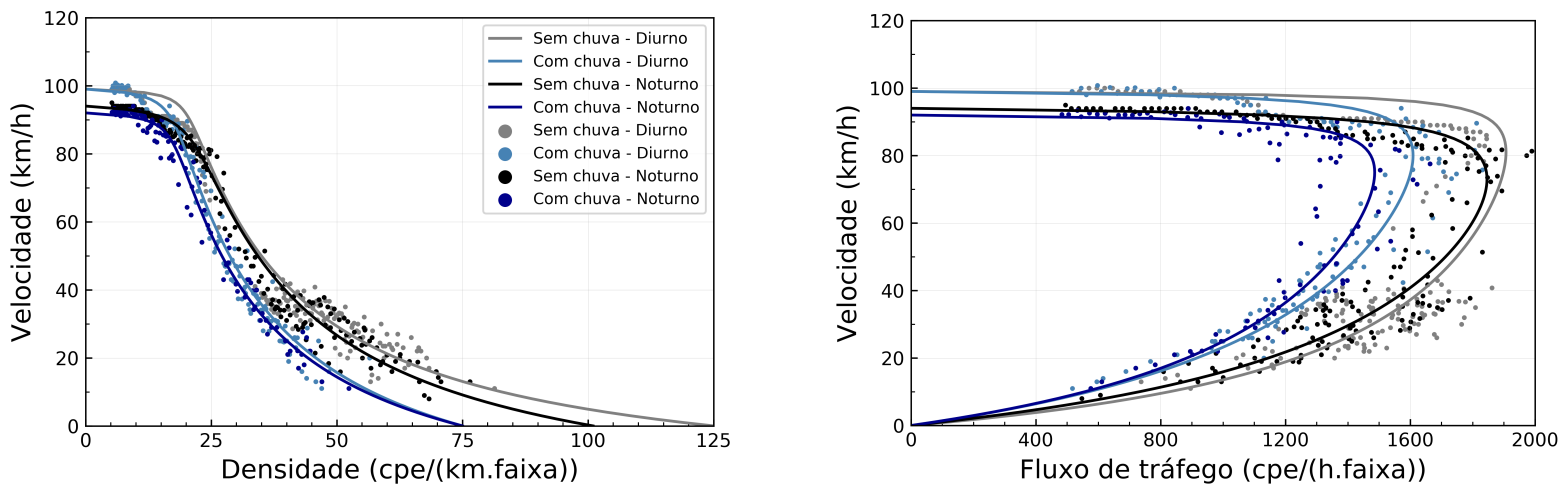

SP-330, km 55,2 Norte
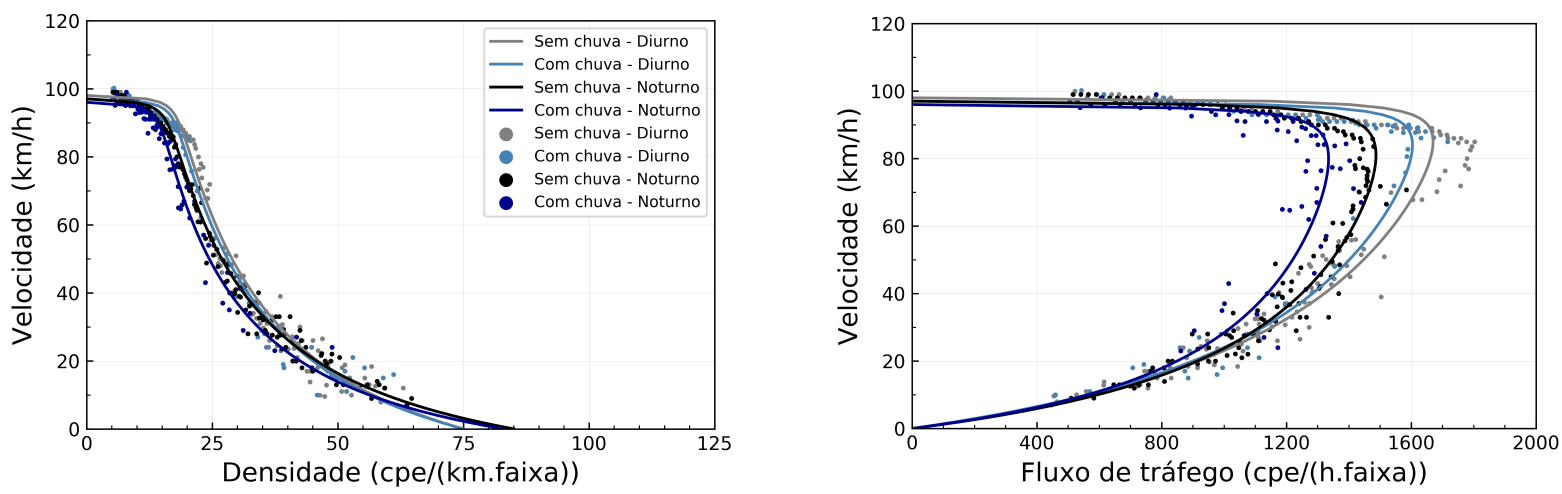

SP-330, km 55,2 Sul
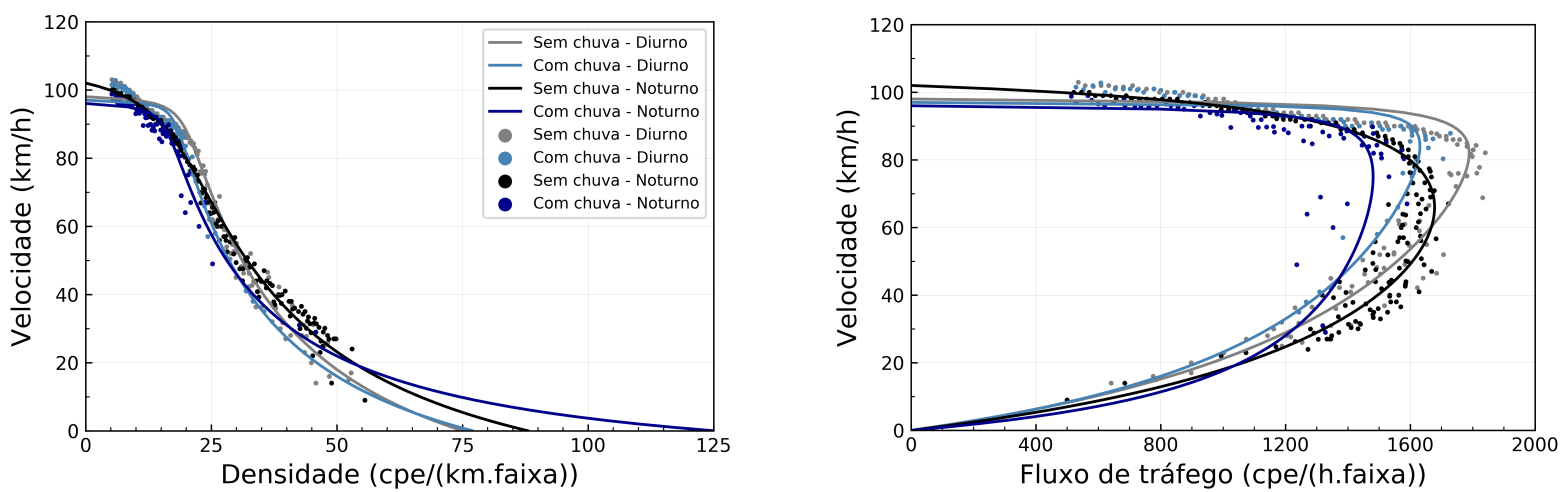

Fluxo de tráfego (cpe/(h.faixa)) 
SP-055, km 276,9 Oeste
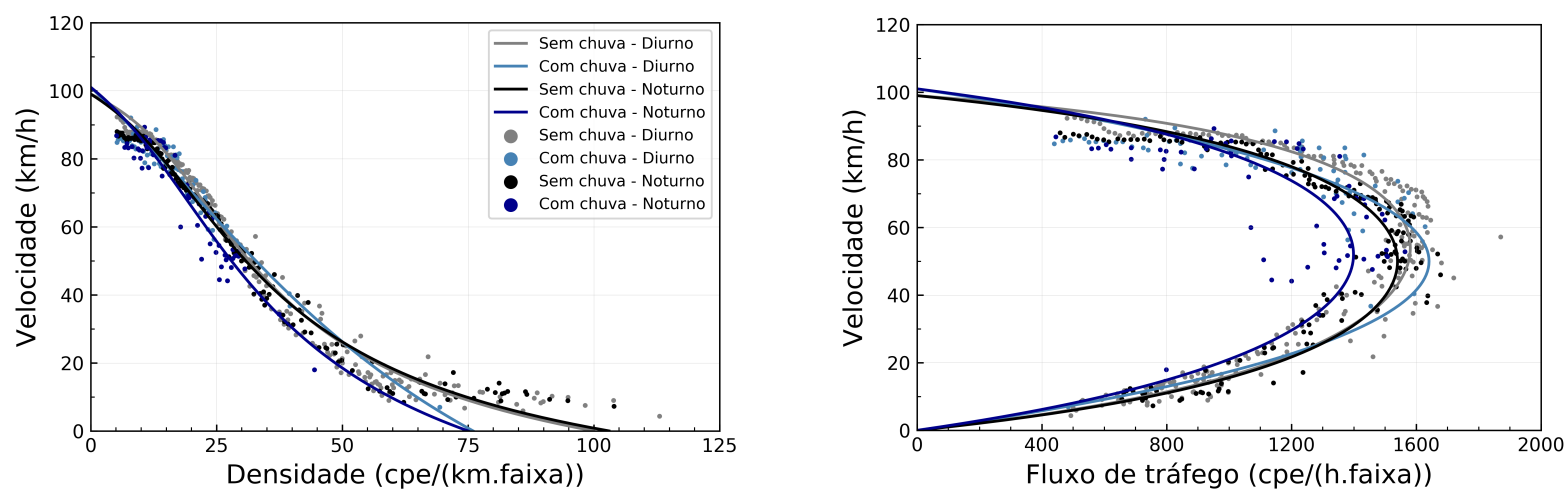

SP-070, km 30,0 Oeste
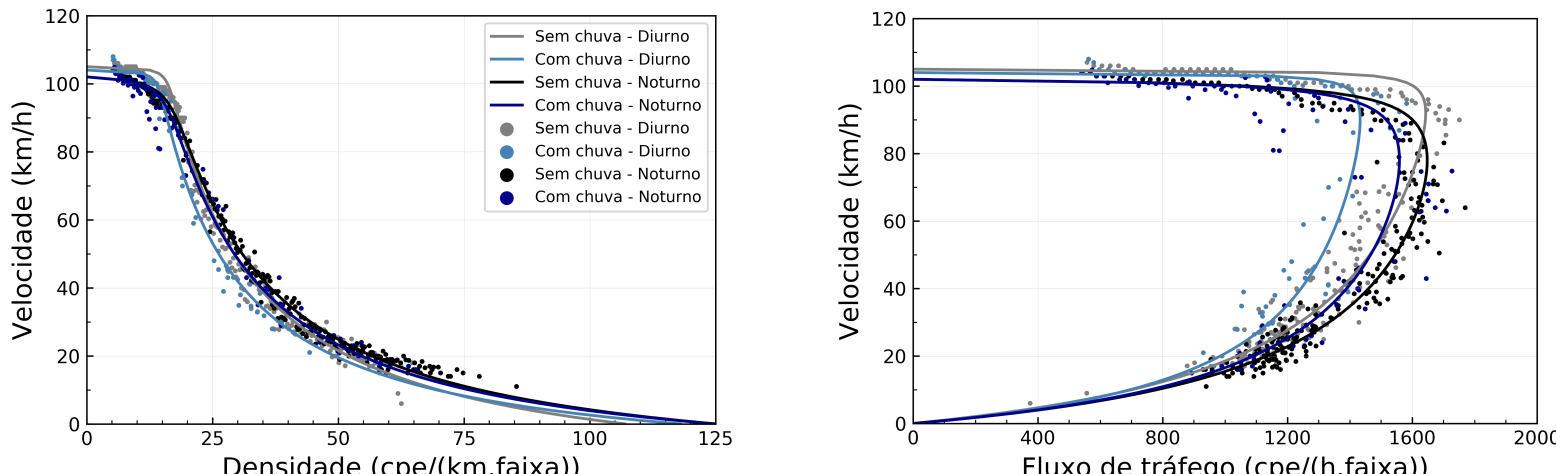

SP-070, km 54,1 Oeste
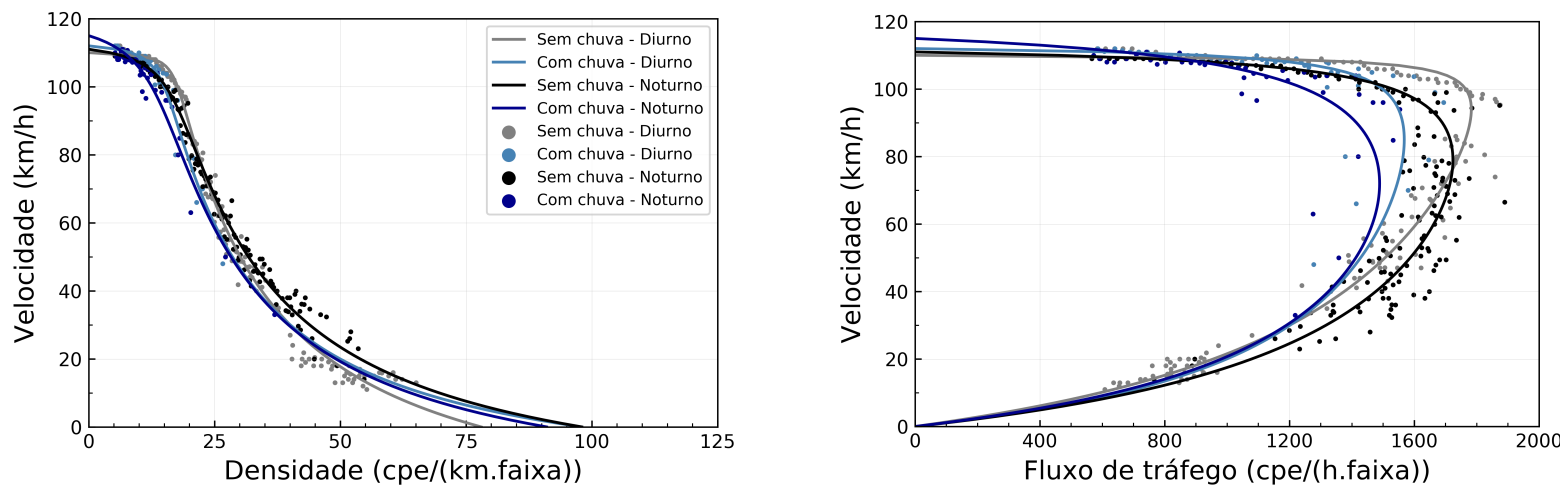

SP-280, km 37,0 Leste
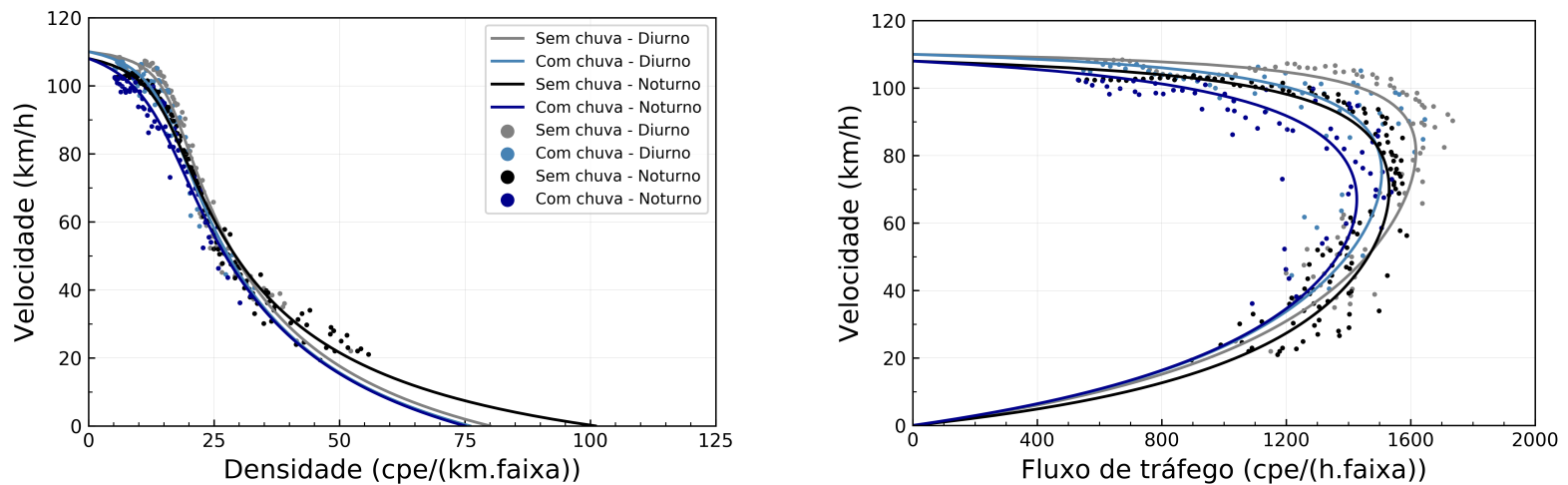

Fluxo de tráfego (cpe/(h.faixa)) 
SP-280, km 51,9 Oeste
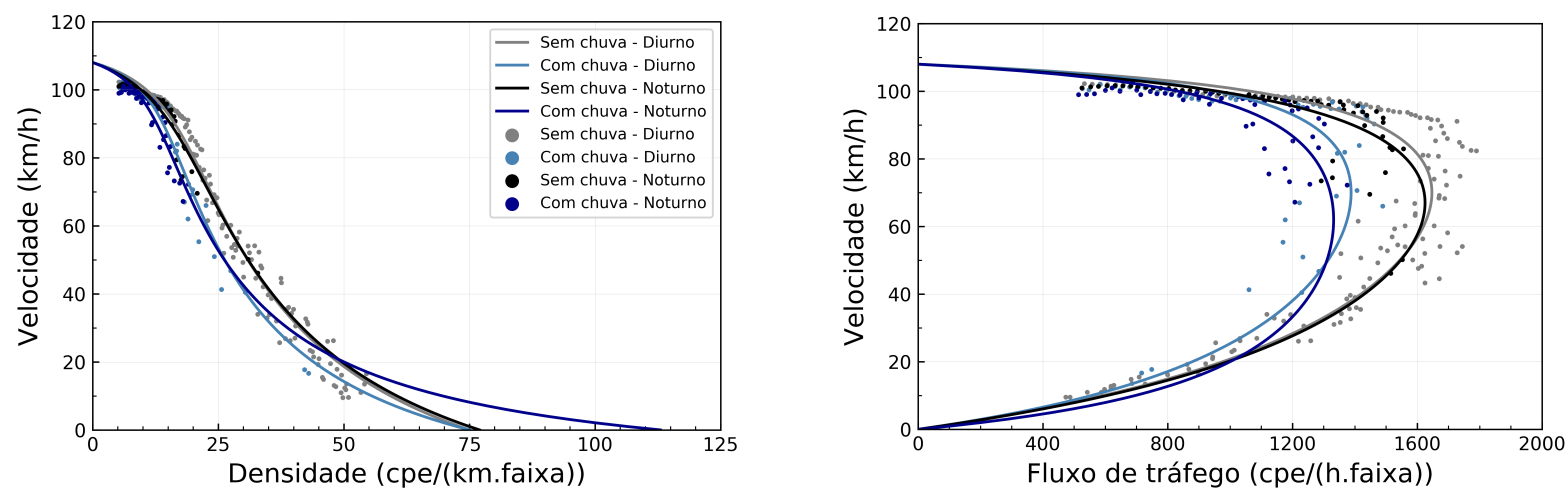

SP-280, km 59,6 Leste
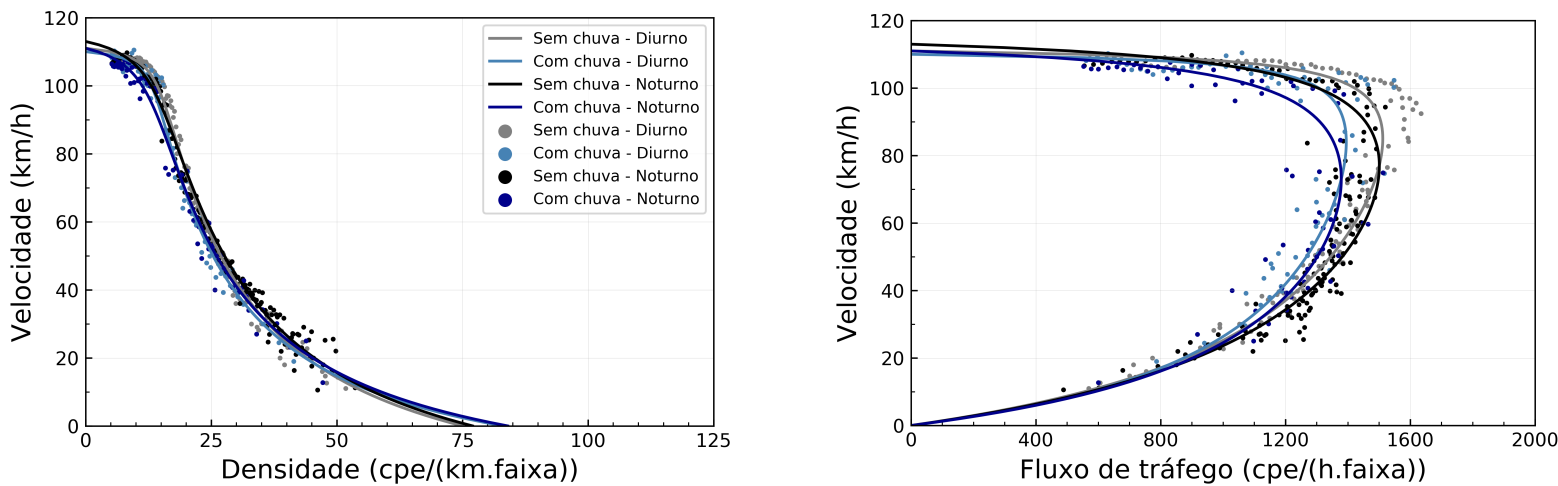

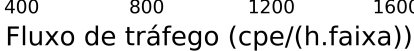

